AUTARQUIA ASSOCIADA À UNIVERSIDADE DE SÃO PAULO

\title{
DESENVOLVIMENTO DE UM SISTEMA DE MONITORAÇÃO E DIAGNÓSTICO UTILIZANDO LÓGICA FUZZY APLICADO ÀS VÁLVULAS DE CONTROLE DE PROCESSO DO CEA - CENTRO EXPERIMENTAL DE ARAMAR
}

\section{ALMIR CARLOS SOARES PORTO JÚNIOR}

Dissertação apresentada como parte dos requisitos para obtenção do Grau de Mestre em Ciências na Área de Tecnologia Nuclear - Reatores

Orientador:

Prof. Dr. Álvaro Luiz Guimarães Carneiro 
AUTARQUIA ASSOCIADA À UNIVERSIDADE DE SÃO PAULO

ALMIR CARLOS SOARES PORTO JÚNIOR

Dissertação apresentada como parte dos requisitos para obtenção do Grau de Mestre em Ciências na Área de Tecnologia Nuclear - Reatores

Orientador:

Prof. Dr. Álvaro Luiz Guimarães Carneiro

Versão Corrigida

Versão Original disponível no IPEN 
A DEUS pela força e perseverança à conclusão do trabalho. Ao meu pai Almir (in memoriam) e minha mãe Vânia, pelos ensinamentos de uma vida honesta e íntegra. À minha esposa Suely, meus filhos Marco Aurélio, Cayo e Fernanda, pessoas muito mais puras e inteligentes que eu.

\section{AGRADECIMENTOS}

Ao Professor Dr. Álvaro Luiz Guimarães Carneiro, pela orientação da dissertação, e principalmente pela confiança depositada na minha pessoa no decorrer desse trabalho.

Ao CA (EN) André Luis Ferreira Marques, pela autorização por parte da Marinha do Brasil para desenvolver este trabalho.

Ao Professor Dr. Roberto Navarro de Mesquita, pelos ensinamentos, apoio, espírito crítico e sugestões técnicas.

Ao Centro Tecnológico da Marinha em São Paulo (CTMSP), em especial ao Centro Experimental de ARAMAR, de onde se extraíram os dados para o desenvolvimento do trabalho.

Ao Instituto de Pesquisas Energéticas e Nucleares (IPEN-SP).

Aos Engenheiros Leonardo Biasetto e Joel, ao Técnico Marcelo pela extração dos dados referentes às válvulas de controle.

Aos colegas do Reator IPEN/MB-01, CF(T) Marino Reis Giada, Tecnólogo Marco Antônio Sabo e Téc. Eletrônico Reginaldo pelo incentivo e a todos que de alguma forma colaboraram para o sucesso deste trabalho. 


\title{
DESENVOLVIMENTO DE UM SISTEMA DE MONITORAÇÃO E DIAGNóstICO UTILIZANDO LÓGICA FUZZY APLICADO A VÁLVULAS DE CONTROLE DE PROCESSO DO CEA - CENTRO EXPERIMENTAL DE ARAMAR
}

\begin{abstract}
RESUMO
Considerando a segurança e extensão da vida de uma planta industrial, especificamente das válvulas de controle de processo, o estudo de confiabilidade de componentes é um ponto importante a ser investigado em usinas nucleares e em outras áreas, tais como refinaria ou plataforma de petróleo offshore. O desenvolvimento de monitorização não intrusiva e método de diagnóstico possibilita a identificação de defeitos em componentes da planta durante sua operação normal. O objetivo deste trabalho é apresentar uma análise e diagnóstico de válvulas de controle de uma planta de vapor que simula parte do circuito secundário de um reator de água pressurizada. Esta instalação faz parte do laboratório de testes de equipamentos de propulsão da Marinha do Brasil, em Iperó-SP. A metodologia utilizada no projeto é baseada na análise gráfica de dois parâmetros: a pressão de ar do atuador da válvula e o deslocamento de seu obturador. Estes dados são extraídos por um posicionador inteligente do Sistema de Automação Delta $\mathrm{V}^{\mathrm{TM}}$. É implementada uma análise para detecção de anomalias por meio de uma abordagem que utiliza Sistemas Especialistas baseados na Lógica Fuzzy, considerando regras e conhecimento de inteligência artificial (IA). Uma vez que as medidas de base de válvulas de controle são tomadas, é possível detectar sintomas de falha, vazamento, atrito, fricção, danos, etc. O monitoramento e o sistema de diagnóstico foram projetados utilizando o programa MATLAB $^{\circledR}$ versão 2009a com o FUZZY LOGIC TOOLBOX, que é um pacote integrante de subrotinas dedicado à lógica nebulosa.

A monitoração e o diagnóstico das válvulas de controle são realizados por meio de uma técnica não-invasiva.

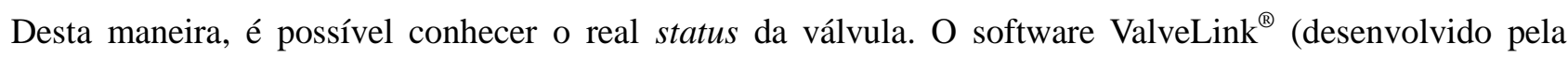
empresa EMERSON) recebe sinais do componente de hardware, posicionador inteligente, o qual é instalado ao lado da válvula de controle de processos. Estes sinais (corrente eléctrica) transformados em informação são utilizados como parâmetros de entrada: Pressão de ar do atuador e deslocamento do obturador da válvula. Com o uso da lógica fuzzy, esses parâmetros são interpretados. Eles sofrem inferências por regras escritas por especialistas em válvulas. Após essas inferências, as informações são tratadas e enviadas como sinais de saída. Esses sinais contém a informação de diagnóstico do estado da válvula.
\end{abstract}




\title{
DEVELOPMENT OF A SYSTEM FOR MONITORING AND DIAGNOSIS USING FUZZY LOGIC IN CONTROL VALVES OF LABORATORY TEST EQUIPMENT OF EXPERIMENTAL CENTER ARAMAR
}

\begin{abstract}
The question of components reliability, specifically process control valves, has become an important issue to be investigated in nuclear power plants and other areas such as refinery or offshore oil rig, considering the safety and life extension of the plant. The development of nonintrusive monitoring and diagnostic method allows the identification of defects in components of the plant during normal operation. The objective of this dissertation is to present an analysis and diagnosis of control valves of a steam plant part that simulates the secondary circuit of a pressurized water reactor. This installation is part of propulsion equipment testing laboratory of the Brazilian Navy, at Iperó-SP. The methodology for design is based on graphical analysis of two parameters, the valve air pressure actuator and the displacement of the valve plug. These data are extracted by a smart positioner, part of Delta V ${ }^{\mathrm{TM}}$ Automation System. An analysis is implemented in detecting anomalies by an approach using Expert Systems by the technique of fuzzy logic. Once the basic measures of control valves are taken, it is possible to detect symptoms of failure, leakage, friction, damage, etc. The monitoring and diagnostic system has been designed in MATLAB ${ }^{\circledR}$ version $2009^{\text {th }}$ by the complement "FUZZY LOGIC TOOLBOX ".

It is a noninvasive technique. Thus, it is possible to know what is happening with the chosen components, just analyzing the parameters of the valve. The software called ValveLink ${ }^{\circledR}$ (developed by Emerson) receives signals from hardware component (intelligent positioner) installed next to the control valve. These signals (electrical current) are transformed into information which are used input parameters: air pressure valve actuator and valve plug displacement. With the use of fuzzy logic, these parameters are interpreted. They suffer inferences by rules written by experts in valves. After these inferences, the information is processed and sent as output signals. These signals lead to diagnostic information of the state of the valve.
\end{abstract}




\section{SUMÁRIO}

1 INTRODUÇÃO 12

2 OBJETIVO 16

2.1 ASPECTOS RELEVANTES E CONTRIBUIÇÕES DO TRABALHO 17

3 HISTÓRICO 18

3.1 O ESTADO DAARTE $\quad 21$

4. SISTEMA ESPECIALISTA 23

4.1 PRINCIPAIS COMPONENTES DO SISTEMA ESPECIALISTA 24

4.2 CARACTERÍSTICAS GERAIS DOS SISTEMAS ESPECIALISTAS 26

4.3 CLASSIFICAÇÕES DE SISTEMAS ESPECIALISTAS 27

4.4 SISTEMA ESPECIALISTA VIA LÓGICA FUZZY 30

5 FUNDAMENTOS TEÓRICOS 33

5.1 LÓGICA NEBULOSA 33

5.1.1 CARACTERÍSTICAS E VANTAGENS DA LÓGICA NEBULOSA 34

5.1.2 CONJUNTO NEBULOSO 36

5.1.3 PRINCIPAIS OPERAÇÕES ENTRE CONJUNTOS NEBULOSOS 38

5.2 FUNÇÃO E DESCRIÇÃO DE UMA VÁLVULA DE CONTROLE 39

5.2.1 PRINCÍPIO DE OPERAÇÃO 45

5.2.2 TIPOS DE VÁLVULAS DE CONTROLE 48

5.2.3 ANOMALIAS EM VÁLVULAS DE CONTROLE 52

6. MATERIAIS E MÉTODOS 53

6.1 RELAÇÃO DE VÁLVULAS ANALISADAS E FALHAS ENCONTRADAS 53

6.2 DELTA $V$ - MÓDULO VALVELINK E A BASE DE DADOS 54

6.3 MATLAB ${ }^{\circledR}$ FUZZY LOGIC TOOLBOX

7 RESULTADOS 58

8. CONCLUSÃO 88

8.1 CONTRIBUIÇÃO E DESENVOLVIMENTO NO CAMPO DA PESQUISA 90

8.2 RECOMENDAÇAOES PARA TRABALHOS FUTUROS 91

REFERENCIAS BIBLIOGRÁFICAS 91 


\section{LISTA DE FIGURAS}

Título

Página

1 Planta tipo pressurized water reactor - PWR1

2 Sala de controle do sistema Delta $\mathrm{V}$

3 Componentes de um SE

4 Diagrama em bloco de um FLS

5 Fuzzificação de duas variáveis de entrada

6 Método do centro de gravidade 38

7 União, Interseção e Complemento 39

8 Visão em corte, atuador, castelo, e corpo (sede) de uma válvula 41

9 Válvulas tipo esfera, globo e gaveta 42

10 Foto de uma válvula de controle com posicionador inteligente 43

11 Ar para abrir - ar para fechar $\quad 47$

12 Válvulas tipo esfera, globo e gaveta 50

13 Posicionador inteligente isolado e acoplado à Válvula de controle tipo 51 borboleta de acionamento pneumático

14 Módulo Valvelink - Sistema Delta V 54

15 Assinatura da válvula FV-100 - "baseline" 54

16 Interface inicial do "FL toolbox" 56

17 Interface de criação de funções de pertinência 56

18 Exemplo de um visor de regras do FL toolbox 57

19 Gráfico em 3-D das entradas e saída do FL toolbox 57

20 Assinatura da válvula FV-100 com anomalias 58

21 Entrada "excvalv" da FV-100 60

22 Entrada "pressat" da FV-100 60

23 Saída "statvalv" da FV-100 61

24 Visor de regras da FV-100 61 
25 Assinatura da TV-462B $\quad 62$

26 Entrada "excvalv" da TV-462B 64

27 Entrada "pressat" da TV-462B 64

28 Saída "statvalv" da TV-462B 64

29 Visor de regras da TV-462B 65

30 Assinatura da PV-472B 65

31 Entrada "excvalv" da PV-472B 67

32 Entrada "pressat" da PV-472B 67

33 Saída "statvalv" da PV-472B 68

34 Visor de regras da PV-472B 68

35 Assinatura da PV-830 69

36 Entrada "excvalv" da PV-830 71

37 Entrada "pressat" da PV-830 72

38 Saída "statvalv" da PV-830 72

39 Visor de regras da PV-830

40 Assinatura da PV-1200 73

41 Entrada "excvalv" da PV-1200 75

42 Entrada "pressat" da PV-1200 76

43 Saída "statvalv" da PV-1200 76

44 Visor de regras da PV-1200 76

45 Assinatura da PV-1110 77

46 Entrada "excvalv" da PV-1110 80

47 Entrada "pressat" da PV-1110 80

48 Saída "statvalv" da PV-1110 80

49 Visor de regras da PV-1110 81

50 Assinatura da PV-482 82

51 Entrada "excvalv" da PV-482 84

52 Entrada "pressat" da PV-482 84

53 Saída "statvalv" da PV-482 84

54 Visor de regras da PV-482 85

55 Assinatura da TV-462A 85 
56 Entrada "excvalv" da TV-462A 87

57 Entrada "pressat" da TV-462A $\quad 87$

58 Saída "statvalv" da TV-462A 88

59 Visor de regras da TV-462A 88 


\section{LISTA DE TABELAS}

Tabela Título

Página

1 Diagrama de blocos do sistema, com a inserção do módulo de monitoração e diagnóstico

2 Elementos finais de controle da planta de processo

3 Status da válvula e faixa de entrada

Status da válvula e faixa de entrada da FV-100

Status da válvula e Diagnóstico da FV-100

Base de regras do Sistema de diagnóstico da FV-100

Funções de pertinência e valores da FV-100

8 Status da válvula e Faixa de entrada da TV-462B

9 Status da válvula e diagnóstico da TV-462B

10 Base de regras do Sistema de diagnóstico da TV-462B

11 Funções de pertinência e valores da TV-462B

12 Status da válvula e Faixa de entrada da PV-472B

13 Status da válvula e Diagnóstico da PV-472B

14 Base de regras do Sistema de diagnóstico (ciclo invertido) PV-472B

15 Funções de pertinência e valores da PV-472B

Status da válvula e Faixa de entrada da PV-830

17 Status da válvula e diagnóstico da PV-830 70

18 Histerese da válvula PV-830 70

19 Base de regras do Sistema de diagnóstico da PV-830 70

20 Funções de pertinência e valores da PV-1200 71

21 Status da válvula e Faixa de entrada da PV-1200 74

22 Status da válvula e diagnóstico da PV-1200 74

$23 \quad$ Histerese da válvula PV-1200 74

24 Base de regras do Sistema de diagnóstico da PV-1200 
27 Status da válvula e diagnóstico da PV-1110

28 Histerese da válvula PV-1110

29 Base de regras do Sistema de diagnóstico da PV-1110

30 Funções de pertinência e valores da PV-1110

31 Status da válvula e Faixa de entrada da PV-482

32 Status da válvula e diagnóstico da PV-482

$33 \quad$ Histerese da válvula PV-482

34 Base de regras do Sistema de diagnóstico da PV-482

35 Funções de pertinência e valores da PV-482

36 Status da válvula e Faixa de entrada da TV-462A

37 Status da válvula e diagnóstico da TV-462A

38 Base de regras do Sistema de diagnóstico da TV-462A

39 Funções de pertinência e valores da TV-462A 
IA: Inteligência Artificial

\section{ABREVIATURAS E SIGLAS}

CEA: Centro Experimental de Aramar

CTMSP: Centro Tecnológico da Marinha em São Paulo

LATEP: Laboratório de Testes de Equipamentos da Propulsão

LABGENE: Laboratório de Geração Núcleo Elétrica

MB: Marinha do Brasil

PWR: Pressurized Water Reactor

PROTER: Protótipo em terra

TGP: Turbo gerador principal TGA :Turbo gerador auxiliar

PHM: Prognostic Healthy Management

IPEN: Instituto de Pesquisas Energéticas e Nucleares

CIANA: Centro de Instrução e Adestramento Nuclear de ARAMAR

EUA: Estados Unidos da América

DAMADICS: Development and application of methods for actuator diagnosis in industrial control systems

VP: variável de processo PV: process variable

PSI: Pressure Square Inch mm: milímetros

KPa: KiloPascal

Psig: Pressure Square Inch absoluto

FC: fail close

FO: fail open

FI: fail indetermined

FL: fail last position

FTO: flow to open

FTC: flow to close

FB: friction bound

FLS: Fuzzy Logic System FL toolbox: Fuzzy logic toolbox

3-D: três dimensões

SE: Sistema Especialista

deg: graus

excvalv: excursionamento da válvula

pressat: pressão no atuador

statvalv: status da válvula

programar_manut: programar manutenção

SnBr: Submarino de Propulsão Nuclear Brasileiro 


\section{1- Introdução}

O tema diagnóstico de válvula de controle por análise de assinatura eletrônica de posicionador inteligente utilizando sistemas dotados de Inteligência Artificial - IA tem se tornado factível devido ao avanço da tecnologia de diagnóstico. O que inicialmente só existia na área de alta tecnologia (espacial), se difundiu para a área de saúde e agora tem chegado às plantas industriais.

Em plantas industriais existem válvulas de controle que necessitam de cuidados especiais, pois a sua inoperância ou mau funcionamento pode causar danos relevantes à instalação, ao pessoal técnico e ao meio ambiente. Com o surgimento dos posicionadores inteligentes foi possível um acompanhamento da operação destas válvulas. Os dados fornecidos por estes posicionadores, processados com auxilio de ferramentas de IA, fornecerá aos engenheiros responsáveis pela planta, a informação necessária para acompanhar o correto funcionamento das válvulas de controle. Permitindo ainda, aumentar a disponibilidade operacional, programando melhor as intervenções de manutenção, e garantindo uma maior segurança. Podendo prever e evitar avarias, estimando inclusive, o tempo de vida útil destes elementos finais de controle.

A proposta do trabalho é fazer uso da lógica fuzzy - uma ferramenta de IA, para auxílio na monitoração e diagnóstico de falhas, utilizando o recurso do MATLAB $^{\circledR}$, através do software fuzzy-logic toolbox. Com o processamento e análise dos dados e variáveis de entrada, é possível conhecer na saída do sistema, as condições operacionais da válvula de controle de forma preditiva, antecipando situações de falhas tais como, emperramento, empenamento, erro de posicionamento etc.

O trabalho foi desenvolvido e aplicado em válvulas de controle existentes nas plantas de processo dos laboratórios do Centro Experimental de Aramar (CEA) do Centro Tecnológico da Marinha em São Paulo (CTMSP) situado em Iperó, interior do estado de São Paulo - SP.

O CEA é dividido em diversas oficinas e laboratórios que compõem o complexo de montagem e testes. Juntos auxiliam o CTMSP a cumprir a sua missão: desenvolver tecnologia autóctone na área nuclear para equipar o primeiro submarino de propulsão 
nuclear de defesa brasileiro [1].

Neste complexo, destacam-se o Laboratório de Testes de Equipamentos da Propulsão (LATEP) e o Laboratório de Geração Núcleo Elétrica (LABGENE). Ambos são partes do programa de propulsão nuclear da Marinha do Brasil (MB).

O primeiro trata-se de uma planta de processos industriais de médio porte, reproduzindo o circuito secundário de um reator nuclear tipo PWR - Pressurized Water Reactor e tem por objetivo testar os conjuntos turbina/gerador de propulsão e auxiliares que irão compor o LABGENE e o submarino. O LATEP se encontra em operação desde a inauguração do CEA, tendo passado por uma revitalização em sua automação no ano de 2009.

O segundo (LABGENE) é considerado um protótipo em terra - PROTER, de um reator tipo PWR de pequeno porte, idêntico ao que mobiliará o submarino brasileiro. Nele será testado todo o conjunto de propulsão com seus subsistemas e, ainda, será a subunidade responsável por treinar as equipes que tripularão o submarino. Este laboratório está em fase de construção.

Para o domínio completo do projeto LABGENE, faz-se necessário que todos os seus equipamentos, estejam devidamente testados e aprovados individualmente e, que seus limites de operação (temperatura, vazão, pressão, rotação, vibração etc) sejam conhecidos. O circuito tipo PWR (fig. 1) é um dos mais usados em plantas nucleares e em sistemas de propulsão naval, submarinos e navios militares e civis.

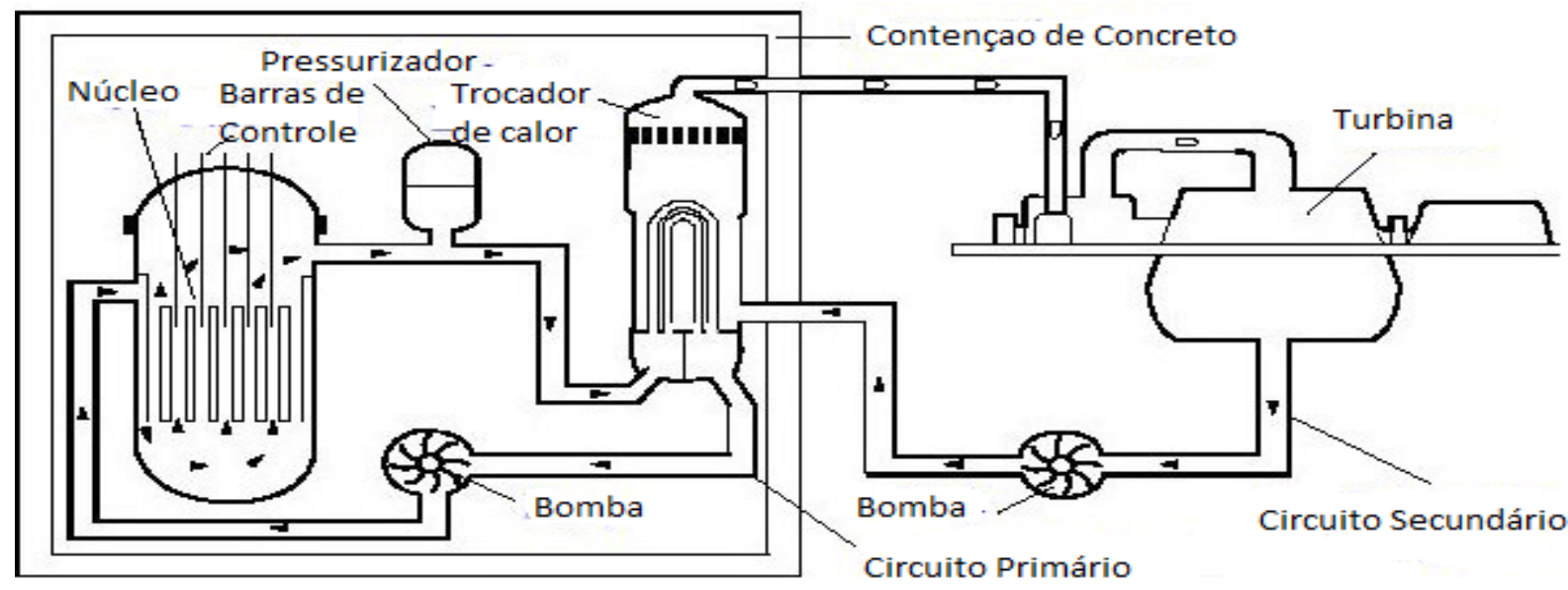

Figura 1 - Planta sintética do tipo PWR - pressurized water reactor?.

\footnotetext{
${ }^{2}$ Cortesia da Oracle ${ }^{\circledR}$ Education foundation
} 
Grande parte dos equipamentos constituintes (reator nuclear, trocadores de calor, pressurizador, gerador de vapor, turbinas, bombas, geradores elétricos etc.) já foi fabricada e estão armazenados nas diversas oficinas do CEA. Especificamente os conjuntos turbos geradores estão no LATEP em fase de testes e aprovação. Tratam-se de 4 conjuntos sendo, 2 conjuntos de Turbo geradores principais - TGP's, para propulsão naval (movimentação do conjunto eixo hélice do submarino) e 2 Turbo geradores auxiliares - TGA's para geração de energia elétrica para os diversos sistemas de bordo (iluminação, conforto, sistemas de navegação etc).

Para testar e aprovar os equipamentos acima descritos (turbo geradores), separadamente, a MB construiu o LATEP, planta de processo para simular o circuito secundário do reator nuclear.

Em 2009, esta planta passou por uma modernização em todos os seus sistemas. A sua automação foi revitalizada, e painéis antigos e instrumentos de controle foram substituídos por automação moderna, denominado Delta V. Foi a empresa EMERSON que desenvolveu e customizou este projeto em conjunto com a MB.

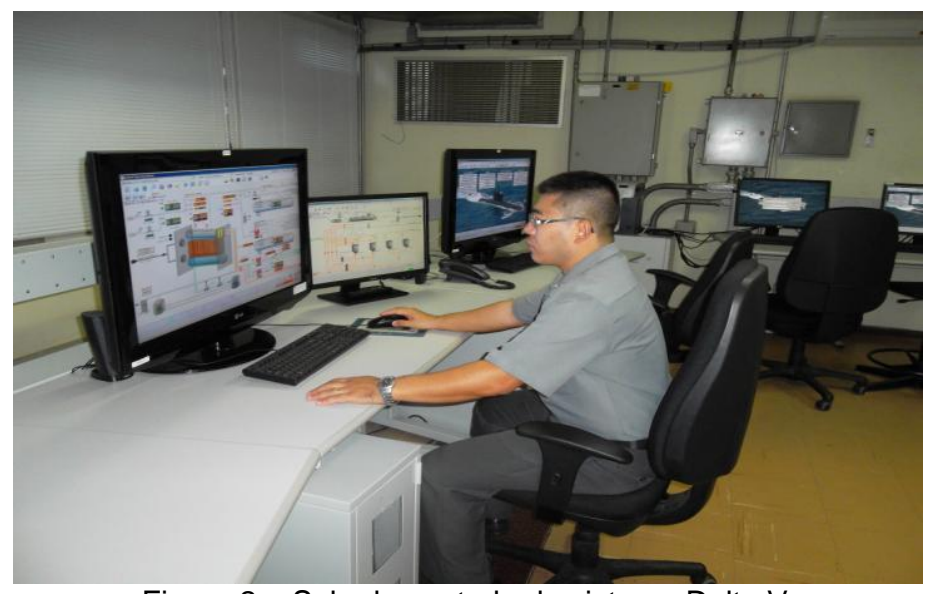

Figura 2 - Sala de controle do sistema Delta V.

A modernização da planta passou também pela verificação de todas as suas malhas de controle. Os elementos iniciais de controle (placas de orifício, termopares, bulbos, bóias, pressostatos, nivelostatos, tubos capilares, etc) foram checados, aferidos e calibrados. Em sua maioria, os controladores existentes foram substituídos por controladores virtuais (intrínsecos ao sistema Delta V). 
Aos principais elementos finais de controle foram instalados posicionadores inteligentes, que fornecem dados na forma de gráficos. Esses gráficos informam o posicionamento da haste da válvula (em MM) pela pressão de ar comprimido no atuador da válvula. Estes dados são transmitidos eletronicamente para a sala de controle, que possui um terminal de engenharia onde, por meio do uso do módulo valvelink, do sistema Delta $V$, é possível verificar as informações de cada válvula cadastrada.

O sistema proposto interpretará as variações dos sinais de cada válvula. O comportamento desses sinais será verificado por monitoração constante e o diagnóstico de cada anomalia será apresentado, de acordo com a detecção das falhas oriundas da análise dos dados, em conformidade com as regras dos especialistas em instrumentação.

Esse sistema de monitoração e diagnóstico se faz relevante, pois auxilia as equipes de operação e manutenção a estabelecer uma programação de reparos e acompanhamento da vida útil do componente. Através da análise da assinatura eletrônica de cada componente, podem-se prever os tipos de falhas que virão a ocorrer e quando elas de fato ocorrerão. 


\section{2- Objetivo}

O presente trabalho tem por objetivo desenvolver um sistema de monitoração e diagnóstico aplicado a válvulas de controle do LATEP e posteriormente ser utilizado no LABGENE, que se encontra em construção.

Os objetivos específicos do trabalho (vide Tabela 1) são:

- Fazer uso do sistema de automação Delta $V$, adquirido pela MB, especialmente do módulo valvelink, para realizar coleta da assinatura eletrônica das válvulas, explorando as informações técnicas operacionais dos dispositivos em questão;

- Implementar recursos de ferramentas de IA, no caso específico a lógica fuzzy ou lógica nebulosa, para análise dos gráficos do módulo valvelink, do sistema de automação Delta $\mathrm{V}$, oriundos dos posicionadores inteligentes instalados na planta de processo do LATEP; e - Realizar a análise das assinaturas das válvulas, identificando de forma preditiva, sintomas de defeitos, principalmente em estado incipiente, e falhas como: desgaste, má instalação, dano, vazamento etc.

Tabela 1 - Diagrama de blocos do sistema, com a inserção do módulo de monitoração e diagnóstico (Sistema de Lógica Fuzzy).

Válvula/Posicionador
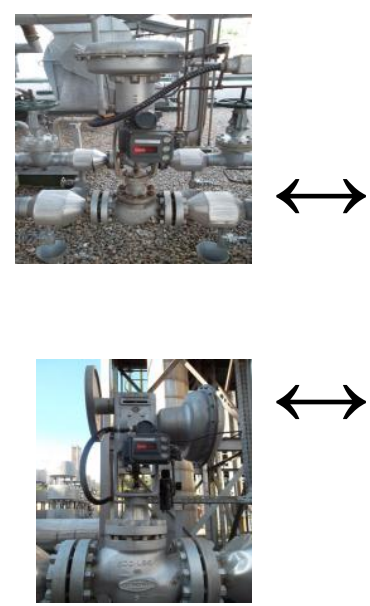

Campo
Delta V

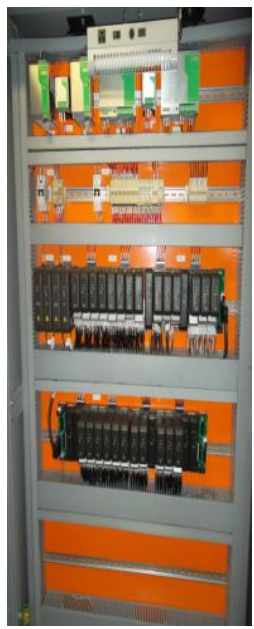

Sala de Controle
Interface Homem-Máquina

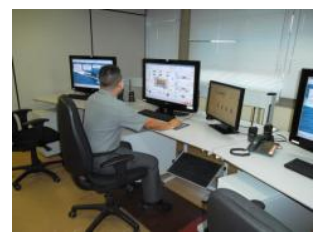

Sistema

de

Lógica Fuzzy

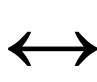

Sala de Controle 


\section{1- Aspectos relevantes e contribuições do trabalho}

A seguir são apresentados os aspectos relevantes e as contribuições devidas por esse trabalho:

- Implementação de um sistema, que monitore e forneça um diagnóstico das condições operacionais de válvulas de controle de acionamento pneumáticos utilizados em plantas nucleares que necessitam de acompanhamento integral de funcionamento, contribuindo na identificação de falha de forma antecipada;

- Utilização de um recurso da IA, a Lógica Nebulosa, largamente utilizada em modelagens de problemas que, através de regras desenvolvidas por especialistas, permite diagnosticar falhas através de comparações com situações de referência, fazendo uso de métodos de inferência;

- Ampla utilização dos recursos técnicos disponíveis na planta: o sistema de automação industrial DELTA $V^{\circledR}$, acrescido de seu módulo VALVELINK ${ }^{\circledR}$, e da integração com a linguagem MATLAB ${ }^{\circledR}$ através do software fuzzy logic "toolbox" proporciona uma boa interface homem-máquina;

- Implementação futura desse sistema em usinas nucleares e submarinos de propulsão nucleares brasileiros, podendo ser estendido sua aplicação às plantas de processo convencionais que possuam restrições severas quanto às paradas de manutenção; e

- Intercâmbio técnico e científico com instituições nacionais e internacionais de excelência na área de Prognostic Healthy Management - PHM, como IPEN; CTMSP, Departamento de Engenharia Nuclear da Universidade do Tennessee EUA, Departamento de Energia da Universidade Politecnica di Milano, Itália, proporcionado pela participação em conferência Internacional com foco em monitoração e diagnóstico, Milão, Itália - 2013. 


\section{3- Histórico}

A pesquisa bibliográfica realizada, no que tange aos sistemas de monitoramento e diagnóstico, mostra que, desde 1992 [02], cerca de 30\% das malhas de controle tem comportamento oscilatório indesejado devido a problemas nas válvulas de controle.

Em 2001 [03] abordou-se o conceito de stiction, uma combinação de stick (haste) com friction (fricção), ou seja, a quantidade de fricção que a haste ou plug de uma válvula pode sofrer. Este artigo aponta como medir e corrigir via on line, a fricção em válvulas de controle, apresentando algumas técnicas não intrusivas, como por exemplo: ajuste do posicionador da válvula através da variação do ganho proporcional e sem a ação integral.

Em 2002 [04], uma pesquisa realizada na indústria reportou problemas em válvulas de controle em $32 \%$ de malhas de controle com controladores classificados como pobre ou fraco. Este trabalho introduz também o conceito de algumas não linearidades existentes em válvulas de controle como stiction (fricção), backslash (folga entre peças) e deadband (banda morta), que podem causar comportamentos oscilatórios não desejados em válvulas de controle. Dentre as não linearidades citadas, afirma que a fricção é um dos problemas mais comuns encontrados na indústria.

O trabalho [05] de 2004, também detecta e quantifica stiction em válvulas de controle, e afirma que a friç̧ão é um dos maiores problemas em válvulas de controle do tipo diafragma (com atuador a ar comprimido). Em 2005, o mesmo autor, publica outro artigo [06], onde, com um simples teste, pode-se confirmar a presença de fricção nas hastes das válvulas de controle.

Conforme [05], a fricção pode ser facilmente detectada através de meios invasivos como, por exemplo, excursionamento da válvula. Todavia, esta ação causa impacto na segurança operacional, parada de unidade, perdas econômicas, etc.

Afirmam Camila Pinto e Gustavo de Almeida [07], que a principal atribuição da área de monitoramento de processos em indústrias é evitar e minimizar possíveis perdas como, por exemplo: produção fora das especificações, paradas não programadas e operações inseguras. A sequência de etapas em uma atividade de monitoramento é dada pela 
detecção e diagnóstico preciso de falhas, com a posterior recuperação das operações, a partir da intervenção dos operadores.

Conforme Bartys, M.; de Las Heras, S.; Syfert, M.; Patton, R.; Quevedo, J. [8,9], na área de controle de processos industriais, a bancada chamada DAMADICS - Development and application of methods for actuator diagnosis in industrial control systems é usada como estudo de caso e pode simular 19 (dezenove) tipos de falhas, abruptas ou incipientes, para 03 (três) elementos finais de controle.

O sistema de detecção de falhas deve ser submetido a condições normais e anormais de operação. E para o caso de falhas incipientes, deve ser acompanhado com maior interesse. Pois ao contrário da falha abrupta, que é de pronto conhecida e causa impacto na planta de processo, levando a necessidade de uma ação de correção imediata; a incipiente, devido à detecção precoce, permite a redução e minoração de perdas, que é impossível de se fazer em falhas abruptas [07].

Existem vários estudos publicados sobre métodos invasivos e não invasivos, a saber: Sharif e Grosvenor, 1998 [10]; Gerry and Ruel, 2001 [11]; Horch, 1999 [12]; Rengaswamy et al., 2001[13]; Stenman et al., 2003 [14].

O método Horch [11] detecta fricção através da correlação entre a entrada e saída de um controlador. Correlação da variável de processo - VP ou process variable - PV, como entrada, por exemplo, nível, temperatura, pressão, vazão, e do sinal pneumático ou elétrico como saída do controlador. É um método muito aplicado para detecção de fricção em válvulas de controle de fluxo. Todavia é desaconselhado o seu uso em malhas de controle com ação integral ou aquelas que transportam fluidos compressíveis.

Outro método, o de Rengaswamy [13], trata-se de um modelo baseado em detecção de fricção por medidas de confiabilidade, utilizando a análise no domínio da frequência de sistemas de loop fechado.

O método de Stenman [14] descreve um modelo baseado na segmentação de um sinal de ruído de comprimento limitado, utilizando um banco de filtros multi modo para detectar a fricção. Este método requer um processo de ajuste de vários parâmetros (banda morta, 
amplitude dos picos de ruído, variância, posição da válvula, largura dos pulsos, etc.), o qual para obter em uma malha de controle fechada em operação de rotina, torna mais complexo o processo de aquisição de dados. Ademais, estes métodos somente detectam fricção, mas não a quantificam.

Conforme apontado em [04], um método passivo, ou não invasivo que possa classificar automaticamente a confiabilidade de uma válvula de controle em uma malha de controle fechada é uma necessidade premente da indústria. Uma vez implementado, este método reduziria o custo de manutenção das malhas de controle, pois seriam indicadas e relacionadas todas as válvulas que necessitariam de intervenção.

O método proposto nesta dissertação é do tipo passivo/não invasivo e consiste na análise gráfica do excursionamento da válvula em $(\mathrm{mm})$ e da pressão de alimentação de ar comprimido (em PSI - Pressure Square Inch), utilizando IA. Ainda não muito explorado, bem indicado para válvulas de controle, tem uma fácil modelagem, e não se trata de uma implementação custosa e complexa. Pode-se ressaltar a existência de outras técnicas de monitoração como, por exemplo:

a) Monitoração visual: requer a presença do especialista ou operador diretamente na área industrial a fim de verificar o funcionamento da válvula;

b) Acústica: analisa o comportamento acústico do escoamento fluido, podendo identificar pelas diferenças das assinaturas acústicas, a válvula em bom funcionamento ou com degradação, todavia é mais para fluidos bifásicos;

c) Por vibração: mais indicado para elementos rotativos como turbinas e geradores, todavia consiste de sensores instalados em partes do equipamento a fim de captar sinais dos equipamentos, que interpreta como defeitos, folgas, desbalanceamentos etc.;

d) Por tribologia: através da análise do óleo lubrificante pode-se determinar a condição do próprio óleo e do equipamento no qual ele está circulando (atende apenas a válvulas que possuem sistema de lubrificação). A comparação/constatação de vestígios de metais através da composição química dos detritos existentes no óleo pode indicar o risco ou probabilidade de falha de determinado equipamento. 


\section{1- Estado da Arte}

Um método de monitoração e diagnóstico semelhante foi desenvolvido por Guimarães Carneiro [15] para aplicação em válvulas moto-operadas. Neste trabalho era analisado a assinatura de potência elétrica dos motores de acionamento durante os ciclos de abertura e fechamento.

Os dados deste método eram gerados a partir de um programa em EXCEL ${ }^{\circledR}$, onde se fez uma regressão percentual dos valores das magnitudes das potências em função do tempo nos instantes em que as medidas obtidas apresentavam significativas descontinuidades. Este método é não intrusivo e torna possível a identificação de falhas incipientes contribuindo significativamente no planejamento de manutenção da planta.

O método desta dissertação aplica-se às válvulas de controle com acionamento pneumático. Tanto este método, quanto o desenvolvido por Guimarães são não intrusivos e contribuem para a segurança da planta nuclear, que necessita de uma previsão de falha de componentes, podendo, assim, evitar uma parada não programada de uma unidade e consequentemente elevar o grau de confiabilidade da operação do sistema. Ambos os métodos usam o MATLAB como ferramenta de apoio, em particular o fuzzy logic toolbox.

Não existem no país sistemas de diagnósticos para válvulas de controle de ação pneumática. Existem, entretanto, produtos estrangeiros patenteados e comercializados por empresas nacionais. Como exemplo, a própria empresa EMERSON oferece o serviço de análise de assinatura de válvulas e o preço é bem elevado.

No meio acadêmico verifica-se a existência de vários artigos tratando preferencialmente das válvulas moto-operadas [15]. Uma exceção deve-se ao trabalho de Daniel Uehara [16] que discorre sobre detecção e qualificação de atrito em válvulas de controle. Todavia não há um diagnóstico preciso de problemas que podem ocorrer com a válvula e seu método não faz uso da lógica fuzzy para auxílio na detecção.

Daniel Uehara [16] comenta que o método utilizado no seu trabalho é satisfatório, mas não é preciso na detecção de falhas. Em nível internacional, foi encontrada uma aplicação de lógica fuzzy para válvulas de controle, direcionado ao controle de ar dos colchões 
infláveis de um veículo tipo overcraft para uso em pântano e áreas alagadas [17]. 


\section{4 - Sistema Especialista (SE)}

No século 20 obtiveram-se os primeiros desenvolvimentos de alternativas à teoria da probabilidade e à lógica clássica aristotélica, como paradigmas para acessar mais tipos de incertezas de valores.

Jan Lukasiewicz desenvolveu a lógica discreta de multivalores nos anos 30. Em 1960, Arthur Dempster desenvolve a teoria da evidência, incluindo uma valoração para ignorância ou ausência de informação [18].

De um ponto de vista histórico, os fundamentos da IA surgem na década de 50 . A visão tradicional da lógica clássica começa a ser mudada. A incerteza, que antes era um estado indesejável e deveria ser evitado a qualquer custo, começa a ser aceita.

Quando a lógica matemática clássica era soberana, a Teoria das funções recursivas guiava a formulação de processamento de listas e das linguagens de programação existentes. Surgiam também os computadores interativos, que eram usados para desenvolver e depurar programas incrementais [15].

Em 1965, Zadeh introduz os conjuntos nebulosos, tendo uma profunda influência no pensamento da incerteza [19]. Este fato ocorreu não somente desafiado pela teoria da probabilidade, mas também por outros fundamentos, como a lógica clássica (binária). Surge, então, a ideia da lógica de valor contínuo, denominada de lógica nebulosa (fuzzy).

A incerteza pode ser pensada epistemologicamente como o inverso da informação [19]. A informação sobre um problema particular científico ou de engenharia pode ser incompleto, impreciso, fragmentado, vago ou deficiente. Quando se adquire mais informações sobre um problema, a incerteza sobre sua formulação e solução torna-se menor.

Nesta época (anos 60), psicólogos cognitivos criam caminhos padrões do processo de investigação do raciocínio, modelando o aparente processo de tomada de decisão em regras de produção condicionais. Os pesquisadores de IA tentam simular o complexo processo do pensamento, procurando métodos gerais para resolver uma ampla classe de problemas, entretanto, a despeito de alguns progressos, as dificuldades foram enormes devido ao estágio tecnológico que a sociedade ainda se encontrava. 
Nos anos 70 esforços foram realizados para desenvolver técnicas de como se poderia representar o processo de investigação do raciocínio/tomada de decisão e tornar a sua solução mais fácil de computar, ou seja, trabalhar com ela dentro de uma arquitetura computacional.

Nos anos 80 devido à consolidação e ao avanço da eletrônica e da informática a capacidade computacional em resolver problemas cresceu bastante. Com este crescimento produziram-se programas de computador de propósito particular denominados de SE.

SE são sistemas cognitivos desenvolvidos através da Engenharia do Conhecimento [15] e constituem uma área da IA voltada à aplicação do conhecimento para resolver problemas técnicos específicos, utilizando métodos inferenciais. Eles são programas destinados a solucionar problemas em campos específicos de conhecimento. Estes programas devem ter desempenho comparável ao dos especialistas humanos na execução dessas tarefas.

O conhecimento de um SE consiste em fatos e heurísticas. Os fatos constituem um corpo de informações que são largamente compartilhadas, publicamente disponíveis e geralmente aceitas pelos especialistas em um determinado campo.

As heurísticas são regras privadas de raciocínio plausível e boa conjectura, que caracterizam a tomada de decisão no nível de um especialista da área. De maneira geral, SE são programas de computador que resolvem problemas que os seres humanos resolveriam emulando o raciocínio de um especialista, por meio da aplicação de conhecimentos específicos e inferências. O nível de desempenho de um sistema especialista é função, principalmente, da qualidade do banco de conhecimento que possui.

\section{1- Principais componentes do SE}

Baseando-se na premissa de que SE não possuem domínio total da informação de sua especialidade, o SE necessita oferecer ao usuário uma resposta mais próxima das respostas ideais, logo, a resposta próxima da ideal será a escolhida para saída do SE. 
Dentro das muitas arquiteturas de SE, existe uma que se destaca pela simplicidade de compreensão, sendo denominada de "Estruturação Básica". Ela é dividida em três partes básicas: Base de Conhecimento, composta de fatos e regras que abrigam o conhecimento adquirido do especialista do domínio; o mecanismo de inferência; e a interface com o usuário [20]. Abaixo, na figura 3 tem-se uma representação gráfica das interligações dos componentes da Estrutura Básica.

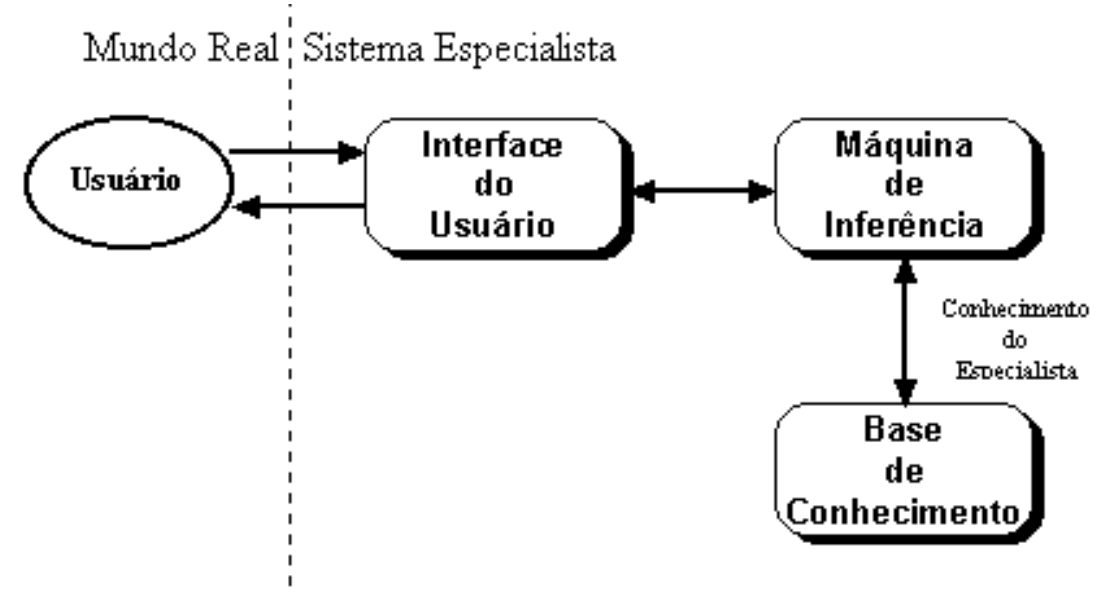

Figura 3 - Componentes de um SE baseado na Estrutura Básica.

A base do conhecimento (fatos e regras) pode ser subdividida em: coleções de Objetos, que são as conclusões a que o Sistema deve chegar; e atributos, que são as propriedades que servem para caracterizar os objetos.

Os mecanismos de inferência podem ser do tipo "Encadeamento para diante" ou "Encadeamento para trás". No primeiro, selecionam-se atributos até obter uma combinação deles que caracterize um objeto; no segundo seleciona-se um objeto, como sendo a hipótese de estudo, e busca-se determinar a viabilidade da aceitação dessa hipótese pela ocorrência ou não dos atributos adequados. Caso a hipótese falhe seleciona-se outra hipótese e prossegue-se com as tentativas.

Uma memória de trabalho contém os dados acessíveis globalmente pelos restantes dos componentes do SE. A máquina de inferência controla o processo dedutivo da base do conhecimento.

Trabalha-se ainda com estruturas do tipo "IF" e estes componentes denominam-se base 
de regras. Dependendo do software de suporte empregado em seu desenvolvimento, um "IF" pode apresentar outros componentes tais como:

- Editores dedicados, que acompanham o processo de inferência passo a passo com a ideia de corrigir falhas no desempenho do sistema;

- Editores gráficos, que suportam a implementação de recursos gráficos aumentando a capacidade interativa do SE;

- Interfaces para outros sistemas de informação, que suportam o acesso do "IF" à informação armazenada na base de dados, planilhas eletrônicas, etc; e

- Módulo de explicação, que são mecanismos que fornecem a sequência de heurística a ser empregada para obter certa conclusão.

\section{2- Características gerais do SE}

Para entender quais são as características do SE, é apresentada a seguir, as ações por eles executadas [21]:

1. Resolvem problemas complexos, tão bem, ou melhor, que especialistas humanos;

2. Raciocinam heuristicamente, usando regras práticas;

3. Interagem com usuários humanos utilizando inclusive linguagem natural;

4. Manipulam e raciocinam sobre descrições simbólicas;

5. Funcionam com dados errados e regras incertas de julgamento;

6. Contemplam hipóteses múltiplas simultaneamente;

7. Explicam porque estão fazendo determinada pergunta; e

8. Justificam suas conclusões.

O núcleo de um SE é a potência do corpo de conhecimento acumulado durante sua construção. Este conhecimento é explícito e organizado de forma a simplificar o processo de decisão. A importância deste fato deve ser suficientemente enfatizada, pois a acumulação e codificação de conhecimento é um dos mais importantes aspectos de um SE.

Esta implicação transcende à simples construção de programas para efetuar alguma tarefa, dado que o conhecimento que alimenta o SE é acessível, ao contrário do que ocorre com programas convencionais. 
A maior capacidade de um SE consiste em sua especialidade de alto nível que auxilia na solução de problemas. Este conhecimento especializado pode representar a experiência dos melhores peritos no campo. Sua especialização de alto nível, acompanhada da habilidade de aplicação, torna seu custo competitivo e apto a ganhar espaço no mercado comercial.

O corpo de conhecimento do sistema que define a proficiência de um SE pode também oferecer uma capacidade adicional: a memória condensada. Se a base de conhecimento foi desenvolvida através de interação de pessoas-chave, esta compilação de conhecimento vem a ser "um saber de alto nível", um registro permanente. As pessoas chaves passarão, mas as suas experiências permanecerão.

\section{3- Classificações do SE}

Assim como qualquer outro tipo de sistema, os SE podem ser classificados de diversas formas. Quanto a sua forma de funcionamento, existem 10 possíveis categorias a saber: interpretação, diagnóstico, monitoramento, predição, planejamento, projeto, depuração, reparo, instrução e controle [22]. A seguir será descrito brevemente cada uma das formas possíveis de funcionamento de um SE.

SE de Interpretação são Sistemas que inferem descrições de situações a partir da observação de fatos, fazendo uma análise de dados e procurando determinar as relações com seus significados.

Devem considerar as possíveis interpretações, descartando as que se mostrarem inconsistentes. Partindo do princípio de que um SE possua uma ampla base de conhecimento, ele interpretará e proverá a descrição de situações de solução para determinados problemas. Assim é realizada uma análise nos pontos-chave do problema e relacionando-se com as situações parecidas que este tenha em sua base de conhecimento.

Desta forma, é possível fazer uma análise por aproximação (baseando-se em lógica Fuzzy, por exemplo) das causas que sejam parecidas com a causa do atual problema, e 
oferecer uma solução equivalente à de outros problemas apresentados. As demais soluções que possuam um grau de acerto inferior são descartadas.

Ainda nesta linha de pensamento existem os Sistemas de apoio à decisão dos SE de interpretação. Geralmente, eles são interligados por módulos ao próprio SE de interpretação. As falhas de solução que um SE de interpretação possa gerar são diversas. Tais falhas podem ser de interpretação de dados ou de diagnóstico. Com base nestas falhas, efetua-se uma correção na base de dados dos SE. Desta forma atua-se sobre as possíveis respostas que um SE de interpretação possa concluir, como sendo a resposta mais próxima de estar correta.

SE de Diagnóstico são Sistemas que detectam falhas oriundas da análise de dados. Esta análise pode conduzir a uma conclusão diferente da simples interpretação de dados. Eles detectam os problemas mascarados por falhas dos equipamentos. Estes SE já têm embutido o sistema de interpretação de dados.

SE de Monitoramento são Sistemas que interpretam as observações de sinais sobre o comportamento monitorado. Realiza-se uma verificação de um determinado comportamento em limites preestabelecidos, e sinaliza-se quando forem requeridas intervenções para o sucesso da execução. Um sinal poderá ser interpretado de maneiras diferentes, de acordo com a situação global percebida naquele momento, e a interpretação varia de acordo com os fatos que o sistema percebe a cada momento.

Eles atuam em conjunto com sistemas comuns, e monitoram determinado comportamento desses sistemas e informam ao usuário humano, as intervenções necessárias do usuário. Desta forma, eles realizam uma interpretação do status do sistema, aguardando momentos onde o sistema necessite de entradas humanas para que a operação seja concluída com sucesso. Um exemplo é o Adobe Acrobat Updater.

SE de Predição: a partir de uma modelagem de dados do passado e do presente, este sistema permite uma determinada previsão do futuro. Ele baseia sua solução na análise do comportamento dos dados recebidos no passado, e tem mecanismos para verificar os vários futuros possíveis a partir da análise do comportamento desses dados. Este SE faz uso de raciocínios hipotéticos, sendo ainda verificada a tendência de acordo com a 
variação dos dados de entrada.

Diferentemente de um SE de planejamento, este sistema apenas informa aos usuários humanos, os possíveis problemas futuros e não toma decisão alguma de alterações, que fica a cargo do operador humano do sistema.

SE de Planejamento: Neste caso, o sistema prepara um programa de iniciativas a ser tomado para se atingir um determinado objetivo. São estabelecidas etapas e subetapas e, em caso de etapas conflitantes, são definidas as prioridades. Este SE possui características parecidas com o sistema para a predição. Normalmente, ele opera em problemas de grande porte e de solução complexa. O princípio de funcionamento, em alguns casos, é por tentativas de soluções, cabendo a análise mais profunda ao especialista que trabalha com esse sistema. Ele enfoca os aspectos mais importantes e divide de maneira coerente um problema em subproblemas menos complexos, estabelecendo sempre o relacionamento entre eles.

SE de Projeto: este SE tem características parecidas com os SE de planejamento, e devem confeccionar especificações tais, que sejam atendidos os objetivos dos requisitos particulares do projeto. É um sistema capaz de justificar a alternativa tomada para o projeto final, e de fazer uso dessa justificativa para alternativas futuras. Ele busca soluções alternativas a problemas encontrados pelos SE de planejamento, oferecendo alternativas com o mínimo de alterações no resultado final. Logo, ele gera justificativas plausíveis para explanar sobre as mudanças nas fases de planejamento, atacando as subtarefas geradas pelos SE de planejamento.

SE de Depuração: Trata-se de sistemas que possuem mecanismos para fornecerem soluções para o mau funcionamento provocado por distorções de dados. Ele possui soluções para mitigar este possível mau funcionamento provocado por distorção das bases de dados e de regras do sistema. Desta forma, ele age como um agente de validação de quebra de regras de um SE, validando os processos executados dentro do sistema e identificando possíveis procedimentos danosos ao programa.

SE de Reparo: Este sistema desenvolve e executa planos para administrar os reparos verificados na etapa de diagnóstico. Um SE para reparos segue um plano para 
administrar alguma solução encontrada em uma etapa do diagnóstico. São poucos os sistemas desenvolvidos porque o ato de executar um conserto em alguma coisa do mundo real é uma tarefa complexa. Este SE executa correções sugeridas pelos SE de depuração, administra falhas que necessitam de paradas de sistema para conserto e agenda tais paradas para efetuar a manutenção. Como se tratam de sistemas complexos de alto impacto, muitas paradas de processo são ocasionadas neste caso.

SE de Instrução: este SE tem um mecanismo para verificar e corrigir o comportamento do aprendizado dos estudantes. Normalmente, incorporam como subsistemas, um sistema de diagnóstico e de reparo, e tomam por base uma descrição hipotética do conhecimento do aluno. Seu funcionamento consiste em interagir com o treinando. Em alguns casos, apresenta uma pequena explicação e, a partir daí, sugere situações para serem analisadas pelo treinando. Dependendo do comportamento deste, se vai aumentando a complexidade dos cenários e encaminha-se o assunto, de maneira didática, até o nível intelectual desejado. SE de instrução tem por objetivo de propor desafios a seu operador, de forma a instruí-lo a realizar determinadas tarefas, de forma a ensinar sobre determinado assunto a um possível estudante, que irá operar o sistema. Este SE pode incorporar sub SE, como de depuração ou reparo, para que o estudante possa obter situações parecidas durante a operação com o sistema.

SE de Controle: É um Sistema que governa o comportamento geral de outros sistemas. É o mais completo, pois deve interpretar os fatos de uma situação atual, verificando os dados passados e fazendo uma predição do futuro. Apresenta os diagnósticos de possíveis problemas, formulando um plano para sua correção. Este plano é executado e monitorado para que o objetivo seja alcançado. Trata-se de um SE de maior nível de complexidade, que controla diversos tipos de sistemas, não somente os computacionais. Realiza análises baseadas nos SE de diagnóstico e predição, de forma a determinar horizontes de negócio para os próprios SE incorporados a ele.

\section{4- SE via Lógica Fuzzy}

A lógica digital convencional trata uma variável assumindo apenas dois possíveis estados: falso ou verdadeiro. Embora boa parte dos casos, essa representação seja suficiente, há situações em que se desejam valores intermediários. Poder-se-iam usar valores 
analógicos, mas neste caso haveria equações matemáticas complexas e muitas vezes requer alto custo computacional, inviabilizando a resposta adequada em tempo hábil. Neste ponto é que aparece a lógica nebulosa ou lógica difusa, ou ainda a lógica fuzzy. Ao Lotfi Zadeh é atribuído o reconhecimento de grande colaborador do Controle Moderno. Desde a década de 60, Prof. Zadeh observou que os recursos tecnológicos disponíveis eram incapazes de automatizar as atividades relacionadas a problemas de natureza industrial, biológica, química ou nuclear, que compreendessem situações ambíguas, não passíveis de processamento através da lógica computacional fundamentada na lógica booleana. Procurando solucionar esses problemas, o Prof. Zadeh publicou em 1965 um artigo resumindo os conceitos dos conjuntos nebulosos, revolucionando o assunto com a criação dos sistemas especialistas nebulosos ou difusos (fuzzy) [23].

Em 1974, o Prof. Mamdani do Queen Mary College, Universidade de Londres, após inúmeras tentativas frustradas em controlar uma máquina a vapor com tipos distintos de controladores, somente conseguiu fazê-lo através da aplicação do raciocínio nebuloso (fuzzy). Neste mesmo ano ele descreve SE via lógica fuzzy para plantas industriais usando síntese linguística [24].

A tecnologia da lógica fuzzy alcançou sucesso em diversas aplicações desde então, como por exemplo, produtos de consumo em massa (eletrodomésticos).

Algumas aplicações de SE via lógica fuzzy no controle de sistemas mecânicos são [25]:

- Aspiradores de pó Matsushita usam controladores de quatro bits rodando algoritmos que ajustam o poder de sucção;

- Máquinas de lavar Hitachi usam controladores fuzzy para controle de peso, verificação de tipo de tecido e sensores de sujeira, que automaticamente designam os ciclos de lavagem para uso otimizado de potência, água e detergente;

- Ar condicionado industrial projetado pela Mitsubishi usa vinte e cinco regras de resfriamento e de aquecimento. Um sensor de temperatura fornece a entrada, com controle de saída alimentado por um inversor, uma válvula compressora e um ventilador. Comparado com o projeto anterior, o ar-condicionado com controlador 
fuzzy aquece cinco vezes mais rápido, reduz o consumo de potência em $24 \%$ e usa menos sensores; e

- Uma máquina de lavar prato "inteligente" baseado em um controlador fuzzy e um módulo sensor que combina um tiristor (para medida de temperatura), um sensor condutivo (para medir o nível de detergente através dos íons presentes na água), um sensor de turvação, que difunde a medida e transmite luz para medir a sujeira na lavagem, e um sensor magnético para ler a taxa de giro. O sistema determina uma otimização no ciclo de lavagem para qualquer carga, de forma a obter os melhores resultados com o mínimo de energia, detergente e água.

Outra aplicação interessante de SE via lógica fuzzy é a determinação de parâmetros de controle de altitude e condução de aeronaves não tripuladas (Rockwell Corp.), onde existe uma série de regras baseadas em variáveis e valores linguísticos. Podem ainda serem exemplificadas aplicações em diversas áreas como [25]: Operação do metrô de SendaiJapão (Hitachi), Transmissão automática (Nissan, Subaru), Docagem dos ônibus espaciais (NASA), Elevadores (Hitachi, Fujitech, Mitsubishi), Análise do mercado de ações (Yamaichi), Ajuste da imagem de TV (Sony), Autofoco para câmera de vídeo (Canon), e Estabilizador de imagens de vídeo (Panasonic).

As aplicações de SE via lógica fuzzy na área nuclear são extensas. Muitas dessas aplicações foram implementadas no campo por suas características práticas. De maneira geral podem ser citadas: Aplicação de SE via Lógica Fuzzy para avaliação de confiabilidade humana para ensaios de ultrassom na Usina de Angra 2; para seleção de áreas capazes de receber sítios nucleares de potência no território brasileiro; para diagnosticar a saúde de válvulas de controle de processo em plantas nucleares [26]; Prognóstico de Gerenciamento de saúde em Plantas Nucleares de Potência [27]; e Predição de vida útil remanescente em um cenário de falha de um sistema nuclear [28]. 


\section{1- Lógica nebulosa}

Os fundamentos de IA se estabelecem nos anos 50, incluindo lógica matemática e teoria de funções recursivas. Também computadores interativos surgem, tornando possíveis ambientes para desenvolvimento e depuração de programas incrementais [15].

Nos anos 60, pesquisadores de IA tentam simular o complexo processo do pensamento. Conforme afirmou Lofti Zadeh em 1965 [19] a imprecisão definida em classes denota um importante papel no pensamento humano, particularmente no reconhecimento de padrões, na comunicação da informação e abstração.

Daí o conceito de sistemas especialistas: sistemas cognitivos desenvolvidos através de engenharia do conhecimento para resolver problemas técnicos específicos utilizando métodos inferenciais.

Este conhecimento consiste de fatos (informações largamente compartilhadas, publicamente disponíveis e geralmente aceitas pelos especialistas de determinada área) e heurísticas (regras privadas de raciocínio plausível e boa conjectura, que caracterizam a tomada de decisão) [15].

Os principais componentes de um sistema especialista são: dispositivos de inferência, base de conhecimento, e interface com o usuário. Podem ser classificados como interpretadores, de diagnóstico, de monitoramento, de predição, de planejamento, de projeto, de depuração, de reparo, de instrução e de controle [22].

O trabalho desenvolvido nesta dissertação contempla a monitoração e diagnóstico de válvulas de controle utilizando sistemas especialistas de IA, com aplicação da Lógica Fuzzy, ou lógica nebulosa.

A lógica digital tradicional trabalha apenas com dois estados: 0 ou 1. Todavia, quando há necessidade de valores intermediários a situação se torna mais complexa. Surge então a lógica nebulosa. Baseados nisso, alguns conceitos fuzzy em engenharia podem ser definidos. Conceitua-se a seguir os termos e seu uso contextual: correlação (baixa, média, alta e perfeito), estabilidade (instável, estável etc), erros (grande, médio, pequeno, não tão grande, muito grande, muito pequeno, quase zero etc), frequência (alta, baixa, ultra-alta etc), largura de banda (banda larga e banda estreita), amostra (taxa baixa, taxa média, taxa alta etc), resolução (alta e baixa) etc. 
Também em [19] Zadeh afirma que esta imprecisão difere a lógica nebulosa da lógica clássica de dois valores. No sistema clássico de dois valores, todas as classes têm fronteiras perfeitamente definidas. Desta maneira, o membro de uma classe, não pode ser membro de outra. Um bom exemplo disso são as classes do tipo gênero: macho ou fêmea e vivo ou morto. O que se percebe é que a lógica nebulosa é uma generalização da lógica clássica de dois valores. Esses sistemas também são chamados de lógica de multivalores.

O sucesso do Prof. Mandani, do Queen Mary College [24], da Universidade de Londres, na técnica desenvolvida pelo Prof. Zadeh no controle de uma máquina a vapor estimulou muitas outras aplicações no mundo acadêmico e industrial, por exemplo, controle nebuloso para plantas industriais, refinarias, processos biológicos e químicos, tratamento de água, sistema de operação automática de trens etc. Ademais tem o referido professor uma grande contribuição no módulo de lógica nebulosa presente no toolbox do software MATLAB ${ }^{\circledR}$, que Inclusive tem o seu nome [29].

\subsection{1- Características e vantagens da lógica nebulosa}

A lógica nebulosa tem como vantagens a aproximação do pensamento humano, devido ao uso das variáveis linguísticas, a requisição de poucas regras, valores e decisões, o que simplifica a aquisição da base de conhecimento e proporciona um rápido protótipo dos sistemas, simplificando a solução de problemas [15].

Um bom exemplo a ressaltar foi o uso de recursos existentes no software MATLAB com lógica nebulosa, aplicado na indústria automobilística, que foi encomendado à academia, realizado por um grupo da Universidade de Ohio [30], a pedido do Departamento de Energia Americano.

Outra vantagem da lógica nebulosa é a aquisição da experiência dos operadores da planta e a rapidez de processamento de dados inerente aos computadores. Os resultados numéricos de vários módulos de processamento de sinais são fuzzificados, e tem incorporado o intelecto dos engenheiros e analistas através das regras nebulosas. 
O sistema nebuloso, baseado em regras, pode usar vários processos de inferência nebulosa. O método Mandani é um dos mais conhecidos. As regras nebulosas e os "fatores de peso" são combinados em um módulo particular que gerará a saída a ser fuzzificada.

Os pesos são escolhidos para refletir a confiança de cada sinal de entrada processado, que pode propriamente identificar uma falha dada em um sistema ou equipamento em particular. A carga computacional para um sistema nebuloso é tal que a análise do sinal pode ser realizada em tempo real. A arquitetura modular permite a inserção de novas técnicas no estado da arte.

Uma base de regras é criada permitindo que a percepção humana de uma situação seja representada matematicamente. Uma base de regras de lógica nebulosa tem uma abordagem genérica no senso que as regras são óbvias para a variável de estado particular que está sendo medida. Estando baseadas em palavras e não em números, os valores verdade são expressos linguisticamente (quente, frio, longe, perto etc) e possuem modificadores de predicado (muito, pouco, grande, pequeno etc).

O uso desta "probabilidade linguística", interpretada como números nebulosos, manuseia valores entre 0 e 1 . Por requerer poucas regras, valores e decisões, o uso dessas variáveis linguísticas aproxima o sistema do pensamento humano [15].

A seguir, a fig. 4, conforme ensina Mendel [31], é apresentado um diagrama em blocos típico de um Fuzzy Logic System - FLS largamente utilizado em controladores Fuzzy Logic e aplicações de processamento de sinais. O FLS mapeia entradas crisp para saídas crisp. O termo crisp é como Mendel nomeia as variáveis provenientes da lógica clássica. O diagrama contém quatro blocos, a saber: regras, fuzzificador, mecanismo de inferência e defuzzificador.

Uma vez estabelecidas as regras, o diagrama pode ser expresso por uma relação $y=f(x)$. Um dos maiores objetivos do FLS é obter fórmulas explícitas para mapeamentos não lineares entre x e y. As regras são providas pelos especialistas ou podem ser extraídas dos dados numéricos (onde entrará a expertise do especialista em válvulas e a massa de 
dados a ser informada pelo grupo de instrumentação da planta de processo).

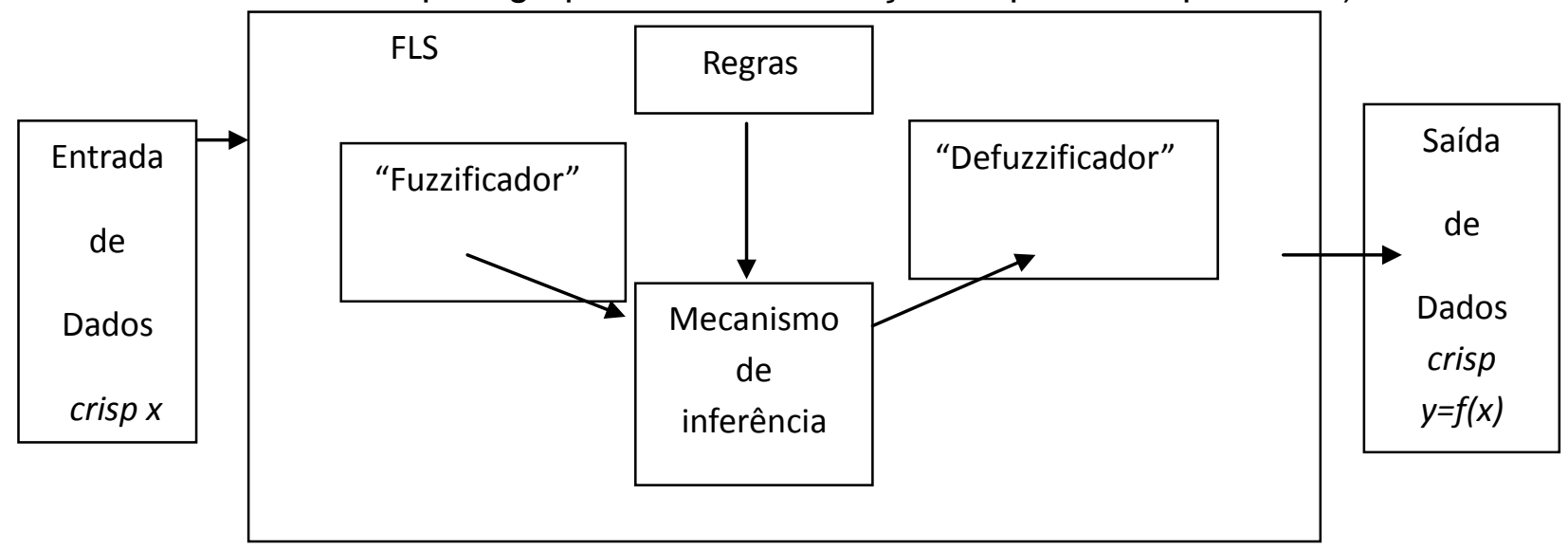

Figura 4 - Diagrama em bloco de um FLS [24].

Os dados de entrada, fig.4, considerados como entrada crisp, serão fuzzificados (transformação de um dado ou variável de entrada em grau de pertinência - valores de 0 a 1, de acordo com a função de pertinência adotada - fig.5) e tratados pelo mecanismo de inferência, comparados com gráficos de uma válvula "saudável" e de acordo com as regras carregadas pelos especialistas (conhecimento tácito sobre os mais variados defeitos existentes nas válvulas e na sua operação) seguirão para o último bloco do sistema onde serão defuzzificados para sinais de saída na forma crisp. O termo crisp é uma nomenclatura que se refere a valores do tipo escalar.

\subsection{2- Conjunto nebuloso}

Para melhor compreender, as etapas de fuzzificação e defuzzificação, na fig.4 se introduz o conceito de conjunto nebuloso. Ao contrário da teoria clássica de conjuntos e sua rigidez matemática, a lógica nebulosa apresenta o termo pertinência como uma questão de grau com variações graduais. Sejam $A$ e $B$ dois conjuntos:

Conjunto clássico $A=\{0,1\}$ valores discretos 0 e $1 ; e$

Conjunto nebuloso $B=[0,1]$.

A função pertinência pode assumir valores contínuos no intervalo de 0 a 1 . A pertinência " $x$ " de um subconjunto nebuloso " $B$ " de " $x$ " pode ser descrito como:

$\mu в: x \rightarrow[0,1]$;

onde $\mu в$ é o grau de pertinência. A função de pertinência pode assumir várias formas geométricas (trapezoidal, triangular, senoidal, gaussiana etc). O conjunto nebuloso será

$$
B=\{(x, \mu B(x)) / x \in X\} .
$$

Cada par $\left(X, \mu_{B}(X)\right)$ é chamado de singleton com uma pertinência $\mu_{B}(X)$ em um universo de discurso [32]. Na fig. 5, tem-se duas entradas ( $i$ e $j$ ) e duas regras (1 e 2), 
respectivamente, que realizam a fuzzificação do sinal através da função de pertinência triangular, resultando nas áreas B1 e B2.

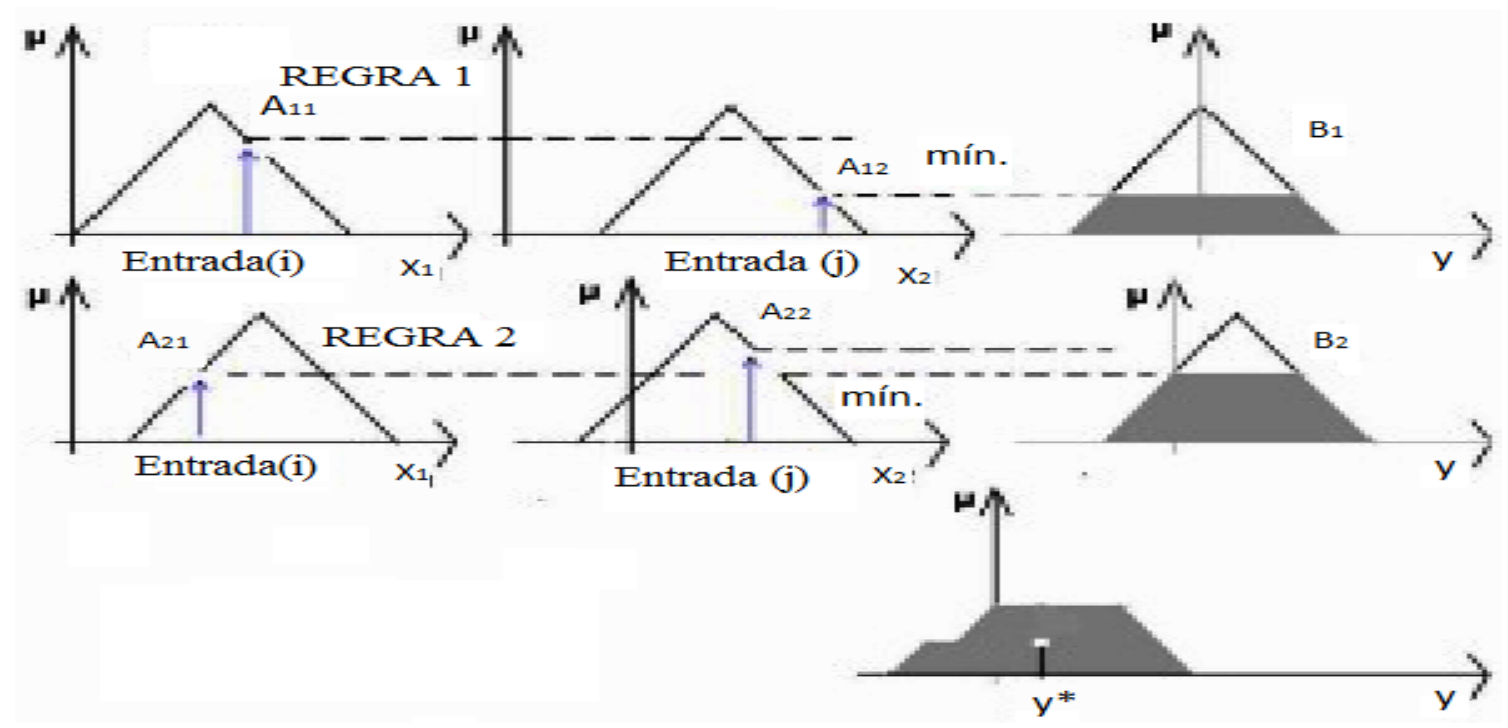

Figura 5 - Fuzzificação de duas variáveis de entrada [15].

As principais operações entre os conjuntos nebulosos são a união, a intersecção, a potência, o produto algébrico e a interpolação. Assim o conjunto fuzzy pode ser escrito como abaixo:

$$
B=\mu_{B}\left(X_{1}\right) / X 1 v \ldots . . v \mu_{B}\left(X_{8}\right) / X_{8}=\sum \mu_{B}\left(X_{i}\right) / X_{i} \text { para } x_{i} \in X .
$$

Obs.: o símbolo " $v$ " significa união.

O mecanismo de inferência é um algoritmo que trata as regras que representam o conhecimento de um especialista, ou seja, é um procedimento utilizado para avaliar as descrições linguísticas fuzzy. O que é descrito pelo ser humano (especialista) é tomado como base para desenvolver as regras. Cada regra faz parte de uma estrutura condicional com uma ou mais cláusulas, do tipo "Se A então B senão C".

As regras podem ser classificadas como multi-antecedente ou multi-consequente, incompletas, mistas, sentenças, comparativas, quantificadoras, etc [20]. A saída do mecanismo de inferência gera um valor numérico de saída - é o processo de defuzzificação. Ou seja, é a conversão de uma quantidade fuzzy em uma quantidade precisa, justamente o inverso da fuzzificação. A fuzzificação ajuda a valorar as regras, mas a saída final do sistema deve ser um número crisp.

A saída de um processo pode ser a união lógica de duas ou mais funções de pertinências nebulosas definidas em um universo de discurso de uma variável de saída.

Dentre os métodos de defuzzificação existentes, tem-se:

a) altura - também conhecido como método de máximo e é limitado pelo pico na função de saída; 
b) altura modificada - que apresenta melhor desempenho computacional, todavia é restrita as funções de pertinência com saídas simétricas;

c) média do máximo - que gera uma ação de controle que representa o valor médio de todas as ações de controle individuais cujas funções de pertinência assumem o valor máximo; e

d) centróide - a ação de controle é calculada obtendo-se o centro de gravidade da distribuição de possibilidades da ação de controle global, ou seja, o ponto onde a linha vertical divide o conjunto agregado em duas regiões de massa iguais.

A fig.6 apresenta o método de defuzzificação centróide ou método de centro de gravidade, que foi escolhido para o projeto em questão, por se tratar de um método que melhor representa a solução do problema sendo, ainda, o mais utilizado dentre todos os métodos de defuzzificação [18]. Verificar-se-á, adiante, que a extração de dados na fuzzificação tem funções de pertinência com geometria semelhante a apresentada neste método. A sua expressão algébrica é

$$
C G=\int \mu_{A}(x) \cdot x d x / \int \mu_{A}(x) d x,
$$

onde $\int$ representa uma integração algébrica de um ponto $a$ até um ponto $b$. CG representa o centro de gravidade do conjunto nebuloso $A$, no intervalo $a \rightarrow b$.

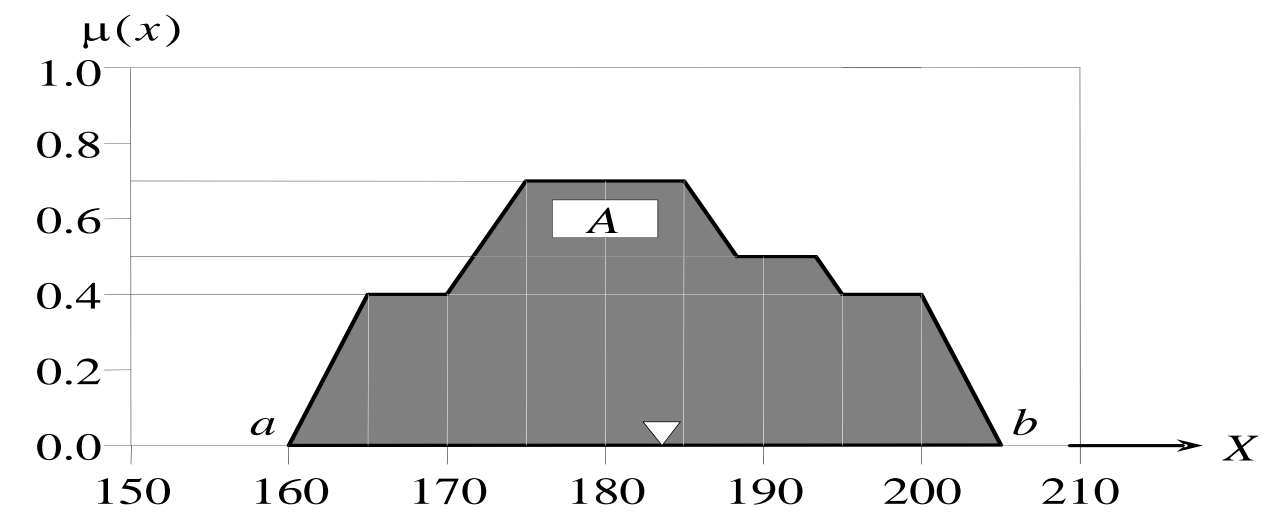

Figura 6 - Método do centro de gravidade.

\subsection{3- Principais operações entre conjuntos nebulosos}

As principais operações de conjuntos são a união, a interseção e o complemento. Essas operações representadas são respectivamente conforme abaixo [32]:

$$
\mu_{A \cup B}(x)=\mu_{A}(x) \vee \mu_{B}(x) ;
$$




$$
\begin{aligned}
& \mu A \cap B(x)=\mu A(x) \wedge \mu B(x) ; e \\
& \mu \bar{A}(x)=1-\mu A(x) .
\end{aligned}
$$

A representação gráfica das operações entre conjuntos segue abaixo:
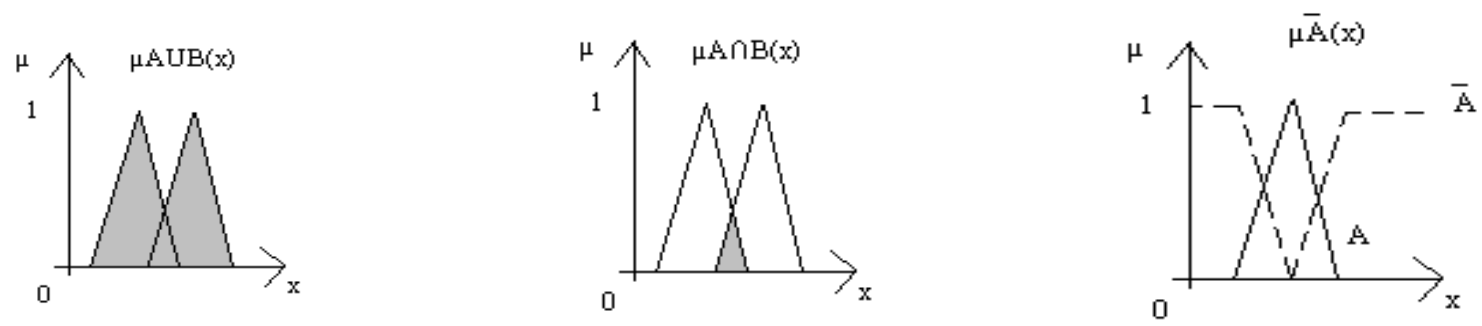

Figura 7 - União, Interseção e Complemento entre conjuntos nebulosos [18].

\section{2- Função e descrição de uma válvula de controle}

Em plantas industriais, o componente "válvula" representa aproximadamente $5 \%$ de seu custo total [33]. Em termos de números de unidades, as válvulas ficam atrás apenas das conexões de tubulações. As válvulas são utilizadas em tubulações, entrada e saída de vasos e tanques, nas mais variadas aplicações.

Quanto à segurança, as válvulas de controle são classificadas como normalmente fechada (NF) ou normalmente aberta (NA). Ou seja, na falta de energia de acionamento, permanecerão nestas posições descritas por segurança do processo. Quanto ao seu uso, as válvulas de controle podem ser classificadas como liga e desliga (on-off), de controle proporcional, de vazão reversa, de controle e alívio de pressão, de controle de vazão direcional, de amostragem, de limitação de vazão, de selagem de vaso ou de tanque. Dentre todas essas aplicações, destaca-se o controle automático de processos.

O controle de um processo industrial é composto de uma variada gama de malhas de controle. Uma malha de controle é composta de 03 (três) elementos básicos, a saber: elemento sensor, controlador e elemento final de controle (a válvula de controle propriamente dita). O controle pode ser manual ou automático. Se automático, o sinal para a válvula provem de um controlador, tem-se então o controle automático da válvula; caso 
contrário, se manual, provém de um operador. Se provier do operador, através de uma estação manual de controle, tem-se o controle manual remoto; no controle manual local, o operador atua diretamente no volante da válvula.

O controle da válvula pode ser realizado de modo contínuo (analógico) ou "on-off" - ligadesliga (digital). No primeiro modo, a válvula pode assumir infinitas posições, desde totalmente aberta até totalmente fechada. No segundo modo, apenas duas posições, aberta ou fechada. Este segundo modo, não é o ideal para o controle proporcional de qualquer variável física. Tal controle (liga-desliga) é realizado por chaves manuais ou automáticas comandadas normalmente por pressão, nível, vazão ou temperatura. Neste modo, a válvula mais utilizada é do tipo solenoide (atuação elétrica).

Quanto às válvulas pneumáticas, seu sinal de controle pode ser pneumático ou eletrônico. A válvula de controle com atuador pneumático é o elemento final de controle da maioria absoluta das malhas industriais existentes. Mesmo com o aumento da instrumentação eletrônica, a válvula com atuador pneumático ainda é o elemento final de controle mais utilizado.

As funções básicas de uma válvula de controle são:

a) conter o fluido de processo suportando todos os rigores da operação, resistindo a pressão, temperatura, corrosão, erosão, sujeira e contaminantes do fluido e;

b) responder ao sinal de atuação do controlador, que é aplicado ao seu atuador, que o converte em força mecânica, movimentando uma haste, cuja extremidade inferior encontra-se o obturador, que varia a passagem do fluido pela haste, variando a área de passagem do fluido controlado, absorvendo a queda da variável de pressão da linha de processo.

Em uma válvula de controle podem existir acessórios que facilitem seu desempenho, como, posicionador, booster, chaves, volantes, transdutores de corrente elétrica para ar comprimido, relés de inversão etc. Uma válvula divide-se basicamente em três partes (fig.8): atuador, castelo, e corpo.

O atuador normalmente pode ser de motor elétrico, solenóide, servo mecanismo, pneumático (diafragma/mola, pistão) ou hidráulico; e tem como funções básicas posicionar o obturador corretamente, mantendo-o na posição desejada, fornecer a carga 
de assentamento adequada com a classe de vedação da válvula, e fornecer o deslocamento da haste no tempo necessário ao processo.

As válvulas de controle contínuo são geralmente atuadas pneumaticamente. O atuador também é responsável pela conversão do sinal pneumático padrão do controlador em força - movimento da válvula. Um atuador, por exemplo, do tipo pneumático a diafragma, recebe o sinal pneumático e o converte em força mecânica que movimentará a haste da válvula. Em posição contrária há a força de uma mola que se opõe ao movimento da haste, ou seja, do diafragma.

O castelo (bonnet) conecta o corpo ao atuador. A haste se movimenta através do engaxetamento do castelo. O engaxetamento serve para alojar e guiar a haste e o obturador no seu excursionamento, de tal modo que não haja vazamento do interior da válvula para fora, nem haja atrito que dificulte o movimento, provocando histerese e distúrbios na ação de controle. Para facilitar o movimento da haste, com a devida vedação, normalmente faz-se a lubrificação do conjunto através de pinos lubrificadores existentes em suas laterais.

O corpo da válvula é essencialmente um vaso de pressão com uma ou duas sedes, onde se assenta o plug, que está na extremidade da haste e que é acionada pelo atuador.

Figura 8 - Visão em corte do atuador, castelo, e corpo (sede) de uma válvula.

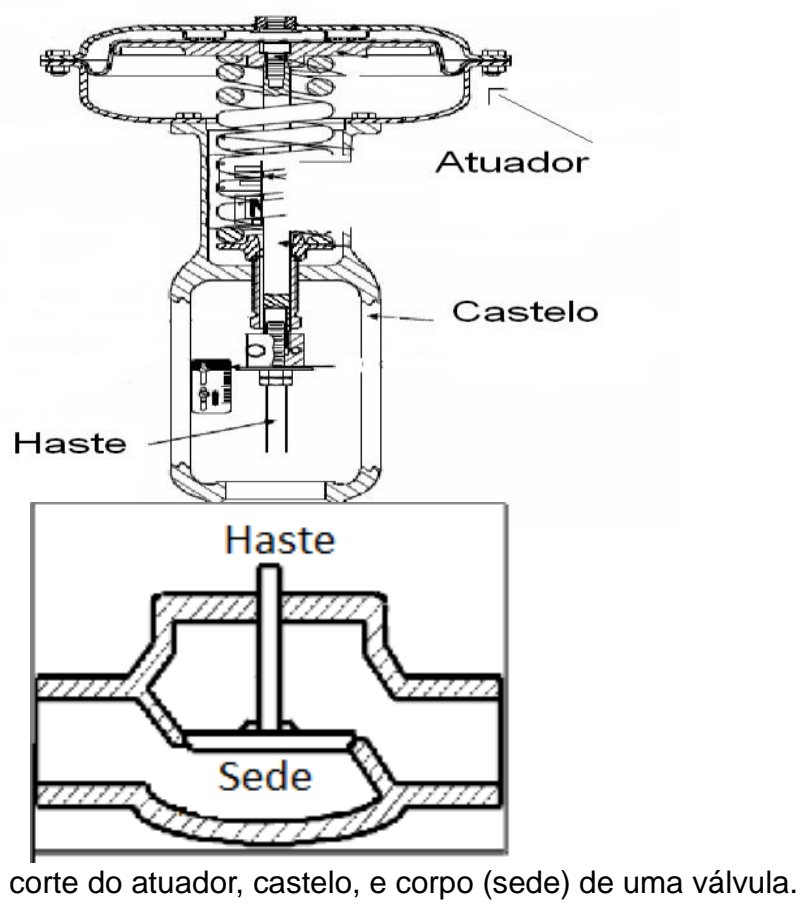


Várias são as funções de uma válvula de controle em um processo industrial. Para o controle proporcional e contínuo, a válvula mais utilizada é a do tipo globo, que apresenta mais estabilidade e previsibilidade. Nos controles liga e desliga, encontram-se válvulas tipo globo, esfera e gaveta. As válvulas esferas normalmente tem abertura mais rápida que as do tipo gaveta e globo. As válvulas do tipo esfera, globo e gaveta estão apresentadas na figura 9.

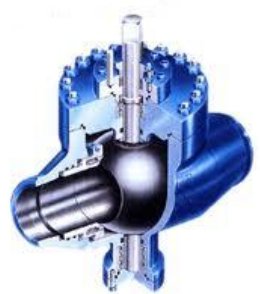

(a)

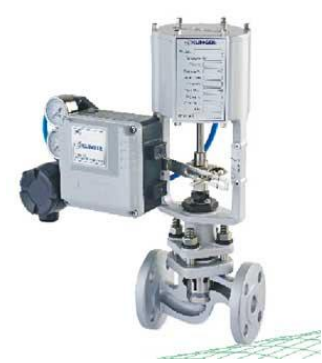

(b)

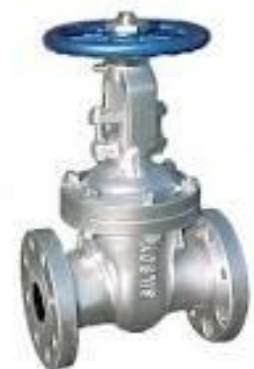

(c)

Figura 9 - Válvulas tipo esfera (a), globo (b) e gaveta (c).

Outro aspecto importante a ser considerado em uma válvula é a sua capacidade de vedação. Quase todas as válvulas podem prover vedação total, quando totalmente fechadas, todavia, há impacto no custo e na complexidade da válvula. Em alguns tipos a vedação é uma característica de sua construção, por exemplo, a tipo esfera, gaveta e globo. Geralmente uma válvula de controle, quando em operação, não provê vedação completa, o que ocorre é a modulação da válvula em várias posições intermediárias, de maneira a satisfazer as condições de projeto.

Considerando a proposta deste trabalho, a planta industrial que compõe as válvulas analisadas é um laboratório experimental, ou seja, não funcionam 24 horas / 07 dias na semana. Ocorrem períodos de operação de até 04 dias, e períodos de parada para ajustes experimentais. Isto posto, as válvulas trabalharão, ora modulando o curso de suas hastes em várias posições, e ora fornecendo vedação total, necessário na parada da planta.

As válvulas objetos deste estudo são do tipo globo. Estas válvulas possuem o corpo esférico, com sede simples ou dupla, com obturador guiado pela haste. As válvulas globo são geralmente mais rápidas para abertura e fechamento que a válvula gaveta. As superfícies da sede são menos sujeitas a desgaste e a capacidade de provocar grandes 
quedas de pressão torna a válvula conveniente para o controle.

De outro modo, a queda de pressão também pode ser uma desvantagem em alguns sistemas. Por exemplo, válvulas de grandes dimensões (diâmetro da sede maior que 1 metro) requerem muita potência para operar, necessitando de alavancas e engrenagens. Estas válvulas são normalmente mais pesadas que outras, e são muito utilizadas em controle de processo contínuo; e podem ser consideradas como válvulas de controle de vazão de uso geral.

Para esta aplicação, a válvula globo é projetada com a sede do corpo com material mais duro, pois o serviço severo pode causar desgaste e erosão. A fig.10 apresenta a instalação de uma válvula de controle com o posicionador inteligente montado em primeiro plano.

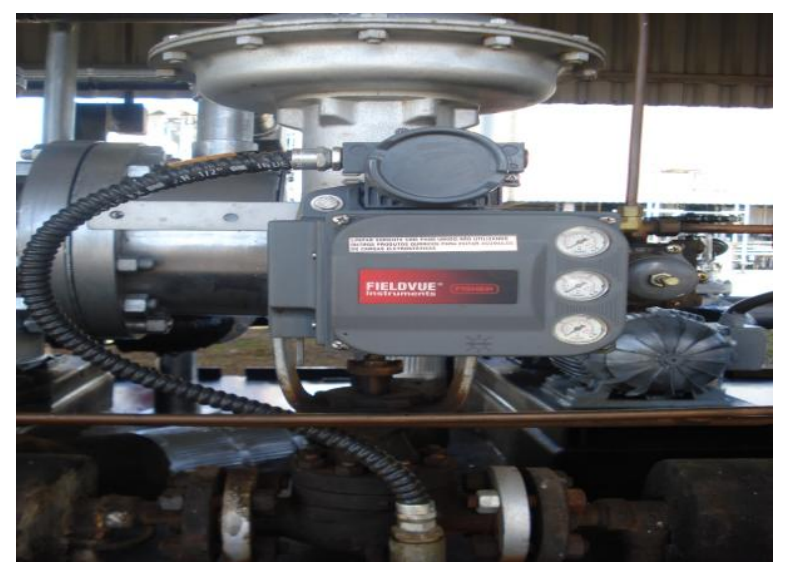

Figura 10 - Foto de uma válvula de controle com posicionador inteligente.

As válvulas podem ser classificadas conforme seu princípio de acionamento [34]:

a) Manual - a operação da abertura e fechamento é realizada pelo homem;

b) Autorreguladora - a operação de abertura e fechamento é realizada utilizando a energia contida no fluido; e

c) Controle - faz uso de uma força auxiliar para operação e, o acionamento é realizado de acordo com os sinais provenientes de controladores.

Quanto ao tipo de corpo as válvulas podem ser classificadas como:

a) de deslocamento linear - São exemplos, as válvulas dos tipos Globo Convencional, 
Três vias, Gaiola, Angular, Diafragma, Bi partido e Guilhotina; e

b) de deslocamento rotativo - São exemplos, as válvulas dos tipos Borboleta, Esfera, Obturador Excêntrico, e Segmento de Esfera.

Quanto à vedação, as válvulas de controle seguem classificação definida pela norma ANSI/FCI 70-2 e sua equivalente europeia IEC 60534-4. São elas: CLASSE I, II, III, IV, V e VI. A seguir cada uma das classes são brevemente descritas.

CLASSE I: construção idêntica as classes II, III e IV, porém não se realiza teste de vedação.

CLASSE II: Vedação por contato metálico-metálico (OBTURADOR-SEDE). Vazamento máximo: 0,5\% de vazamento em relação à capacidade máxima considerando a pressão diferencial de serviço (especificada) ou 50 psig, o que for menor; e temperatura entre 10 e $52^{\circ} \mathrm{C}$. Fluído utilizado no teste de vedação: ar entre 45 e 60 psig.

CLASSE III: Vedação por contato metálico-metálico (OBTURADOR-SEDE). Vazamento máximo: $0,1 \%$ de vazamento em relação à capacidade máxima considerando a pressão diferencial de serviço (especificada) ou 50 psig, o que for menor; e temperatura entre 10 e $52^{\circ} \mathrm{C}$. Fluído utilizado no teste de vedação: ar entre 45 e 60 psig. CLASSE IV: Vedação por contato metálico-metálico (OBTURADOR-SEDE). Vazamento máximo: 0,01\% de vazamento em relação à capacidade máxima considerando a pressão diferencial de serviço (especificada) ou 50 psig, o que for menor; e temperatura entre 10 e $52^{\circ} \mathrm{C}$. Fluído utilizado no teste de vedação: ar entre 45 e 60 psig.

CLASSE V: Construção por contato metálico-metálico (OBTURADOR-SEDE). Vazamento máximo: 5x10 ml/min.in.psi (mililitros por minuto por polegada de diâmetro do orifício por psi) considerando a pressão diferencial de serviço (especificada) e temperatura entre 10 e $52^{\circ} \mathrm{C}$. Fluído utilizado no teste de vedação: água a 100 psig. CLASSE VI: Vedação por contato metálico-flexível (OBTURADOR-SEDE). Fluído utilizado no teste de vedação: ar ou nitrogênio considerando a pressão diferencial de serviço (especificada) ou 50 psig, o que for menor; e temperatura entre 10 e $52{ }^{\circ} \mathrm{C}$. Os limites máximos de vazamentos dependem dos diâmetros nominais de passagem das válvulas, conforme a seguir:

As aplicações em CLASSE VI são típicas para uso em intertravamentos, onde se deseja bloquear um fluxo para se garantir a segurança em um determinado processo. 
Para aplicações grau nuclear existem normas da Autoridade de regulação nuclear norteamericana que podem ser tomadas como base. O REGULATORY GUIDE 1.26 trata de padrões e classificações para vários componentes, inclusive válvulas grau nuclear.

\subsection{1- Princípio de operação}

Quanto ao princípio ou modo de operação as válvulas, em especial, as com atuador pneumático podem ser do tipo manual ou automático. Todavia, os modos de operação da válvula dependem do seu tipo, localização no processo, função no sistema, tamanho, frequência de operação e grau de controle desejado. Os modos possíveis de operação são manual ou automático.

A atuação manual da válvula pode ser local ou remota. No local pode ser diretamente por volante, engrenagem, corrente mecânica ou alavanca. A atuação manual remota pode ser feita através de um sinal elétrico ou pneumático, que acione o atuador da válvula.

Para ser atuada automaticamente, a válvula deve estar acoplada a mola, motor elétrico, solenóide, servo mecanismo, atuador pneumático ou hidráulico. Frequentemente, é necessário e desejável operar automaticamente a válvula, de modo contínuo ou através de liga-desliga. É possível operar se adicionando à válvula, um dos seguintes acessórios:

- Atuador pneumático ou hidráulico para operação contínua ou de liga-desliga;

- Solenóide elétrico para operação no modo liga-desliga; ou

- Motor elétrico para operação contínua ou de liga-desliga.

Geralmente, um determinado tipo de válvula é limitado a um ou poucos tipos de atuadores. Por exemplo, as válvulas de alívio e de segurança são atuadas por mola; as válvulas de retenção são atuadas por mola ou por gravidade e as válvulas globo de tamanho grande e com alta pressão de processo são atuadas por motores elétricos ou correntes mecânicas. As válvulas de controle contínuo (caso de nosso estudo) são geralmente atuadas pneumaticamente e através de solenoides, quando se tem o controle liga-desliga. Normalmente, estes mecanismos de operação são considerados acessórios da válvula.

A atuação pneumática frequentemente é realizada por meio de um diafragma ou pistão. 
Independente do tipo, o princípio de operação é o mesmo. O atuador pneumático, com diafragma e mola é o responsável pela conversão do sinal pneumático padrão do controlador em força-movimento-abertura da válvula. $\mathrm{O}$ atuador pneumático a diafragma recebe diretamente o sinal do controlador pneumático e o converte numa força que movimentará a haste da válvula, onde está acoplado o obturador que abrirá continuamente a válvula de controle.

O diafragma converte o sinal de pressão em uma força e a função da mola é a de retornar o sistema à posição original. $\mathrm{Na}$ ausência do sinal de controle, a mola leva a válvula para uma posição extrema, ou totalmente aberta ou totalmente fechada. Operacionalmente, a força da mola se opõe à força do diafragma; a força do diafragma deve vencer a força da mola e as forças do processo.

Para a correta operação da válvula, o atuador requer apenas um sinal pneumático padrão, de 20 a $100 \mathrm{KPa}$ (3 a 15 psi). O atuador pneumático consiste simplesmente de um diafragma flexível colocado entre duas câmaras. Uma deve ser vedada à pressão e na outra há uma mola, que exerce uma força contrária. O sinal de ar da saída do controlador segue para a câmara vedada à pressão e sua variação produz uma força variável que é usada para superar a força exercida pela mola, as forças internas dentro do corpo da válvula e as exercidas pelo próprio processo.

O atuador pneumático deve satisfazer basicamente as seguintes exigências:

V operar com o sinal de 20 a $100 \mathrm{KPa}$ (3 a 15 psig);

$\checkmark$ operar sem posicionador;

$\sqrt{ }$ ter uma ação falha-segura quando houver falha no sinal de atuação;

$\checkmark$ ter um mínimo de histerese;

$\checkmark$ ter potência suficiente para agir contra as forças desbalanceadas; e

$\checkmark$ ser reversível.

Basicamente, existem duas lógicas de operação, nas ações do atuador pneumático com o conjunto diafragma e mola:

- Ar para abrir - mola para fechar - falha fecha, e 
- Ar para fechar - mola para abrir - falha abre.

$\mathrm{Na}$ fig.11 têm-se os exemplos ar para abrir - mola para fechar - falha fecha (válvula à esquerda), que apresenta a mola na parte superior (acima do diafragma), e ar para fechar - mola para abrir - falha abre (válvula à direita), que apresenta a mola na parte inferior (abaixo do diafragma).

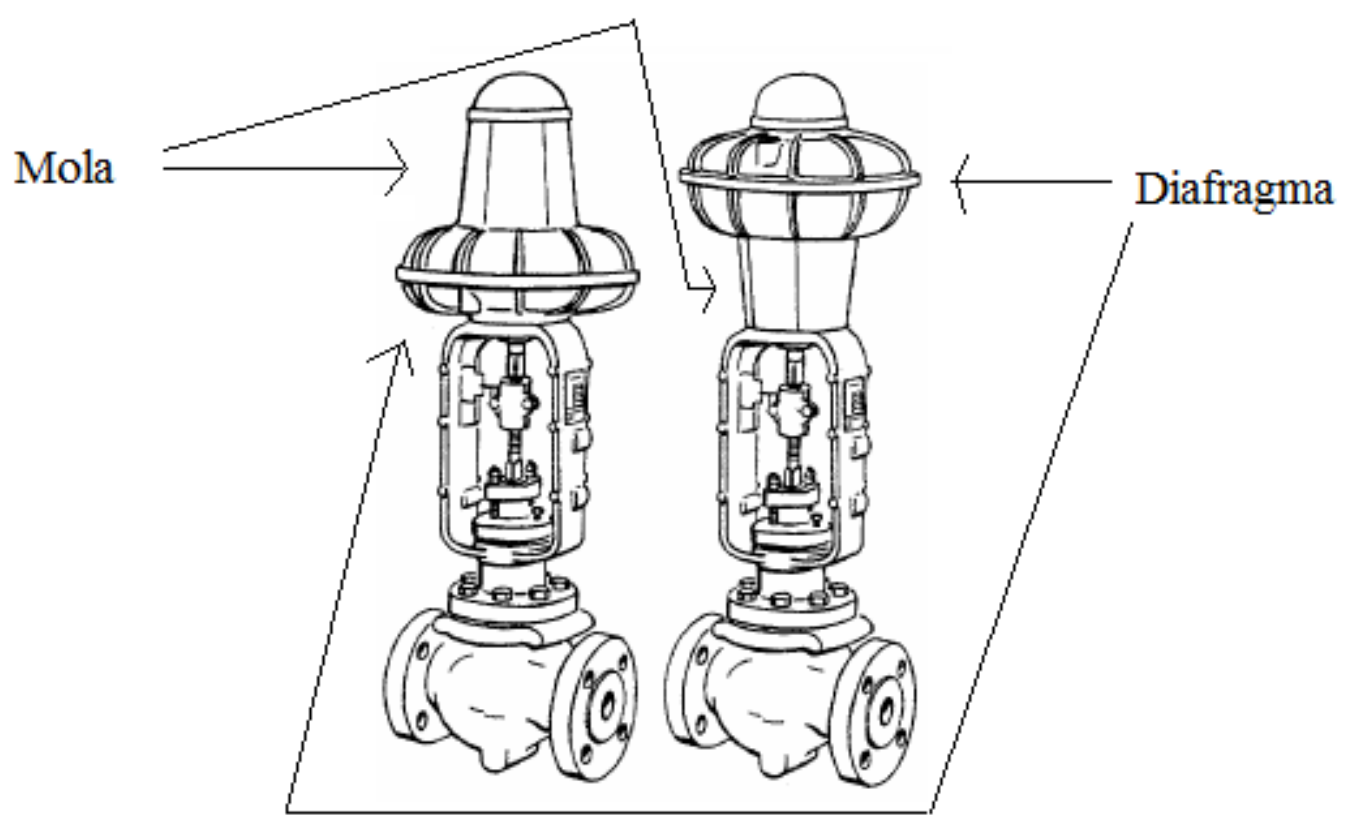

Figura 11 - ar para abrir - ar para fechar.

A operação de uma válvula tipo ar para abrir se faz da seguinte maneira: quando não há pressão no atuador, a válvula está "desligada" e na posição fechada. Quando a pressão de controle, típica entre 20 a 100 KPa (3 a 15 psig) começa a aumentar, a válvula tende a abrir cada vez mais, assumindo posições intermediárias entre totalmente fechada e totalmente aberta. Quando não houver sinal de controle, a válvula retorna imediatamente para a posição fechada, independente da posição em que estiver no momento da falha.

A posição de totalmente fechada é também conhecida como posição de segurança, em caso de falha. É justamente a mola que leva a válvula para esta posição segura. Assim, o sinal pneumático de controle deve vencer a força da mola, a força apresentada pelo fluido do processo, os atritos existentes entre a haste e o engaxetamento, para que se inicie o movimento.

O atuador ar-para-abrir necessita de pressão para abrir a válvula. Para pressões menores que $20 \mathrm{KPa}$ (3 psig) a válvula deve estar totalmente fechada. Com o aumento gradativo 
da pressão, a partir de $20 \mathrm{KPa}$ (3psig), a válvula abre continuamente. A maioria das válvulas é calibrada para estar totalmente aberta quando a pressão atingir exatamente $100 \mathrm{KPa}$ (15 psig).

Calibrar uma válvula é fazer a abertura da válvula seguir uma reta, passando pelos pontos $20 \mathrm{KPa} \times$ 0\% (3 psi x 0\%) e $100 \mathrm{KPa} \times 100 \%$ (15 psi x 100\%) de abertura. A falha do sistema, ou seja, a ausência de pressão deve levar a válvula para o fechamento total.

Uma válvula com atuação ar-para-fechar opera de modo contrário. Na ausência de ar e com pressões menores que $20 \mathrm{KPa}$ (3 psig), a válvula deve estar totalmente aberta. Com o aparecimento de pressões acima de $20 \mathrm{KPa}$ (3 psig) e seu aumento, a válvula diminuirá sua abertura. Com a máxima pressão do controlador, de $100 \mathrm{KPa}$ (15 psig), a válvula deve estar totalmente fechada. Na falha do sistema, quando a pressão cair o zero KPa, a válvula deve estar na posição totalmente aberta.

Certas aplicações exigem uma válvula de controle com um diafragma especial, de modo que a falta do sinal de atuação faça a válvula se manter na última posição de abertura; daí tem-se a falha-última-posição.

\subsection{2- Tipos de válvulas de controle}

Há muitos tipos de válvulas de controle no mercado e, face ao contínuo desenvolvimento, sempre aparece modelos novos, tornando-se difícil a sua classificação. O número de válvulas usadas para controle de fluidos é elevado, onde existem válvulas com simples dispositivos de liga-desliga a válvulas com sistemas de servomecanismos complexos. A dimensão dessas válvulas variam de poucos centímetros, válvulas medidoras usadas em aplicações aeroespaciais, até válvulas industriais com diâmetros de vários metros, pesando centenas de quilos.

As válvulas controlam a vazão de todos os tipos de fluidos, variando de ar e água até produtos químicos corrosivos, metais líquidos e materiais radioativos. Podem operar em pressões na região do vácuo ou até com pressões de 100.000 psi, em temperaturas que variam da faixa criogênica até as faixas de metais derretidos. As válvulas podem ter exigência de vedação total, onde pequenos vazamentos podem ser catastróficos ou podem ser complacentes, permitindo a passagem de quantidades razoáveis de fluido 
quando totalmente fechadas, sem que isso seja grave.

As válvulas podem ser operadas no modo manual, pneumático ou elétrico. Podem responder de um modo previsível a sinais provenientes de sensores de pressão, temperatura e outras variáveis do processo ou simplesmente abrir e fechar independentemente da potência do sinal de atuação.

Aproximadamente todas as válvulas atualmente em uso podem ser consideradas como modificações de alguns poucos tipos básicos. Podem ser classificadas de diferentes modos, tais como tamanho, função, material, tipo do fluido manipulado, classe de pressão, ou modo de atuação. Há válvulas com princípios de funcionamento de domínio público, outras que estão patenteadas e são propriedades e fabricadas por uma única empresa. Uma boa maneira de classificação de válvulas é de acordo com a natureza do meio de operação empregado. Dentre outras, se podem destacar as do tipo, gaveta, globo, esfera, ou borboleta. Por exemplo, numa indústria petroquímica, 90\% de todas as válvulas usadas são do tipo gaveta, globo, retenção, esfera ou borboleta.

Uma das principais questões ao se escolher uma válvula de controle é "o que a válvula deve fazer, quando faltar o suprimento da alimentação?" Esta questão está relacionada com a "posição de falha" da válvula. A segurança do processo determina o tipo de ação da válvula: falha-fechada (FC - fail close), falha-aberta (FO - fail open), falha indeterminada (FI - fail indetermined), falha última-posição (FL - fail last position).

A segurança também implica no conhecimento antecipado da consequência da falha de alimentação na mola, diafragma, pistão. Quando ocorrer falha no atuador da válvula, a posição da válvula não é mais função do projeto do atuador, mas das forças do fluido do processo atuando no interior da válvula e da construção da válvula.

Desta maneira têm-se as seguintes nomenclaturas: vazão-para-abrir (FTO - flow to open), vazão-para-fechar (FTC - flow to close), ficar na última posição (FB - friction bound).

A ação vazão-para-fechar é fornecida pela válvula globo; a ação vazão para-abrir é dada das válvulas borboleta, globo e esfera convencional. As válvulas com plug rotatório, esfera flutuante são típicas para ficar na última posição. 
Além da fig. 9, na fig. 12 tem-se a representação das válvulas esfera, globo e gaveta, sendo que a tipo gaveta é de acionamento manual via volante.

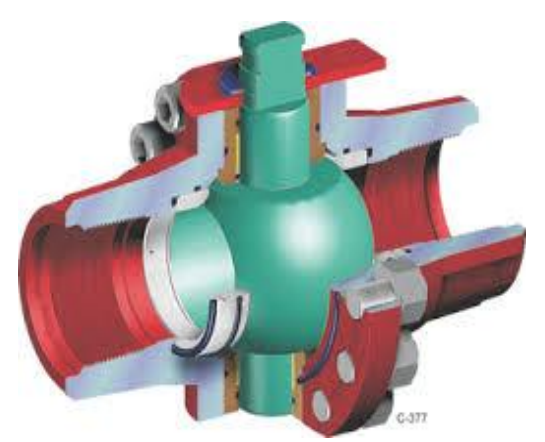

(a)

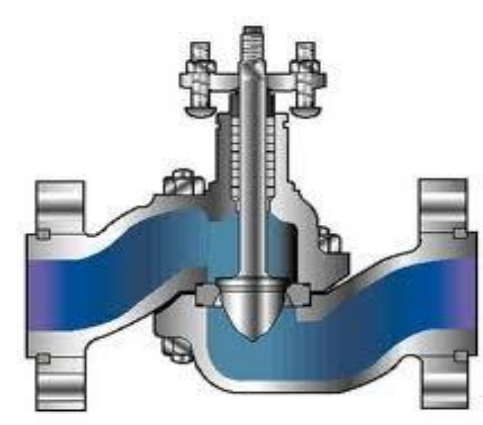

(b)

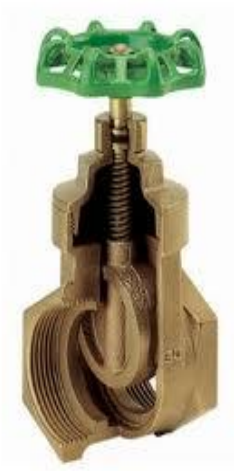

(c)

Figura 12 - Válvulas tipo esfera (a), globo (b) e gaveta (c).

Posicionador, em verdade um acessório da válvula, um acessório opcional. Todavia, algumas plantas industriais padronizaram e tornaram o seu uso extensivo a todas as válvulas de controle existentes. É um dispositivo acoplado à haste da válvula de controle para otimizar o seu funcionamento.

Ao receber o sinal padrão de 20 a $100 \mathrm{KPa}$ (3 a 15 psig), o posicionador gera também, na saída, o sinal padrão de 20 a $100 \mathrm{KPa}$ (3 a 15 psig) e, por isso, é necessária a alimentação pneumática de $120 \mathrm{KPa}(20$ psig).

O posicionador tem como objetivo comparar, o sinal da saída do controlador com a posição da haste da válvula. Se a haste não esta onde o controlador quer que ela esteja, o posicionador soma ou subtrai ar do atuador da válvula, até se obter a posição correta. Há um elo mecânico através do qual o posicionador sente a posição da válvula e monitora o sinal que vai para o atuador.

\section{Justificativas para seu uso}

- Eliminar a histerese e banda morta da válvula, garantindo a excursão linear da haste da válvula, por causa de sua atuação direta na haste;

- Alterar a faixa de sinal pneumático, por exemplo, de 20 a $100 \mathrm{KPa}$ (3 a 15 psig) para 100 a $20 \mathrm{KPa}$ (15 a 3 psig) ou de 20 a $60 \mathrm{KPa}$ (3 a 9 psig) para 20 a $100 \mathrm{KPa}$ 
(3 a 15 psig);

- Aumentar a velocidade de resposta da válvula, aumentando a pressão ou o volume do ar pneumático de atuação, para compensar atrasos de transmissão, e a capacidade do atuador pneumático; e

- Escolher ou alterar a ação da válvula, falha-fechada (ar para abrir) ou falha aberta (ar para fechar).

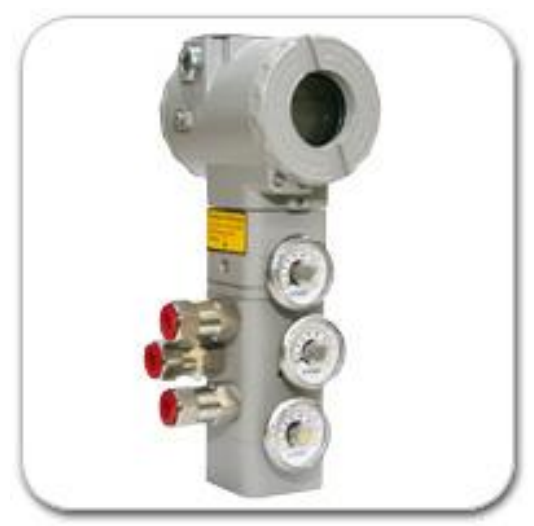

(a)

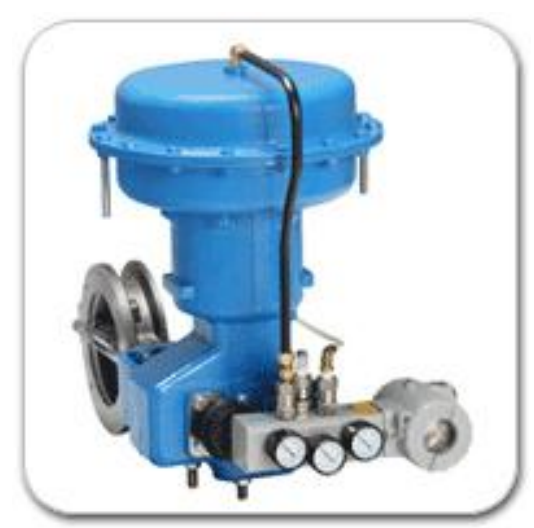

(b)

Figura 13 - Posicionador inteligente isolado (a) e acoplado à válvula de controle tipo borboleta de acionamento pneumático (b) [33].

Vedação e Estanqueidade

Qualquer vazão através da válvula totalmente fechada, quando exposta à pressão diferencial e à temperatura de operação é chamada de vazamento (leakage). O vazamento é expresso como uma quantidade acumulada durante um período de tempo específico, para aplicações de fechamento com vedação completa ou como percentagem da capacidade total, para as válvulas de controle convencionais.

Quase todas as válvulas podem prover vedação total, quando totalmente fechadas, porém, muitas vezes, com alto custo e complexidade de construção. Assim, existem alguns tipos que fornecem vedação de modo natural e mais simples, como as válvulas esfera, gaveta, globo e de plug.

A pior válvula para vedação é a borboleta, que devido a sua construção, não é adequada para altas pressões. A pressão do fluido incide diretamente no disco da válvula e na superfície circunferencial de vedação, que é o ponto mais fraco e suscetível a vazamento - a região circunferencial externa do disco e das paredes internas da tubulação. 
Geralmente a válvula de controle não é aplicada para prover vedação completa, mas para trabalhar com aberturas típicas entre 25 e 85\%, dependendo de sua característica de vazão. No caso da planta nuclear do LATEP, que simula o circuito secundário de um reator nuclear tipo PWR, e devido a especificidades do processo, muitas das válvulas estudadas necessitam garantir estanqueidade.

A classe de válvula grau nuclear segue o padrão das válvulas de classe industriais, acrescidas de algumas observações, conforme o caso. Estas observações são elaboradas por comissões governamentais, como exemplo a NRC - Nuclear Regulatory Comission, dos Estados Unidos da América.

\subsection{3- Anomalias em válvulas de controle}

Muitas são as anomalias existentes em válvulas de processo. Especificamente, as válvulas de controle apresentam falhas de funcionamento e comportamento anômalos como, por exemplo: emperramento, empenamento, fricção, vazamento (falta de vedação), desalinhamento, deficiência, falta de ar comprimido etc.

Poder-se-ia classificar as anomalias ou falhas em válvulas de controle, quanto ao grau de severidade. Neste trabalho, sugere-se a seguinte classificação: incipiente, moderada ou agressiva. Em [07] Camila e Gustavo estudaram três tipos de falhas em cinco cenários, a partir da combinação dos modos abrupto (agressivo) e incipiente. O modo abrupto é causado pela queda de pressão de ar para alimentação do atuador da válvula. O modo abrupto e incipiente, oriundo da mudança inesperada de pressão através da válvula de controle e, por último o método abrupto e incipiente causado pela abertura parcial e/ou total do "by-pass" da válvula.

Afirma Camila [07] que, quanto mais precoce a detecção da falha (incipiente), menor as perdas operacionais. Porém, mais difícil é a detecção. Um sistema com capacidade de monitoramento como o citado consegue acompanhar a evolução da falha, e conhecer o verdadeiro "estado de saúde" de cada componente, equipamento ou dispositivo instalado na planta de processo. 


\section{6- Materiais e métodos}

Foram escolhidos 08 (oito) elementos finais de controle (válvulas) do LATEP, conforme tab.2. Essas válvulas realizam controle de variáveis primárias como pressão, temperatura e vazão do circuito secundário de uma planta nuclear tipo PWR.

A extração de dados se deu por meio do posicionador inteligente acoplado ao castelo destas válvulas. Estes dispositivos extraem informação de pressão de ar (PSI) e deslocamento de haste $(\mathrm{mm})$ que, processado com o conhecimento do especialista, via sistema de automação Delta $\vee^{\circledR}$ e lógica nebulosa, tem-se como saída o status da válvula e seu diagnóstico.

\section{1- Relação de válvulas analisadas e falhas encontradas}

Tabela 2 - Elementos finais de controle da planta de processo.

\begin{tabular}{|l|l|l|l|}
\hline TAG & Nome da válvula de controle & Pág. & Falhas \\
\hline FV-100 & Vazão de água de alimentação da caldeira & 56 & Emperramento fechado \\
\hline TV-462B & Temperatura de óleo na linha de alta pressão & 60 & Dificuldade de fechar \\
\hline PV-472B & Pressão de óleo na linha de baixa pressão & 63 & $\begin{array}{l}\text { Emperramento aberto, } \\
\text { Dificuldade de abrir }\end{array}$ \\
\hline PV-830 & Vazão de água de resfriamento & 67 & Dificuldade de abrir, Histerese \\
\hline PV-1200 & Pressão do desaerador & 71 & Histerese \\
\hline PV-1110 & Pressão de vapor de alta & 75 & Dificuldade de abrir, Obstrução \\
\hline PV-482 & Pressão no cabeçote de alta & 79 & Desajuste de zero \\
\hline TV-462A & Vazão de óleo na linha de alta pressão & 82 & Desajuste de zero \\
\hline
\end{tabular}




\section{2- Delta V - Módulo Valvelink ${ }^{\circledR}$ e a base de dados}

O software valvelink ${ }^{\circledR}$ é parte integrante do sistema de automação Delta $V$, comercializado pela empresa EMERSON PROCESS MANAGEMENT (fig.14).

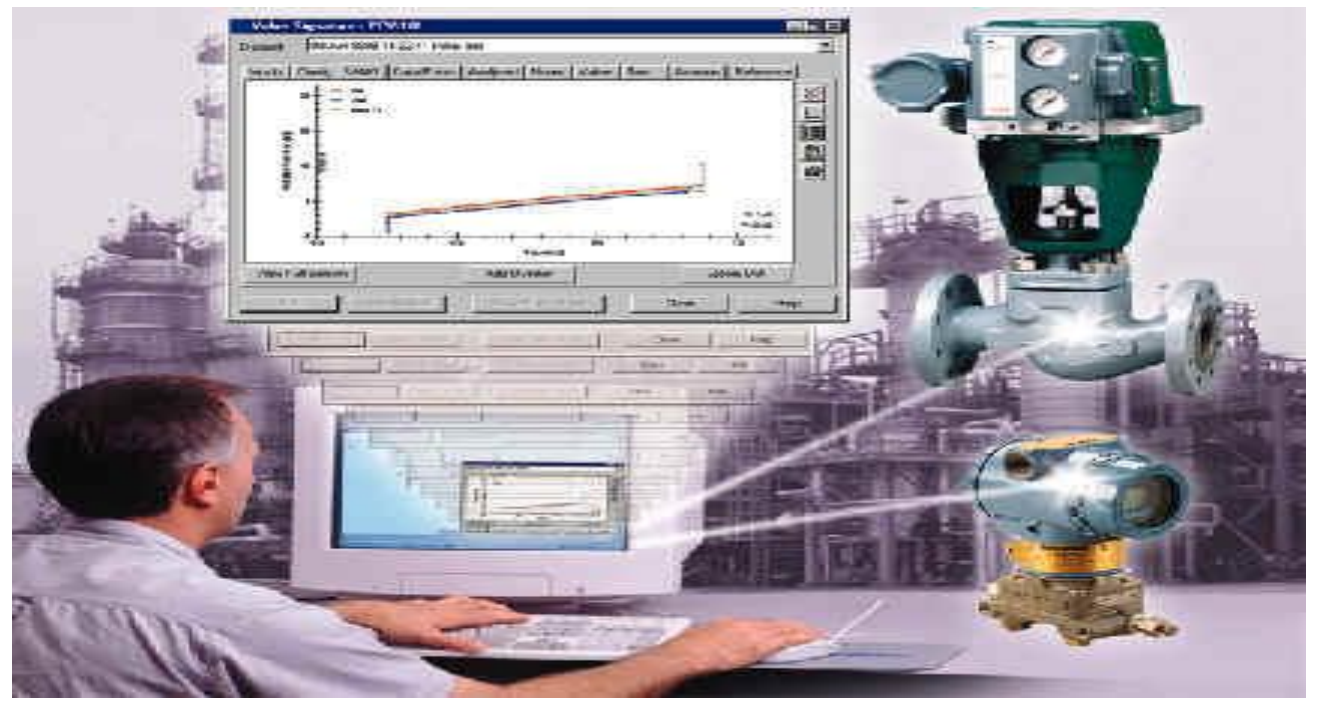

Figura 14 - Módulo Valvelink - Sistema Delta V[34].

O módulo valvelink ${ }^{\circledR}$ permite a leitura da assinatura da válvula e fornece informações gráficas da variação de pressão do atuador da válvula, na grandeza pressure square inch (PSI), como eixo das ordenadas (y) e deslocamento do plug (haste da válvula) em milímetros (mm), como eixo das abcissas $(x)$ [34].

A fig.15 apresenta a assinatura de uma válvula de controle (FV-100), mostrando os ciclos de fechamento (superior) e abertura (inferior) da válvula.

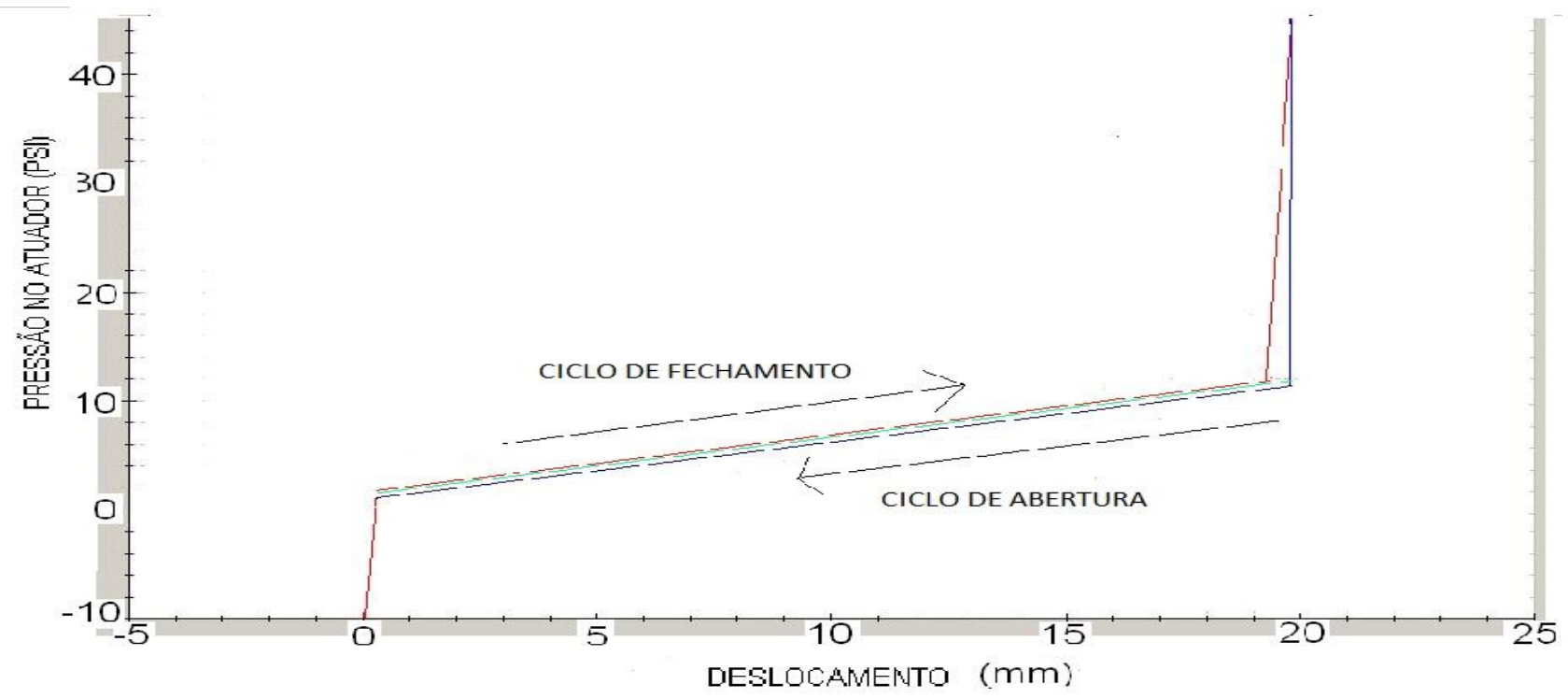

Figura 15 - Assinatura da válvula FV-100 - "baseline".

Como exemplo, a assinatura apresentada é considerada como operação normal, não apresentando nenhuma anomalia e será usada como o baseline de uma válvula 
saudável, que opera normalmente. Neste caso, a válvula estará aberta no par ordenado $(0,0)$ (zero displacement em mm - zero PSI); "1/4" (significando 25\% de deslocamento) com o par (5,4); "1/2" com o par (10,6); "3/4" com o par $(15,8)$ e fechará com o intervalo de $(20,11)$ até $(20,46)$ representando o excesso de ar no atuador para garantir que a válvula estará selada, evitando passagem de fluido.

Tabela 3 - Status da válvula e Faixa de entrada.

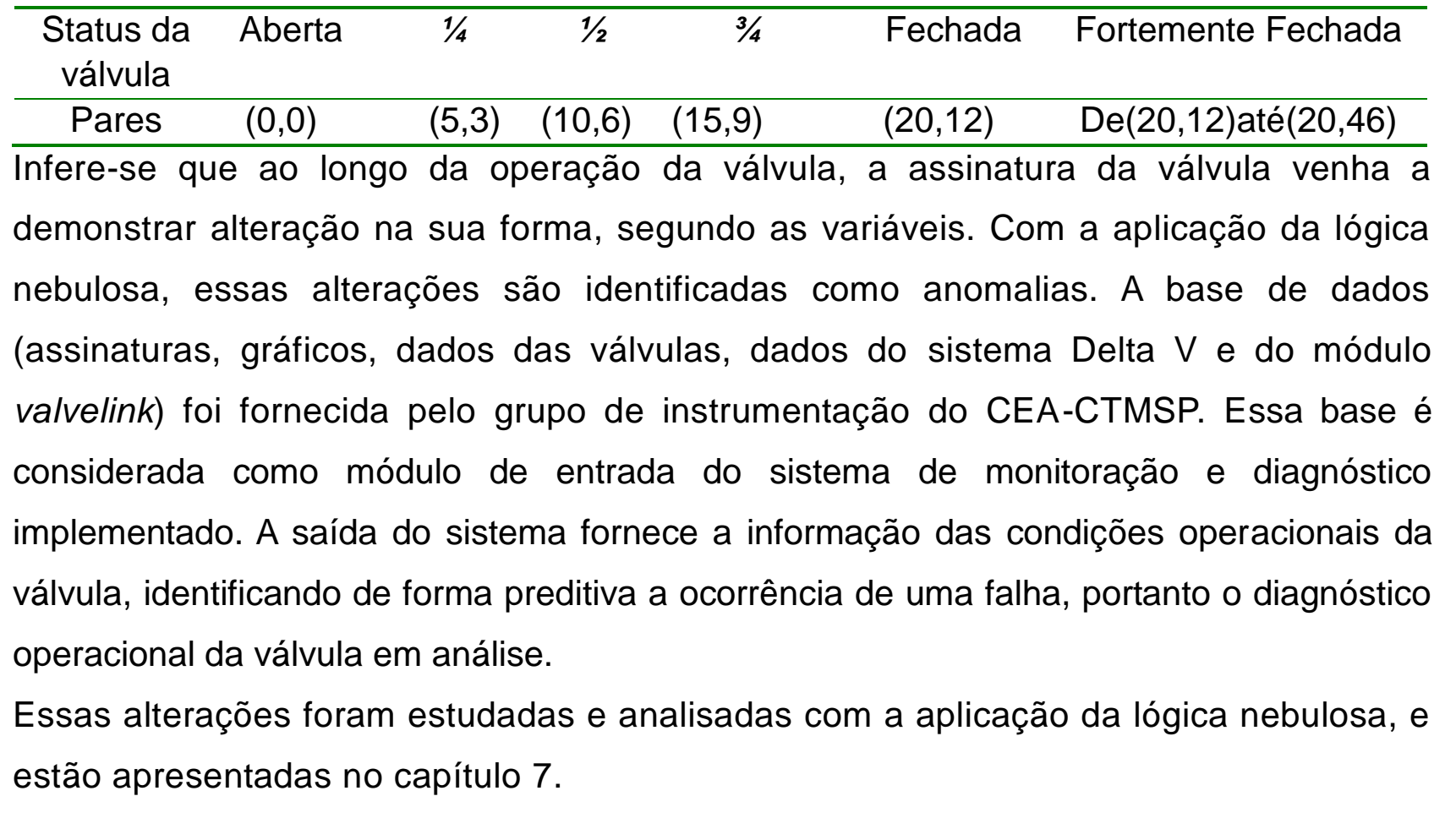

\section{3- MATLAB ${ }^{\circledR}$ FUZZY LOGIC TOOLBOX}

O MATLAB ${ }^{\circledR}$ é uma poderosa linguagem computacional de aplicações matemáticas que possui várias ferramentas de desenvolvimento (toolboxes) de soluções de problemas e ilustrações gráficas [27]. Utiliza linguagem de computação técnica e a versão utilizada é de 32 bits $n^{\circ} 7.8 .0 .347(R 2009 a)$, de 12 de fevereiro de 2009. A interatividade é uma das características deste programa de computador. Entra-se com uma expressão matemática e o programa responde com um resultado gráfico, de onde se pode extrair várias informações relevantes, de acordo com a aplicação utilizada.

Desta maneira, é possível escrever programas em MATLAB ${ }^{\circledR}$, que são essencialmente grupo de comandos executados sequencialmente. O MATLAB ${ }^{\circledR}$ é também uma poderosa ferramenta para se trabalhar com matrizes e vetores. O fuzzy logic toolbox (FL toolbox) foi largamente utilizado no desenvolvimento deste trabalho. 
O FL toolbox apresenta uma interface, fig.16, onde é possível criar variáveis de entrada e de saída. Através da aba "edit", pode-se criar variáveis, remover variáveis, criar funções de pertinência e regras.

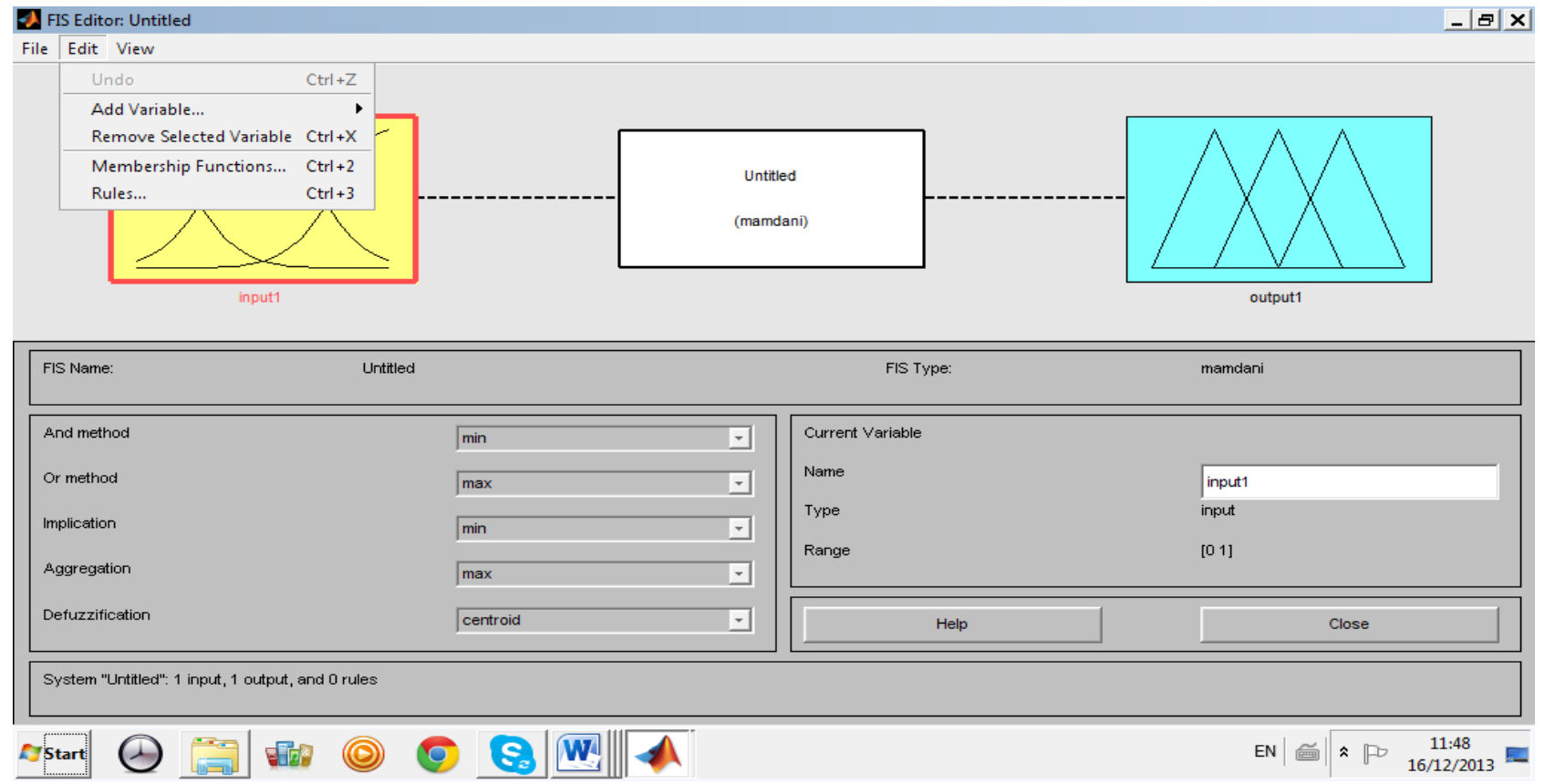

Figura 16 - Interface inicial do "FL toolbox".

$\mathrm{Na}$ fig.17, tem-se a 'possibilidade de criar, customizar e remover funções de pertinência. $\mathrm{Na}$ aba "View" pode-se visualizar as regras criadas (fig.18) e uma apresentação gráfica em três dimensões das variáveis de entrada e saída, fig.19.

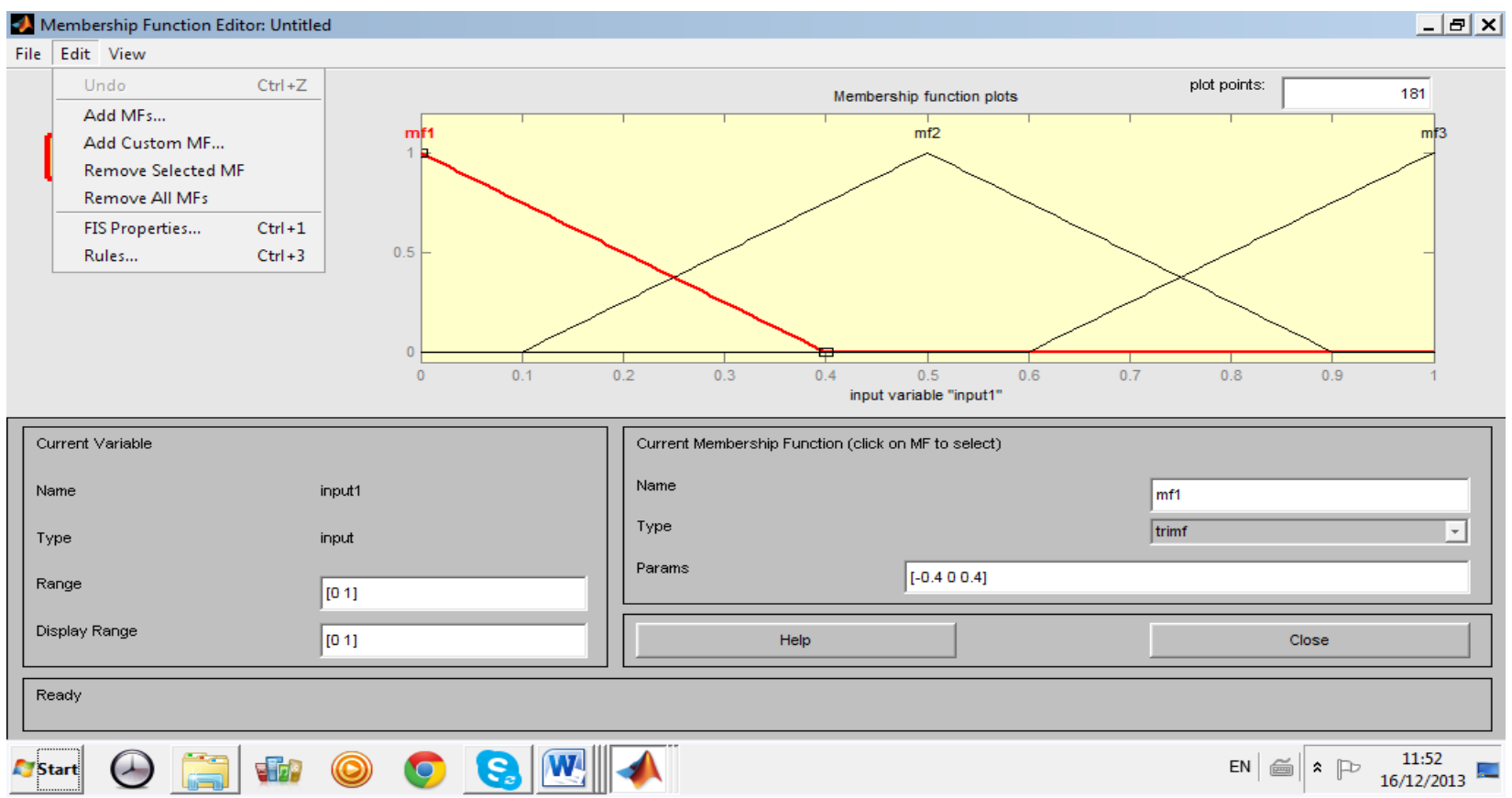

Figura 17- Interface de criação de funções de pertinência. 


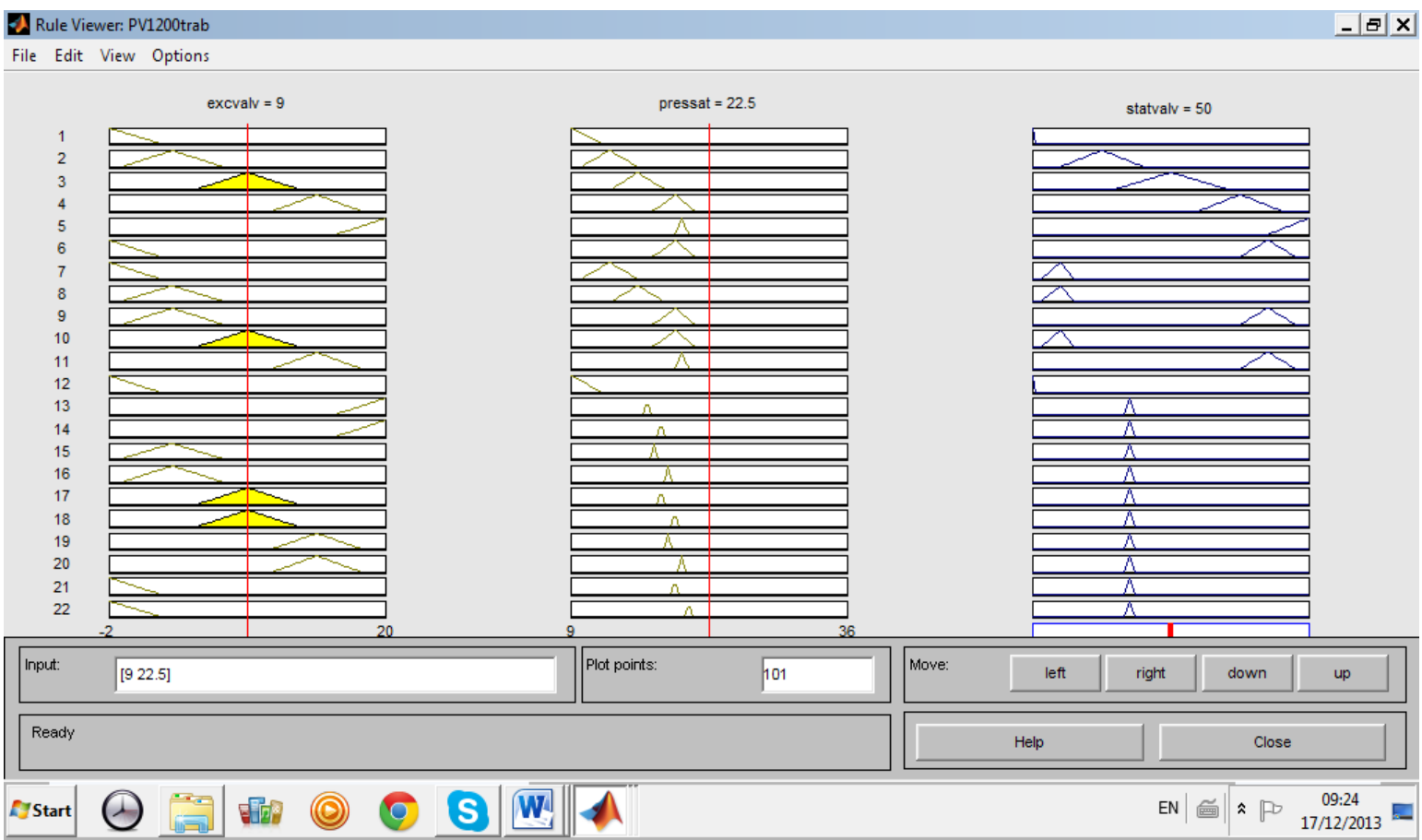

Figura 18- Exemplo de um visor de regras do FL toolbox.

Surface Viewer: PV1200trab

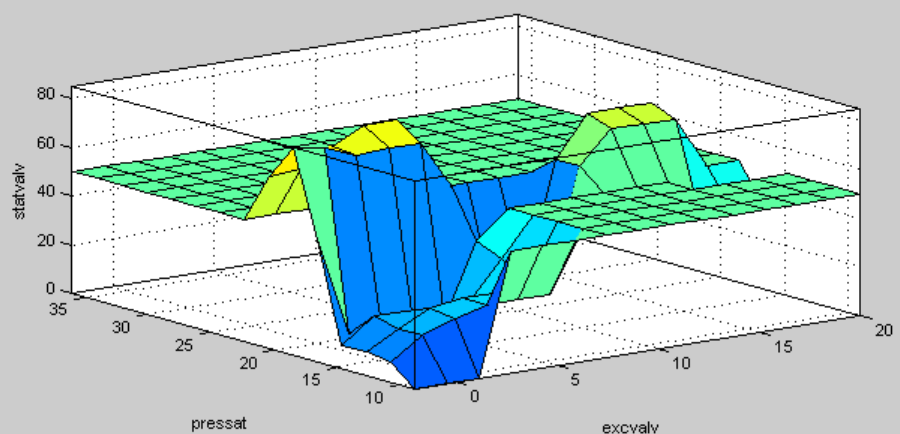

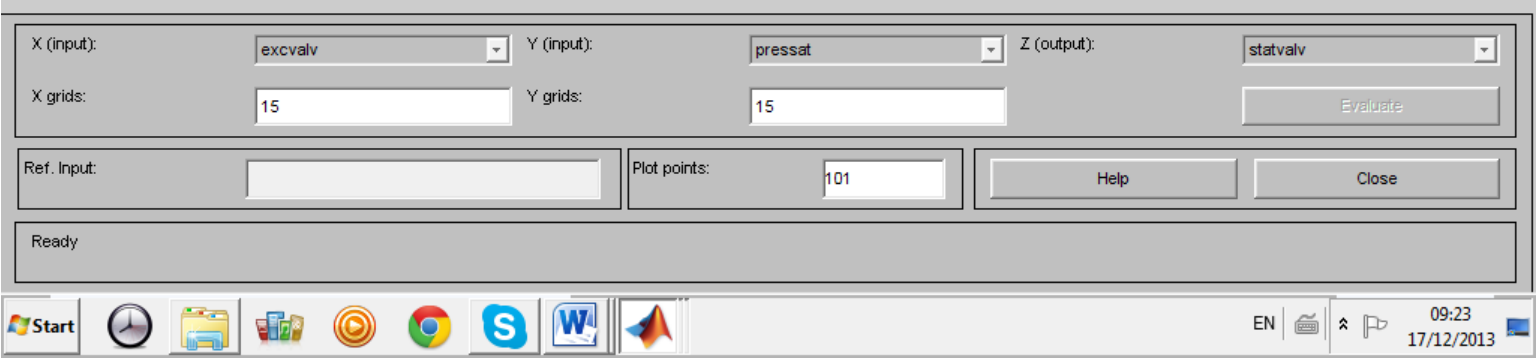

Figura 19- Gráfico em 3-D das entradas e saída do FL toolbox. 


\section{Resultados}

Neste capítulo apresentam-se as assinaturas e os gráficos das válvulas listadas na tabela do item 6.1.

As entradas do sistema são a pressão de ar comprimido do atuador da válvula a diafragma, na unidade de PSI (Pressure Square Inch) e o deslocamento da haste da válvula em milímetros ou em graus (deg). Como variável de saída do sistema tem-se o "status" da válvula, através da porcentagem (0 a 100\%) de abertura/fechamento, com pontos adicionais indicando se a válvula encontra-se emperrada aberta, emperrada fechada, com fricção, com dificuldade de abrir ou necessitando de programar manutenção. Os dados de entrada chegam ao sistema especialista Fuzzy, através do gráfico produzido pelo Sistema de automação Delta $\mathrm{V}^{\mathrm{TM}}$ instalado no laboratório. Através de regras criadas por informações fornecidas por especialistas em válvulas torna-se possível efetuar a inferência proposta por Mandani.

\section{FV-100 - Controle de vazão de água de alimentação da caldeira}

A fig.20 mostra a assinatura da válvula FV-100. Sua função é o controle de vazão de água de alimentação da caldeira. O gráfico apresenta anomalias durante o excursionamento de sua haste. "Ripples" no ciclo de fechamento, "stiction" e emperramento inicial no ciclo de abertura.

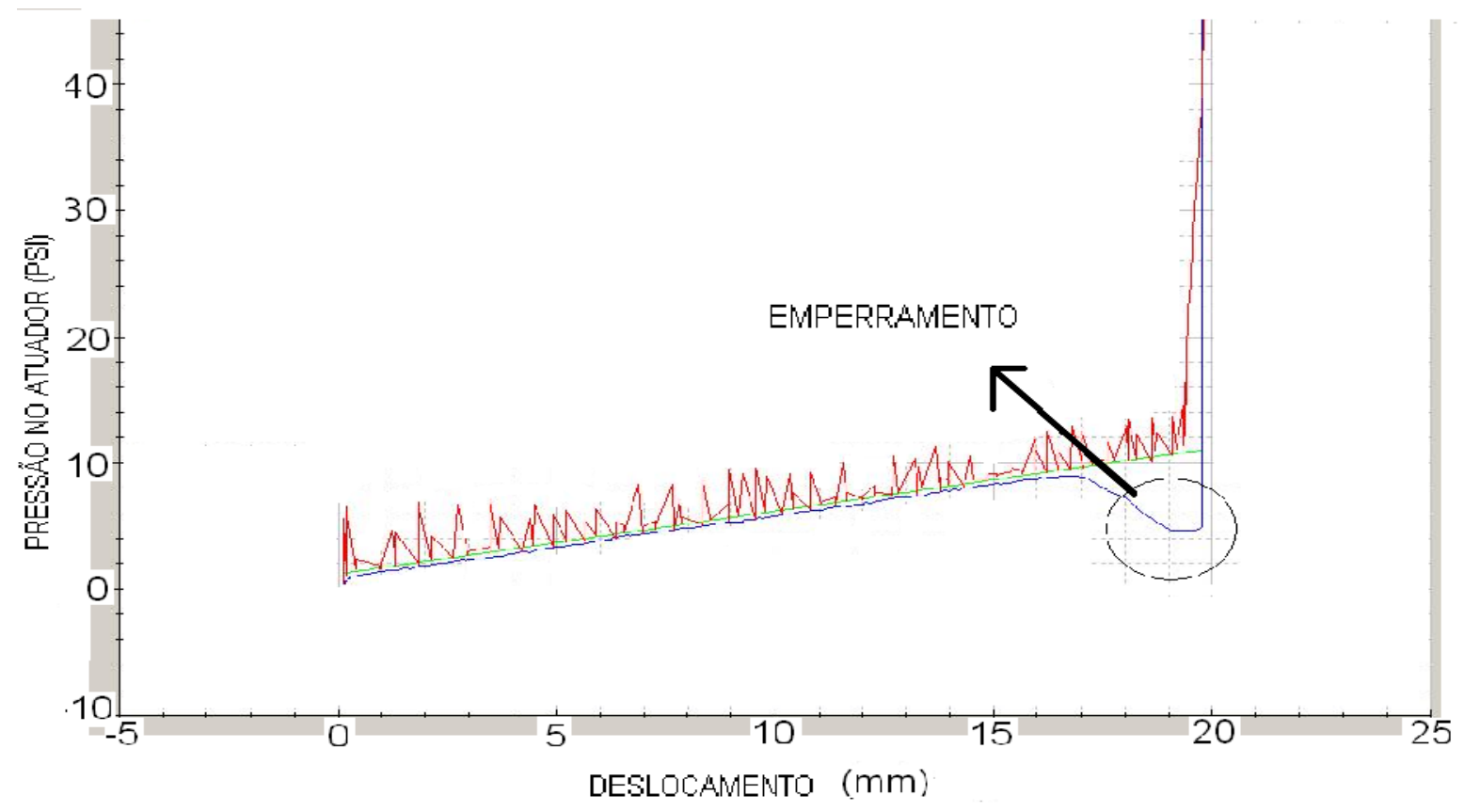

Figure 20: Assinatura da FV-100 com anomalias. 
A válvula tem as seguintes características:

excvalv $\rightarrow 0$ to $20 \mathrm{~mm}$;

pressat $\rightarrow 0$ to $12 \mathrm{PSI}$; e

statvalv $\rightarrow 0$ to $100 \%$ (da abertura ao fechamento).

A pressão de ar decresce de 46 PSI, iniciando o movimento da haste a pressão de 5 PSI, em vez de 11 PSI.

A Tab.4 mostra os valores das variáveis e o respectivo "status" da válvula como variável de saída. O "status" fechado representa que a haste tocou a sede da válvula e o excesso de ar garante que não haverá passagem de fluido. O diagnóstico devido ao "status" da válvula é representado pela Tab.5, que mostra quando a haste está trabalhando normalmente, ou emperrada, ou com dificuldades de movimento.

Tabela 4 - Status da válvula - Faixa de entrada.

\begin{tabular}{ccccccc}
\hline $\begin{array}{c}\text { Status da } \\
\text { válvula }\end{array}$ & Aberta & $1 / 4$ & $1 / 2$ & $3 / 4$ & Fechada & Fortemente Fechada \\
\hline Pares & $(0,0)$ & $(5,3)$ & $(10,6)$ & $(15,9)$ & $(20,12)$ & De $(20,12)$ até $(20,46)$ \\
\hline
\end{tabular}

Tabela 5 - Status da válvula - Diagnóstico da válvula.

\begin{tabular}{cccccc}
\hline $\begin{array}{c}\text { Status da Emperrada } \\
\text { válvula }\end{array}$ & $\begin{array}{c}\text { Fechando } \\
\text { aberta }\end{array}$ & $\begin{array}{c}\text { Abrindo } \\
\text { normalmente }\end{array}$ & $\begin{array}{c}\text { Dificuldade para } \\
\text { normalmente }\end{array}$ & $\begin{array}{c}\text { Emperrada } \\
\text { fechar }\end{array}$ & fechada \\
\hline FV100 & $(20,5)$ & $(20,12)$ a $(0,0)$ & $(0,0) a(20,12)$ & $(0,2) a(8,1)$ & $(20,0)$ \\
\hline
\end{tabular}

Na Tab.5 tem-se o diagnóstico da válvula e a base de regras, na Tab.6.

Tabela 6 - Base de regras do Sistema de diagnóstico.

\section{RULES}

1. If (excvalv is open) and (pressat is open) then (statvalv is open)

2. If (excvalv is a quarter) and (pressat is a quarter) then (statvalv is a quarter)

3. If (excvalv is a half) and (pressat is a half) then (statvalv is a half)

4. If (excvalv is three quarter) and (pressat is three quarter) then (statvalv is three quarter)

5. If (excvalv is close) and (pressat is close) then (statvalv is close)

6. If (excvalv is three quarter) and (pressat is a quarter) then (statvalv is hard to close)

7. If (excvalv is a quarter) and (pressat is a half) then (statvalv is hard to close)

8. If (excvalv is a quarter) and (pressat is three quarter) then (statvalv is hard to open)

9. If (excralv is a close) and (pressat is three quarter) then (statvalv is stuck close)

10. If (excvalv is three quarter) and (pressat is a half) then (statvalv is stuck open)

11. If (excralv is close) and (pressat is strongly_close) then (statvalv is strongly_close)

12. If (excvalv is close) and (pressat is open) then (statvalv is stuck close)

A Tab.7 apresenta as funções de pertinência e as variáveis de entrada e saída. Uma função de pertinência é trapezoidal (situação fortemente fechada) e todas as outras são 
triangulares.

Tabela 7 - Funções de pertinência e seus valores.

\begin{tabular}{|c|c|c|c|c|}
\hline FV100 & Valores (excralv) & $\begin{array}{l}\text { Valores } \\
\text { (pressat) }\end{array}$ & $\begin{array}{l}\text { Valores } \\
\text { (statvalv) }\end{array}$ & $\begin{array}{l}\text { Função De } \\
\text { pertinênci } \\
\text { a }\end{array}$ \\
\hline Aberta & {$\left[\begin{array}{lll}-1 & 0 & 4\end{array}\right]$} & {$\left[\begin{array}{lll}-2 & 0 & 2\end{array}\right]$} & {$\left[\begin{array}{lll}-1 & 0 & 15\end{array}\right]$} & Trimf \\
\hline $1 / 4$ & {$\left[\begin{array}{lll}3 & 5 & 8\end{array}\right]$} & {$\left[\begin{array}{lll}1 & 3 & 5\end{array}\right]$} & {$\left[\begin{array}{lll}10 & 25 & 40\end{array}\right]$} & Trimf \\
\hline Half open & {$\left[\begin{array}{lll}7 & 10 & 13\end{array}\right]$} & {$\left[\begin{array}{lll}4 & 6 & 8\end{array}\right]$} & {$\left[\begin{array}{llll}30 & 50 & 70\end{array}\right]$} & Trimf \\
\hline $3 / 4$ & {$\left[\begin{array}{lll}12 & 15 & 19\end{array}\right]$} & {$\left[\begin{array}{lll}7 & 9 & 11\end{array}\right]$} & {$\left[\begin{array}{lll}60 & 75 & 90\end{array}\right]$} & Trimf \\
\hline Fechada & {$\left[\begin{array}{lll}17 & 20 & 21\end{array}\right]$} & {$\left[\begin{array}{lll}10 & 12 & 14\end{array}\right]$} & {$\left[\begin{array}{llll}85 & 100 & 105\end{array}\right]$} & Trimf \\
\hline Fortemente fechada & Não aplicável & {$\left[\begin{array}{llll}11 & 13 & 45 & 46\end{array}\right]$} & {$\left[\begin{array}{llll}88 & 95 & 120 & 125\end{array}\right]$} & Tramf \\
\hline Emperrada aberta & & & {$\left[\begin{array}{lll}5 & 10 & 15\end{array}\right]$} & Trimf \\
\hline Dificuldade para fechar & & & {$\left[\begin{array}{llll}60 & 65 & 70\end{array}\right]$} & Trimf \\
\hline Emperrada fechada & & & {$\left[\begin{array}{llll}80 & 85 & 90\end{array}\right]$} & Trimf \\
\hline
\end{tabular}

Nas figuras 21, 22 e 23 apresentam-se, o gráfico das funções de pertinência das entradas "excvalv", "pressat", e da saída "statvalv", respectivamente.

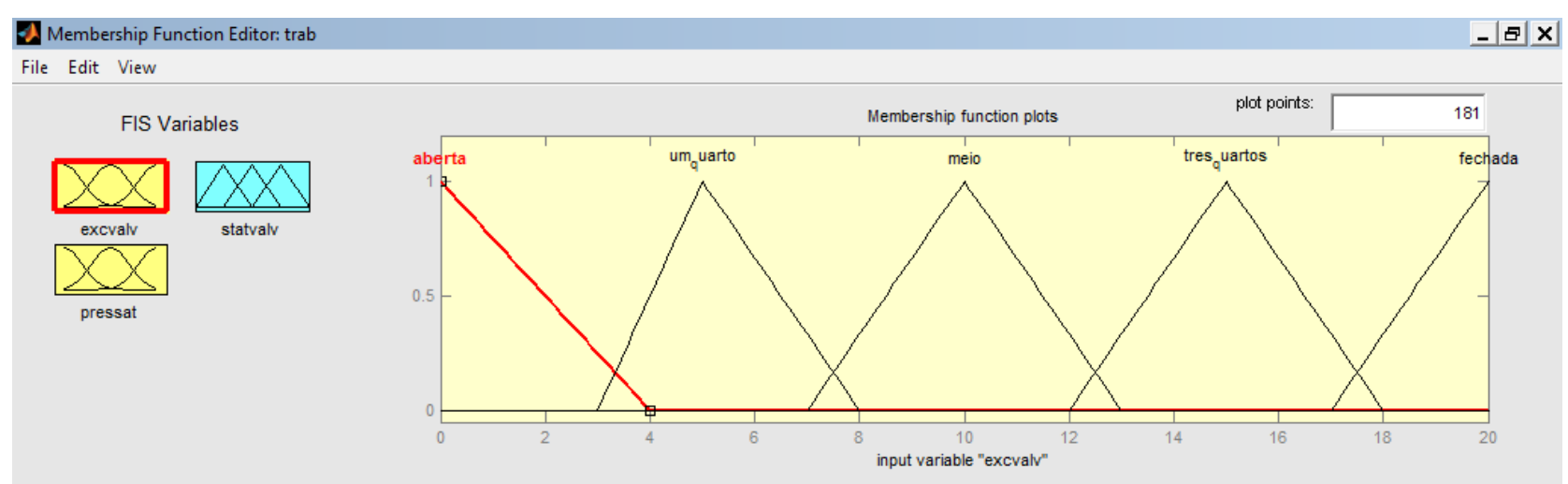

Figura 21 - Entrada "excvalv".

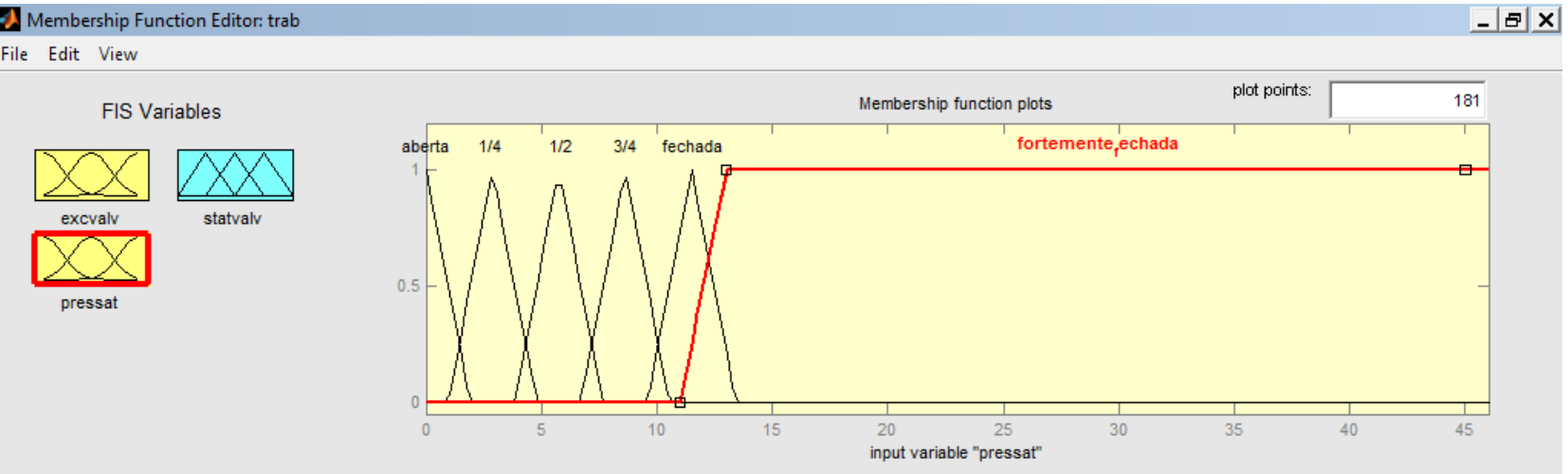

Figura 22 - Entrada "pressat". 

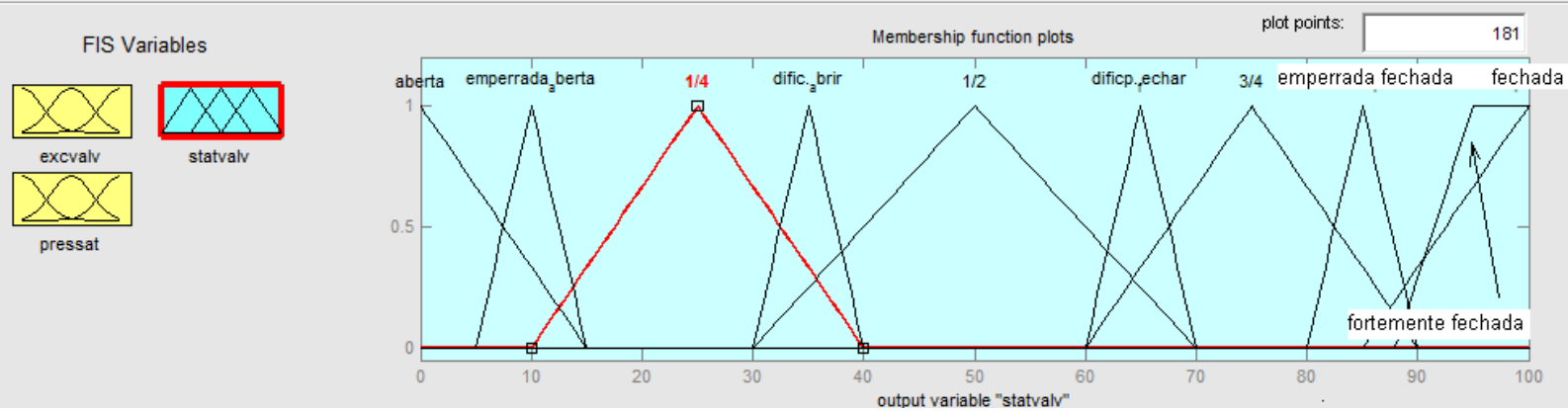

Figura 23- Saída "statvalv".

Na figura 24 tem-se o visor de regras com o exemplo da regra 9. Devido as entradas "excvalv" e "pressat" apresentarem-se como "close" e "three quarter", tem-se a variável "statvalv" com o diagnóstico "emperrada fechada" ou "stuck close", demonstrando uma falha no início do fechamento da válvula.

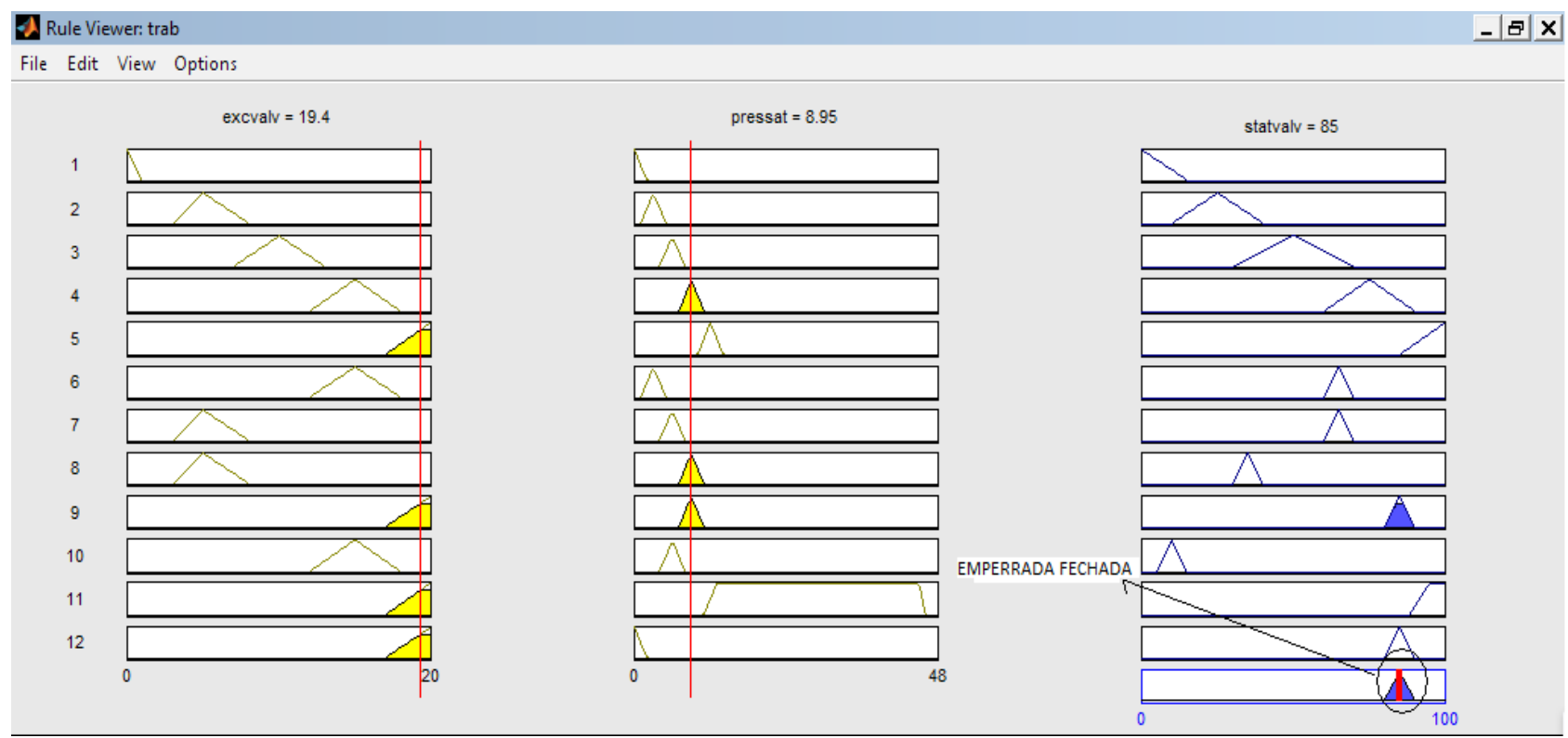

Figura 24 - Visor de regras.

A figura 24 mostra ainda o visor de regras do MATLAB ${ }^{\circledR}$ fuzzy logic toolbox com as 12 regras da Tabela 6 implementadas. Percebe-se a variável EXCVALV com 04 regras acionadas e a variável PRESSAT com 03 regras acionadas, demonstrando ainda que a regra 9 é completada e aciona a saída STATVALV. A saída da regra 9 é o diagnóstico da válvula.

\section{TV-462B - Controle de temperatura de óleo lubrificante da turbina de propulsão}

A válvula a seguir é de controle de temperatura de resfriamento do óleo lubrificante da turbina de propulsão principal do circuito secundário. 
A Figura 25 representa a assinatura eletrônica da válvula e a Tabela 8 mostra os valores das variáveis e o respectivo "status" da válvula como variável de saída. O "status" fechado representa que a haste tocou a sede da válvula e o excesso de ar garante que não haverá passagem de fluido. O diagnóstico devido ao "status" da válvula é representado pela Tabela 9, que mostra quando a haste está trabalhando normalmente, ou emperrada, ou com dificuldades de movimento.

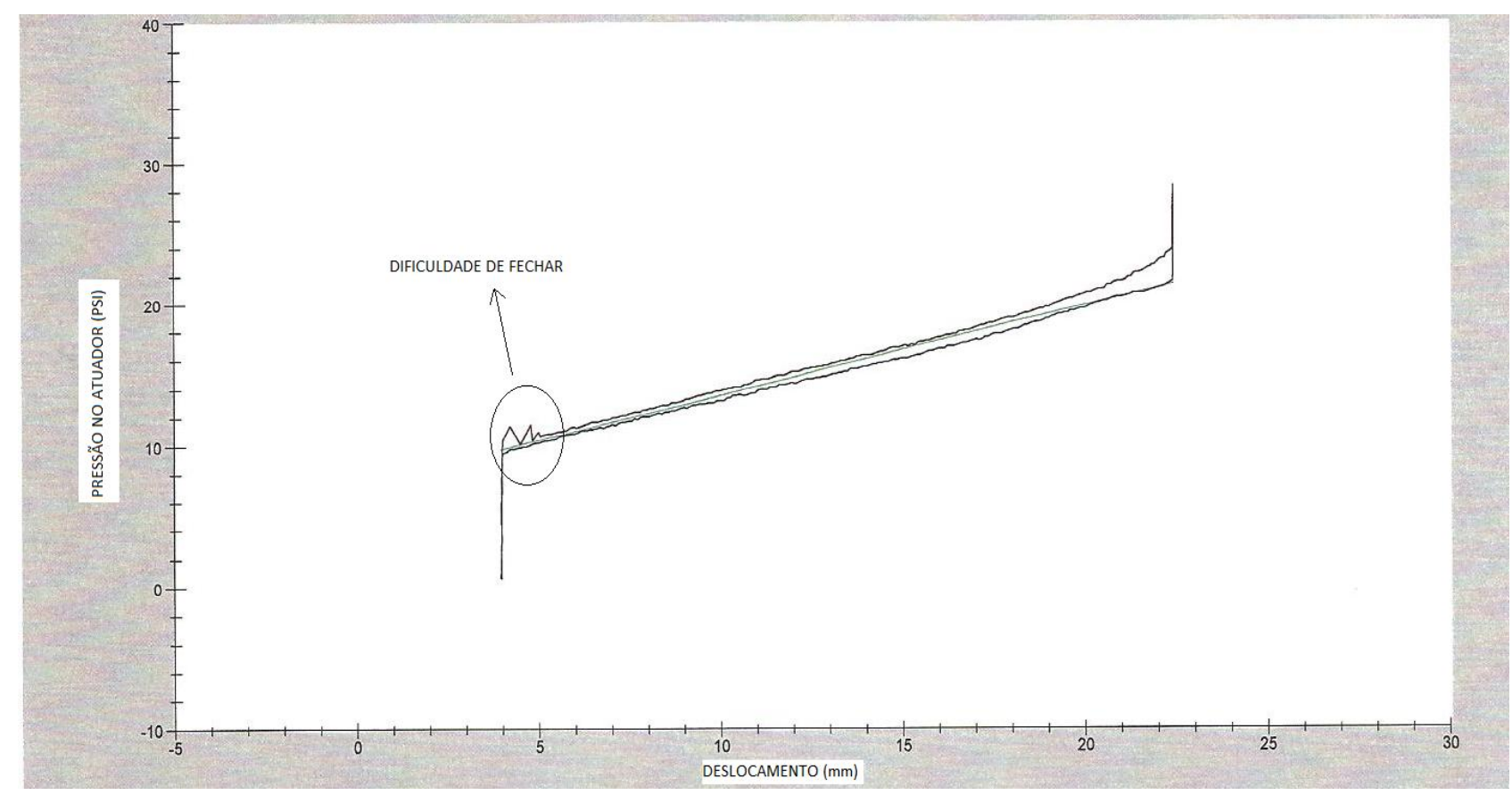

Figura 25 - Assinatura da TV-462B.

A válvula tem as seguintes características:

excvalv $\rightarrow 4$ to $23 \mathrm{~mm}$

pressat $\rightarrow 0$ to $28 \mathrm{PSI}$

statvalv $\rightarrow 0$ to $100 \%$ (da abertura ao fechamento)

Tabela 8 - Status da válvula - Faixa de entrada.

\begin{tabular}{ccccccc}
\hline $\begin{array}{c}\text { Status da } \\
\text { válvula }\end{array}$ & Aberta & $1 / 4$ & $1 / 2$ & $3 / 4$ & Fechada & Fortemente Fechada \\
\hline Pares & $(4,0)$ & $(9,12.5)$ & $(14,15)$ & $(19,17.5)$ & $(23,20)$ & De $(23,20)$ até $(23,28)$ \\
\hline
\end{tabular}

Tabela 9: Status da válvula - Diagnóstico da válvula.

\begin{tabular}{ccccccc}
\hline $\begin{array}{c}\text { Status Emperra } \\
\text { da }\end{array}$ & $\begin{array}{c}\text { Fechando } \\
\text { da }\end{array}$ normalmente & $\begin{array}{c}\text { Abrindo } \\
\text { normalmente }\end{array}$ & $\begin{array}{c}\text { Dificuldade } \\
\text { para fechar }\end{array}$ & $\begin{array}{c}\text { Necessitando } \\
\text { manutenção }\end{array}$ & $\begin{array}{c}\text { Emperrada } \\
\text { fechada }\end{array}$ \\
válvula & aberta & & & & & \\
\hline TV462B & $(4,28)$ & $(4,0)$ a & $(23,28)$ a & $(4,12)$ a $(5,12)$ & $(20,17)$ a & $(20,0)$ \\
& & $(23,28)$ & $(23,20)$ & & $(20,1)$ & \\
\hline
\end{tabular}


As regras utilizadas são as constantes na Tabela 10. A sua ação de funcionamento é ar para fechar - falha abre. A Figura 25 demonstra no ciclo superior (fechamento) uma anomalia. Esta anomalia, de acordo com a base de regras, proporcionará uma saída, diagnosticando uma falha, ainda que incipiente, que denota a dificuldade de movimento.

Tabela 10: Base de regras do Sistema de diagnóstico.

1. If (excvalv is open) and (pressat is open) then (statvalv is open)

2. If (excvalv is a quarter) and (pressat is a quarter) then (statvalv is a quarter)

3. If (excvalv is a half) and (pressat is a half) then (statvalv is a half)

4. If (excvalv is three quarter) and (pressat is three quarter) then (statvalv is three quarter)

5. If (excvalv is close) and (pressat is close) then (statvalv is close)

6. If (excralv is open) and (pressat is strongly close) then (statvalv is stuck-open)

7. If (excvalv is a quarter) and (pressat is three quarter) then (statvalv is stuck-close)

8. If (excvalv is three quarter) and (pressat is a quarter) then (statvalv is hard to close)

9. If (excvalv is a quarter) and (pressat is a half) then (statvalv is hard to close)

10. If (excvalv is close) and (pressat is three quarter) then (statvalv is hard to open)

11. If (excvalv is close) and (pressat is a half) then (statvalv is stuck-open)

12. If (excvalv is close) and (pressat is a quarter) then (statvalv is stuck close)

13. If (excralv is three quarter) and (pressat is a half) then (statvalv is hard to open)

14. If (excvalv is close) and (pressat is strongly_close) then (statvalv is strongly_close)

15. If (excvalv is close) and (pressat is open) then (statvalv is stuck-close)

A Tabela 11 mostra as funções de pertinência e as variáveis de entrada e saída. Uma função de pertinência é trapezoidal (situação fortemente fechada) e as demais são triangulares.

Tabela 11 - Funções de pertinência e seus valores.

\begin{tabular}{|c|c|c|c|c|}
\hline TV462B & Valores (excvalv) & $\begin{array}{l}\text { Valores } \\
\text { (pressat) }\end{array}$ & $\begin{array}{l}\text { Valores } \\
\text { (statvalv) }\end{array}$ & $\begin{array}{l}\text { Função de } \\
\text { pertinência }\end{array}$ \\
\hline Aberta & {$\left[\begin{array}{lll}3 & 4 & 7\end{array}\right]$} & |[0 $\left.\begin{array}{lll}0 & 10 & 12\end{array}\right]$ & [-1 0015$]$ & Trimf \\
\hline $1 / 4$ & {$\left[\begin{array}{lll}6 & 9 & 12\end{array}\right]$} & {$\left[\begin{array}{llll}11 & 12.75 & 14.5\end{array}\right]$} & {$\left[\begin{array}{llll}10 & 25 & 40\end{array}\right]$} & Trimf \\
\hline Half open & {$\left[\begin{array}{lll}11 & 14 & 17\end{array}\right]$} & [14 15.5 17] & {$\left[\begin{array}{lll}30 & 50 & 70\end{array}\right]$} & Trimf \\
\hline $3 / 4$ & {$\left[\begin{array}{lll}16 & 19 & 22\end{array}\right]$} & {$\left[\begin{array}{llll}15.75 & 17 & 19\end{array}\right]$} & 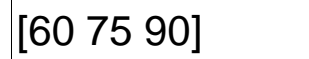 & Trimf \\
\hline Fechada & {$\left[\begin{array}{llll}21 & 23 & 26\end{array}\right]$} & [19 21 24] & {$\left[\begin{array}{llll}85 & 100 & 105\end{array}\right]$} & Trimf \\
\hline Fortemente fechada & Não aplicável & {$\left[\begin{array}{llll}19 & 21 & 30 & 32\end{array}\right]$} & {$\left[\begin{array}{llll}88 & 95 & 120 & 125\end{array}\right]$} & Tramf \\
\hline Emperrada aberta & & & {$\left[\begin{array}{lll}-3 & 0 & 5\end{array}\right]$} & Trimf \\
\hline Dificuldade para fechar & & & {$\left[\begin{array}{lll}3 & 10 & 15\end{array}\right]$} & Trimf \\
\hline $\begin{array}{l}\text { Necessitando de } \\
\text { manutenção }\end{array}$ & & & {$\left[\begin{array}{lll}75 & 80 & 85\end{array}\right]$} & Trimf \\
\hline Emperrada fechada & & & [95 100 120] & Trimf \\
\hline
\end{tabular}

As Figuras 26, 27 e 28 apresentam respectivamente o gráfico das funções de pertinência das entradas "excvalv", "pressat" e da saída "statvalv". 
12 Membership Function Editor: TV472B

File इdit Vew
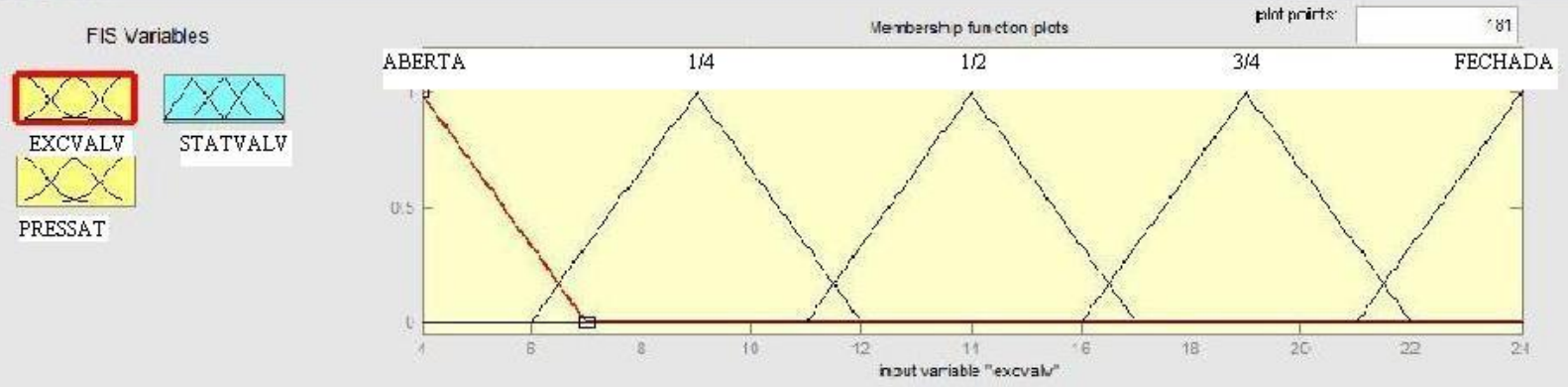

Figura 26 - Entrada "excvalv".

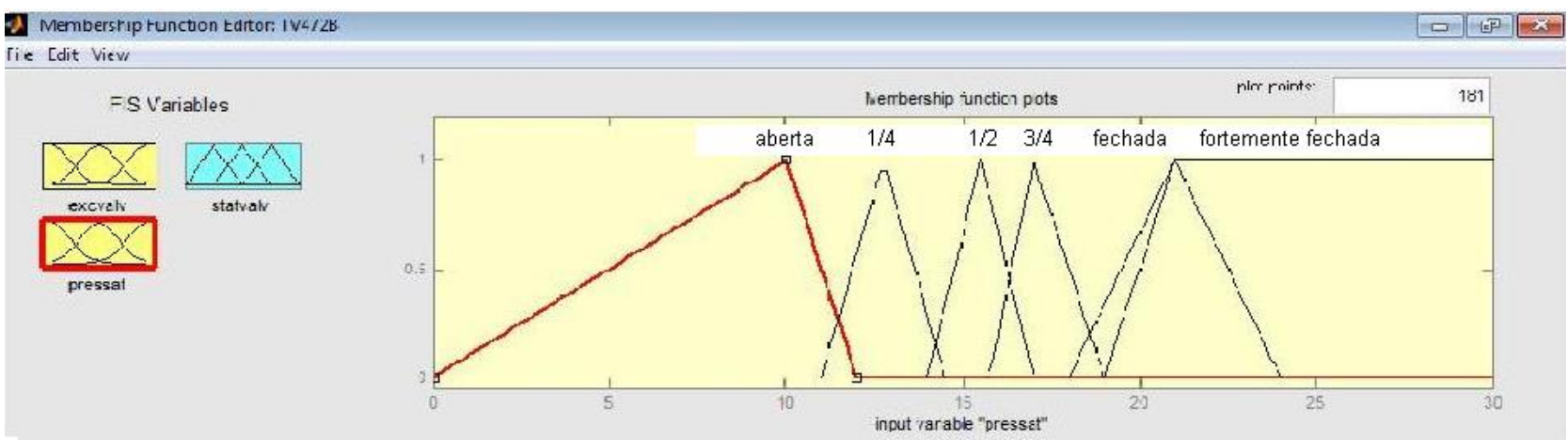

Figura 27 - Entrada "pressat".

Membership Function Editor: TV472B

File Edit View

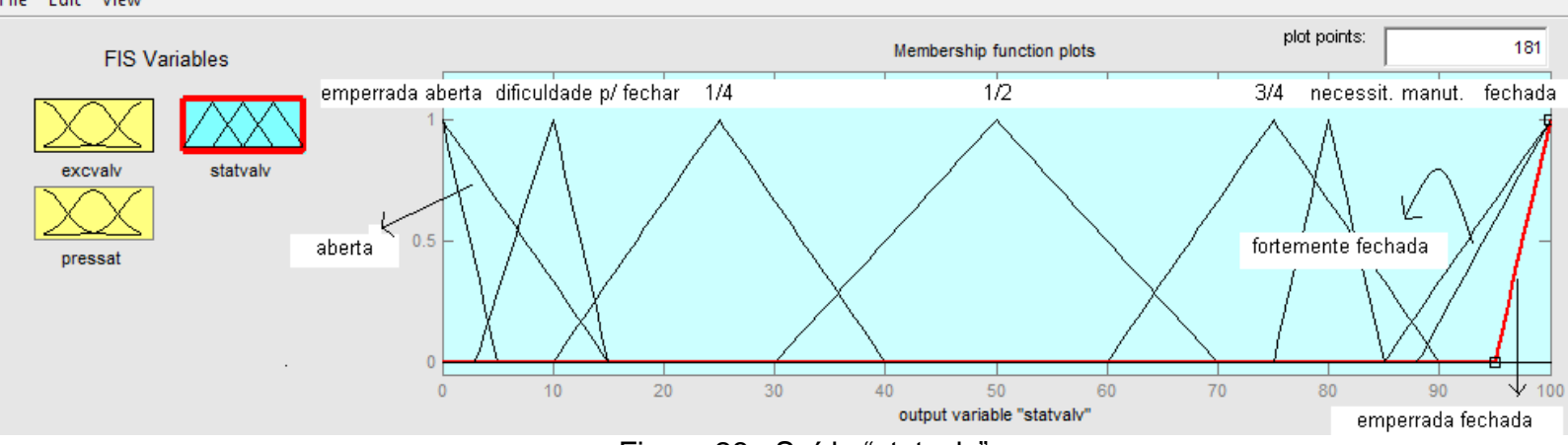

Figura 28- Saída "statvalv".

Na Figura 29 tem-se o visor de regras com o exemplo da regra 8. Devido as entradas "excvalv" e "pressat" apresentarem-se como "aberta" e "um quarto", tem-se a variável "statvalv" com o diagnóstico "difícil para fechar" ou "hard to close", demonstrando uma falha ainda que incipiente, no início do fechamento da válvula. 
excralv $=4.24$

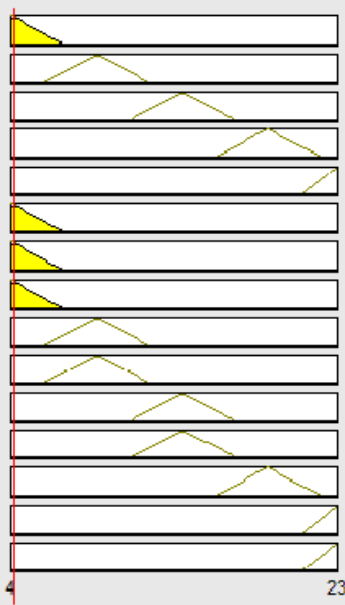

pressat $=13.1$

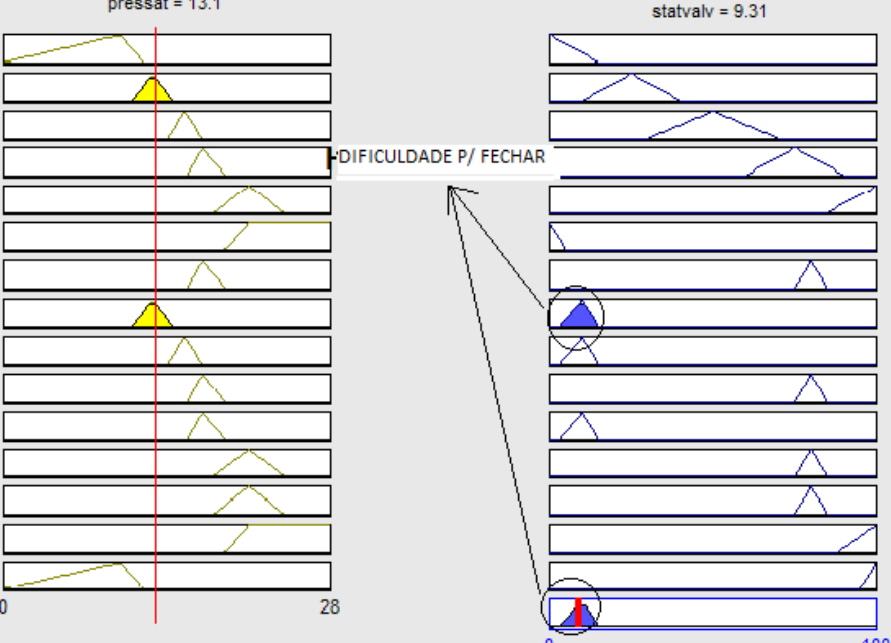

Figura 29 - Visor de regras.

\section{PV-472B - Controle de pressão de óleo}

A Figura 30 mostra a assinatura da válvula PV-472B, controle de pressão de óleo na linha de baixa pressão das turbinas. O gráfico apresenta anomalias durante o excursionamento de sua haste. "Ripples" considerados incipientes nos ciclos de abertura e fechamento. Dificuldades de movimento na abertura e fechamento, apresentando emperramento, e no início do primeiro quarto de abertura apresenta um "calo", que indica uma obstrução, que foi vencida pelo aumento da pressão no diafragma.

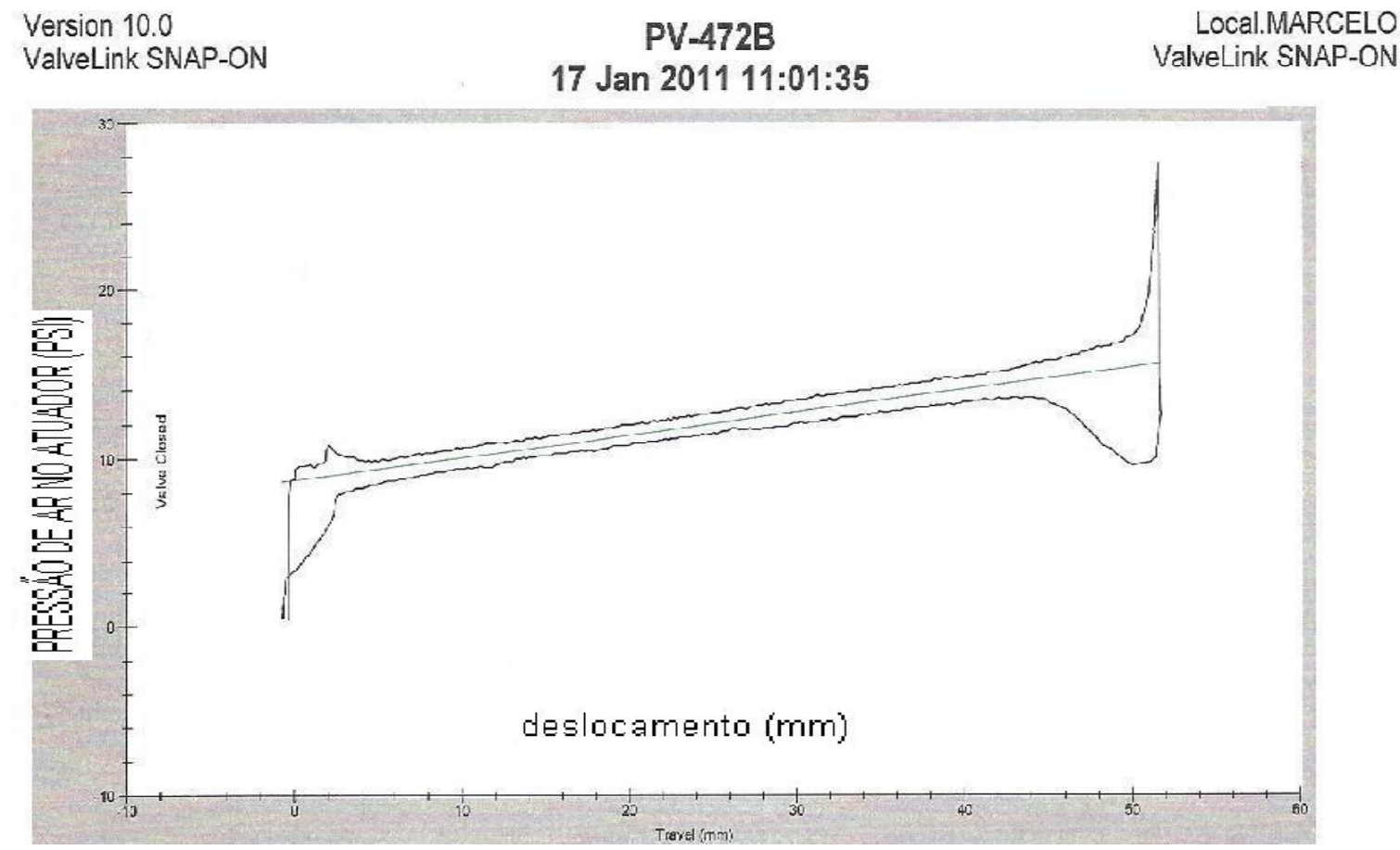

Figura 30 - Assinatura da PV-472B.

A PV-472B tem suas variáveis conforme se segue: 


$$
\begin{aligned}
& \text { excvalv } \rightarrow 0 \text { a } 52 \mathrm{~mm} \\
& \text { pressat } \rightarrow 0 \text { a } 28 \mathrm{PSI} \\
& \text { statvalv } \rightarrow 0 \text { a } 100 \% \text { (do fechamento à abertura) }
\end{aligned}
$$

Tabela 12 - Status da válvula - Faixa de entrada.

\begin{tabular}{lllllll}
\hline Status da válvula & Fechada & $1 / 4$ & $1 / 2$ & $3 / 4$ & Aberta & Fortemente aberta \\
\hline PV-472B & $(0,0)$ & $(13, \mathrm{y})$ & $(26, \mathrm{y})$ & $(31, \mathrm{y})$ & $(52,15)$ & De $(52,15)$ até $(52,28)$ \\
\hline
\end{tabular}

O status "aberta" representa que a haste comprimiu totalmente a mola de retorno da válvula, e o "fortemente aberta" representa o excesso de ar que garante que a válvula manterá esta posição, e também a passagem total do fluido. Com esses dados, modelase o problema de acordo com a Tabela 13 que indica a variável de saída "status da válvula". Ela mostra ainda o diagnóstico indicado pelos especialistas em válvulas.

Tabela 13 - Status da válvula e diagnóstico.

\begin{tabular}{|lllllll|}
$\begin{array}{l}\text { Status da } \\
\text { válvula }\end{array}$ & $\begin{array}{l}\text { Emperrada } \\
\text { fechada }\end{array}$ & $\begin{array}{l}\text { Abrindo } \\
\text { normalmente }\end{array}$ & $\begin{array}{l}\text { Fechando } \\
\text { normalmente }\end{array}$ & Dificuldade de abrir & $\begin{array}{l}\text { Necessitando de } \\
\text { manutenção }\end{array}$ & $\begin{array}{l}\text { Emperrada } \\
\text { aberta }\end{array}$ \\
\hline Pares & $(0,28)$ & $(0,0)$ até(52,28) & $(52,28)$ até(0,8) $(48,16)$ até(52,28) & $(52,13)$ até(52,10) $(52,9)$ \\
\hline
\end{tabular}

O funcionamento desta válvula difere um pouco das duas anteriores, pois seu ciclo de fechamento e abertura é invertido, ou seja, trata-se de uma válvula ar para abrir - falha fecha. A base de regras (Tabela 14) foi desenvolvida pelos especialistas.

Tabela 14: Base de regras do Sistema de diagnóstico (ciclo invertido).

1. If (excralv is open) and (pressat is open) then (statvalv is open)

2. If (excvalv is a quarter) and (pressat is a quarter) then (statvalv is a quarter)

3. If (excralv is a half) and (pressat is a half) then (statvalv is a half)

4. If (excvalv is three quarter) and (pressat is three quarter) then (statvalv is three quarter)

5. If (excralv is close) and (pressat is close) then (statvalv is close)

6. If (excvalv is open) and (pressat is strongly_open) then (statvalv is stuck-open)

7. If (excvalv is a quarter) and (pressat is three quarter) then (statvalv is stuck-close)

8. If (excvalv is three quarter) and (pressat is a quarter) then (statvalv is hard to close)

9. If (excvalv is a quarter) and (pressat is a half) then (statvalv is hard to close)

10. If (excvalv is close) and (pressat is three quarter) then (statvalv is hard to open)

11. If (excvalv is close) and (pressat is a half) then (statvalv is stuck-open)

12. If (excvalv is close) and (pressat is a quarter) then (statvalv is stuck close)

13. If (excvalv is three quarter) and (pressat is a half) then (statvalv is hard to open)

14. If (excralv is close) and (pressat is strongly_close) then (statvalv is strongly_close)

15. If (excralv is close) and (pressat is open) then (statvalv is stuck-close)

A tabela 15 apresenta as funções de pertinência e os valores escolhidos para representar as entradas e a saída. Há uma função trapezoidal para o "status" fortemente fechada e as outras demais são triangulares. 
Tabela 15 - Funções de pertinência e valores da PV-472B.

\begin{tabular}{|c|c|c|c|c|}
\hline Nome & $\begin{array}{l}\text { Valores } \\
\text { (excvalv) }\end{array}$ & $\begin{array}{l}\text { Valores } \\
\text { (pressat) }\end{array}$ & Valores (statvalv) & $\begin{array}{l}\text { Função de } \\
\text { pertinência }\end{array}$ \\
\hline Fechada & {$\left[\begin{array}{lll}-1 & 0 & 7\end{array}\right]$} & {$\left[\begin{array}{lll}0 & 9 & 11\end{array}\right]$} & {$\left[\begin{array}{lll}-1 & 0 & 1\end{array}\right]$} & Trimf \\
\hline $1 / 4$ & {$\left[\begin{array}{lll}5 & 13 & 21\end{array}\right]$} & {$\left[\begin{array}{lll}9 & 10.5 & 12\end{array}\right]$} & {$\left[\begin{array}{llll}10 & 25 & 40\end{array}\right]$} & Trimf \\
\hline $1 / 2$ & [19 26 33] & [10 12 14] & {$\left[\begin{array}{llll}30 & 50 & 70\end{array}\right]$} & Trimf \\
\hline $3 / 4$ & {$\left[\begin{array}{lll}30 & 39 & 48\end{array}\right]$} & [12 13.5 15] & {$\left[\begin{array}{llll}60 & 75 & 90\end{array}\right]$} & Trimf \\
\hline Aberta & [4 $\left.4 \begin{array}{lll}4 & 53\end{array}\right]$ & {$\left[\begin{array}{lll}13 & 15 & 17\end{array}\right]$} & {$\left[\begin{array}{lll}85 & 100 & 105\end{array}\right]$} & Trimf \\
\hline Fortemente aberta & Not applied & {$\left[\begin{array}{llll}14 & 15 & 27 & 28\end{array}\right]$} & {$\left[\begin{array}{lllll}90 & 100 & 120 & 125\end{array}\right]$} & Tramf \\
\hline Travada Fechada & & & {$\left[\begin{array}{lll}-10 & 1.5 & 5\end{array}\right]$} & Trimf \\
\hline Dificuldade de abrir & & & {$\left[\begin{array}{lll}3 & 10 & 15\end{array}\right]$} & Trimf \\
\hline $\begin{array}{l}\text { Necessitando de } \\
\text { manutenção }\end{array}$ & & & [75 85 95] & Trimf \\
\hline Travada aberta & & & [95 100 120] & Trimf \\
\hline
\end{tabular}

Nas Figuras 31, 32 e 33 seguem-se respectivamente os gráficos das funções de pertinência das entradas "excvalv", "pressat" e da saída "statvalv".

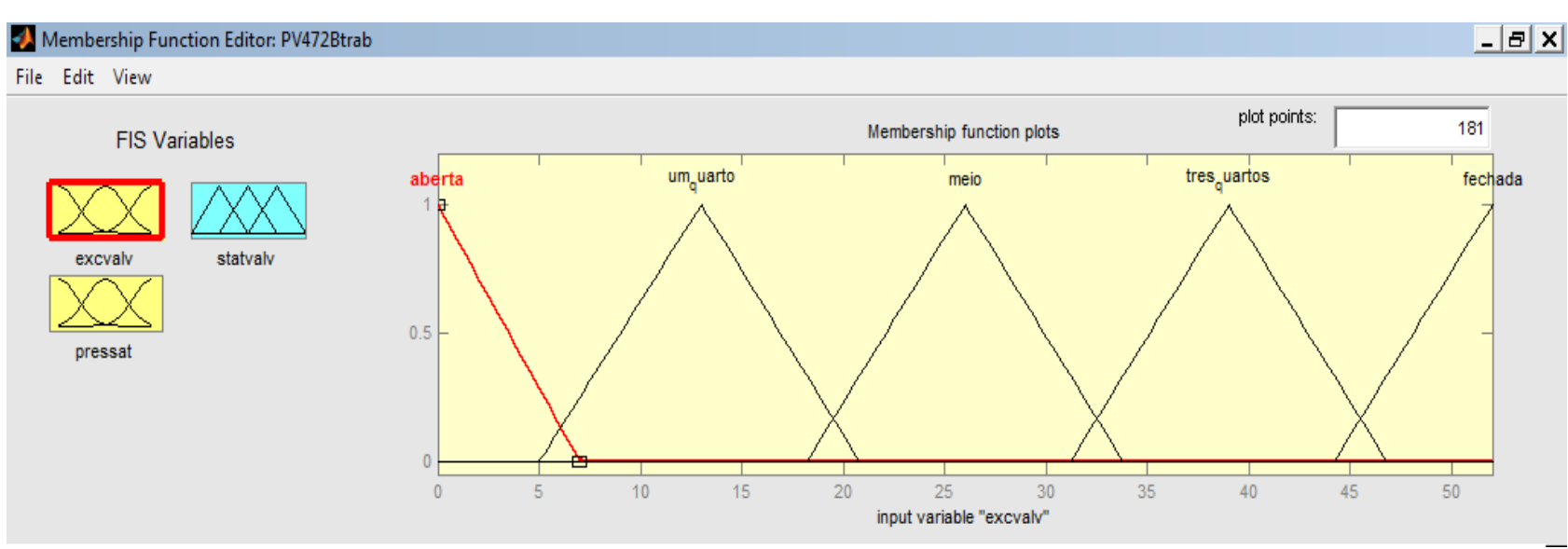

Figura 31 - Entrada "excvalv".

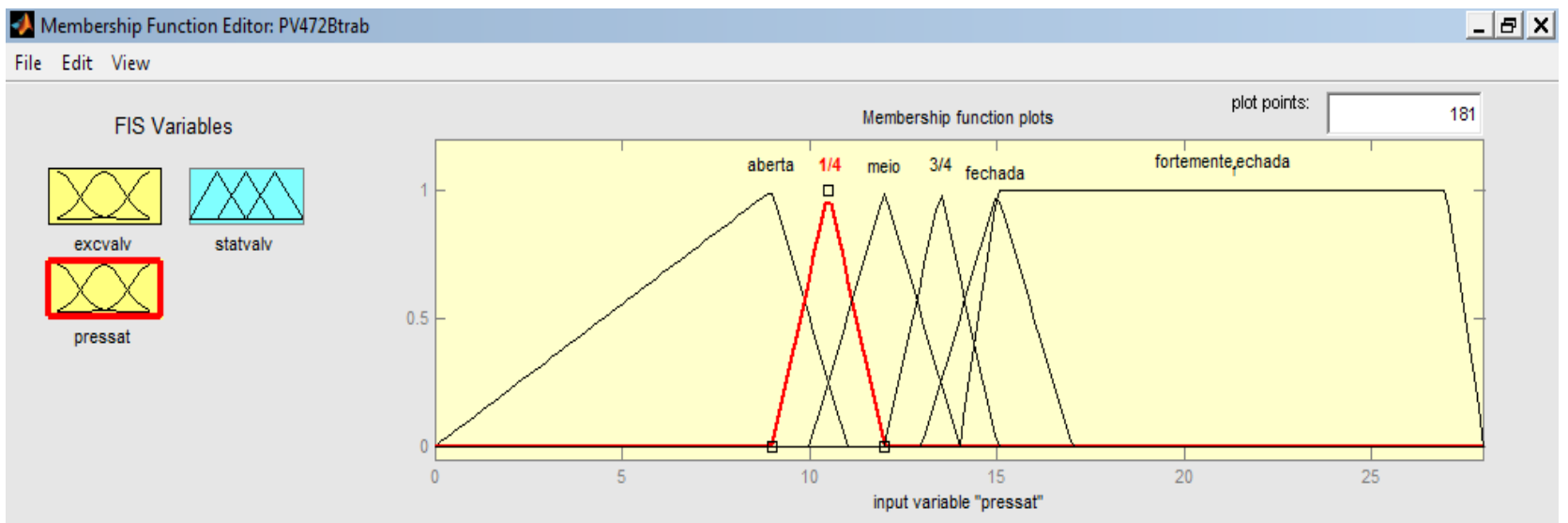

Figura 32 - Entrada "pressat". 


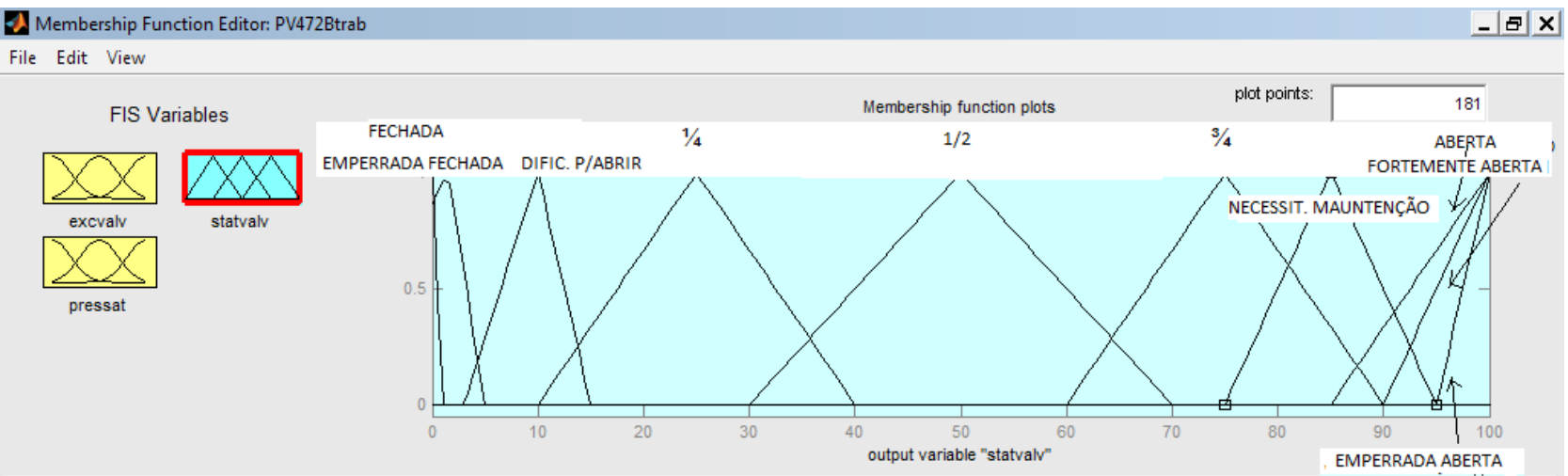

Figura 33 - Saída "statvalv".

Na Figura 34, o visor de regras evidencia o diagnóstico em dois pontos - regras 11 e 12. Ao analisar o gráfico, percebe-se que, pela regra 11, consegue-se diagnosticar uma dificuldade no ciclo de abertura, que é vencida após o aumento de pressão. Trata-se então de uma falha incipiente. No ciclo de fechamento percebe-se uma dificuldade de movimento da haste. A entrada "pressat" decresce sem que a "excvalv" decresça, indicando o diagnóstico emperramento aberto.

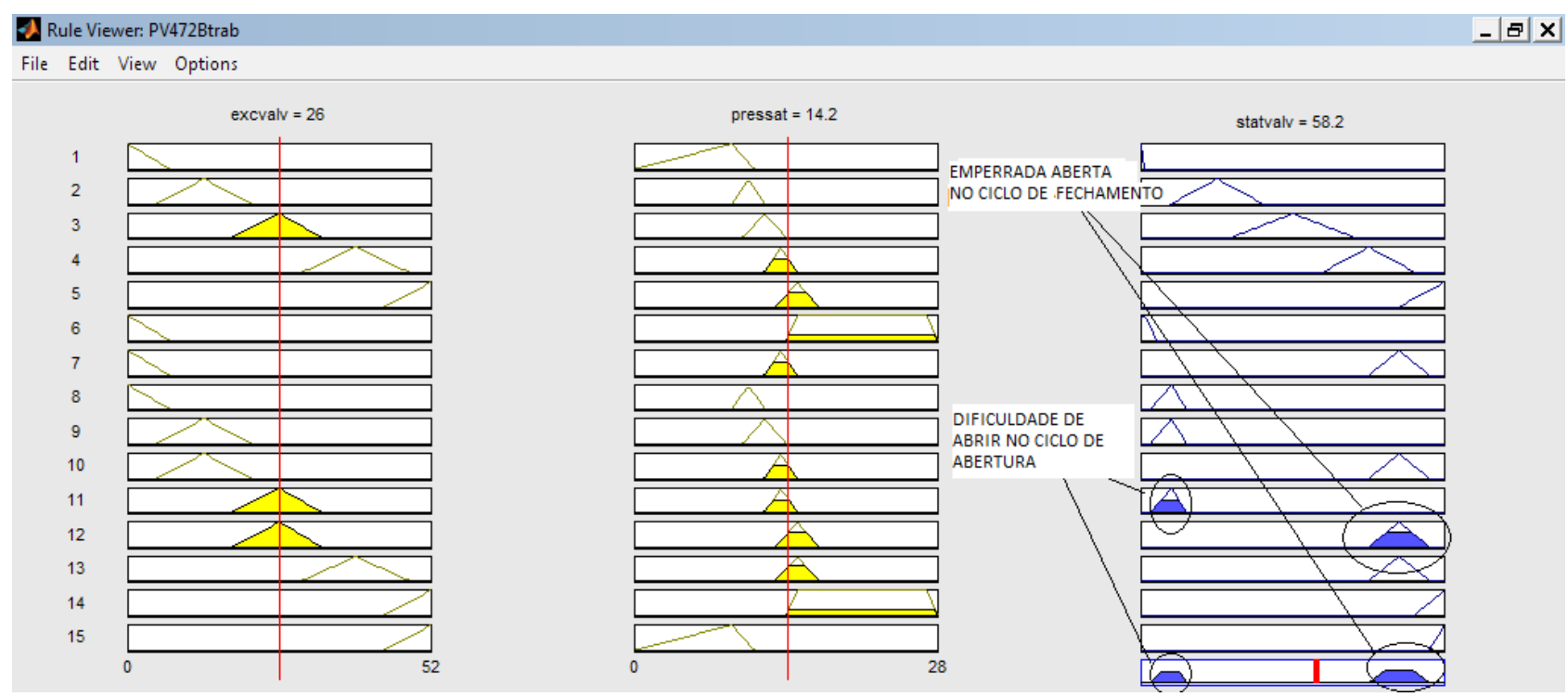

Figura 34 - Visor de regras.

\section{PV-830 - Controle de pressão de água de alimentação da caldeira}

A Figura 35 mostra a assinatura da válvula PV-830, que controla a pressão de água de alimentação para resfriamento da bancada de testes das turbinas. O gráfico apresenta anomalias no início e fim do excursionamento de sua haste. Neste caso não ocorre "Ripple", o que indica que a haste está livre do fenômeno "stiction", que é considerado danoso e indicador de uso prolongado da válvula sem a devida manutenção. 
Tomando a linha de base, e entre o ciclo de abertura e fechamento, percebe-se ainda, uma diferença de pressão de aproximadamente 8 PSI. Trata-se portanto, de histerese, que é um fenômeno que ocorre quando há folga entre as conexões de parafusos e porcas das partes móveis do mecanismo haste-posicionador-atuador.

Valvelink Dataset Report

August 01, 2012

$15: 44: 34$

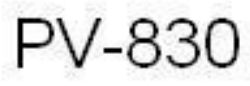

LOCAI ADMINISTRATOR Valvelink SNAP-ON

ValveLink SNAP-ON ValveLIIK SNAP ON
Valvelink SNAP-ON

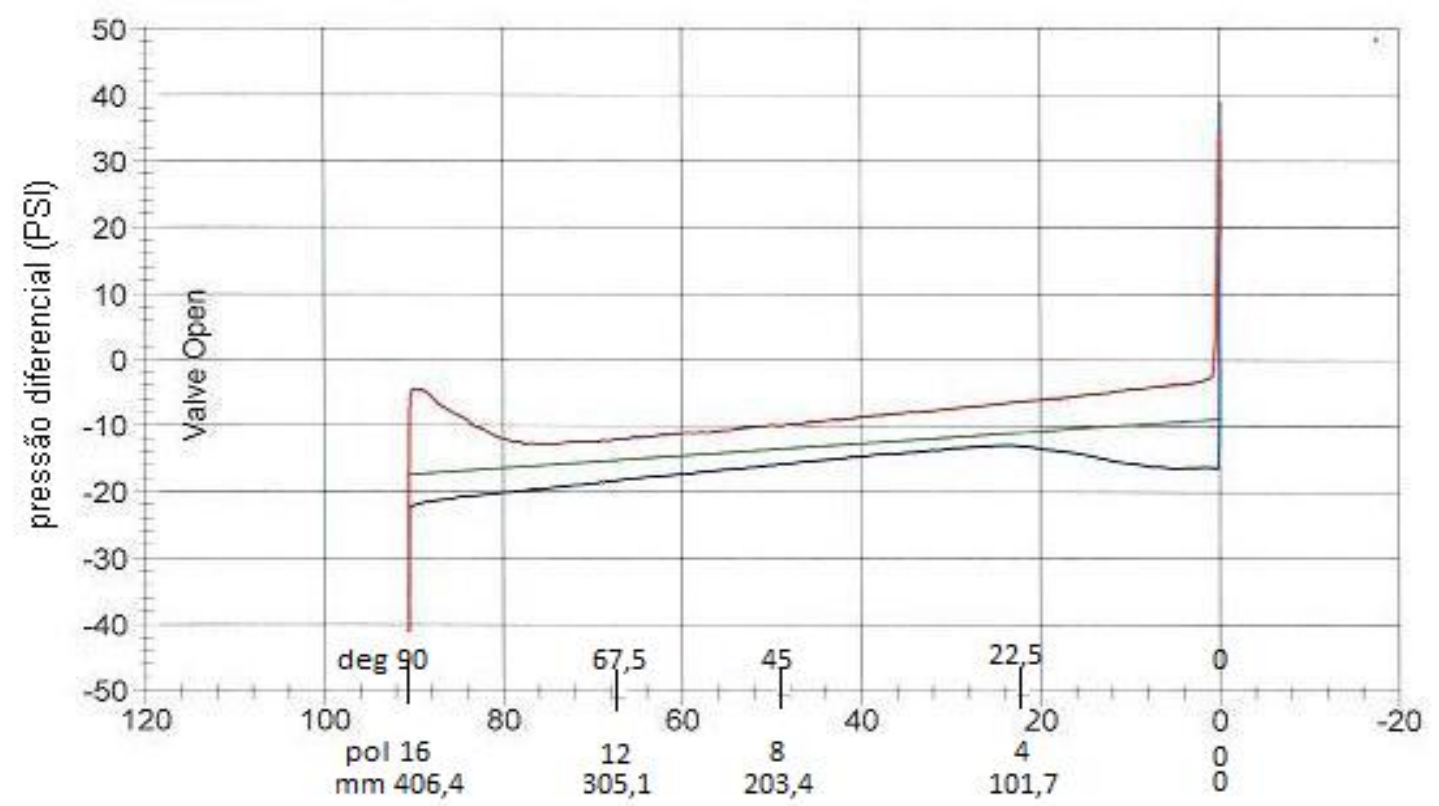

Figura 35 - Assinatura da PV-830.

A PV-830 tem suas variáveis conforme se segue:

excvalv $\rightarrow 90$ a 0 graus ou 406,4 a $0 \mathrm{~mm}$;

pressat $\rightarrow-40$ a 40 PSI (pressão diferencial); e

statvalv $\rightarrow 0$ a $100 \%$ (de abertura ao fechamento).

A Figura 35 representa a assinatura eletrônica da válvula. O deslocamento neste caso se apresenta em graus (deg), por se tratar de uma válvula de controle do tipo borboleta de 16 polegadas. Todavia, a respectiva conversão para milímetros encontra-se na Figura 35 e na Tabela 16, que apresenta os valores das variáveis e o respectivo "status" da válvula como variável de saída. O "status" fechado representa que a haste tocou a sede da válvula e o excesso de ar garante que não haverá passagem de fluido.

Tabela 16: Status da válvula - Faixa de entrada.

\begin{tabular}{ccccccc}
\hline $\begin{array}{c}\text { Status da } \\
\text { válvula }\end{array}$ & Aberta & $1 / 4$ & $1 / 2$ & $3 / 4$ & Fechada & $\begin{array}{c}\text { Fortemente } \\
\text { Fechada }\end{array}$ \\
\cline { 1 - 3 }$($ deg,PSI $)$ & $(90,-16)$ & $(67.5,-14)$ & $(45,-12)(22.5,-10)$ & $(0,-8)$ & De $(0,-8)$ até \\
\cline { 1 - 2 } & $(406,4 ;-16)$ & $(305,1 ;-14)(203,4 ;-12)(101,7 ;-10)$ & & $(0,40)$ \\
\hline
\end{tabular}


O diagnóstico devido ao "status" da válvula é representado pela Tabela 17 e 18, que mostra quando a haste está trabalhando normalmente, ou emperrada, ou com dificuldades de movimento ou histerese.

Tabela 17: Status da válvula - Diagnóstico da válvula.

\begin{tabular}{ccccccc}
\hline $\begin{array}{c}\text { Status da Emperrada } \\
\text { válvula }\end{array}$ & $\begin{array}{c}\text { Fechando } \\
\text { aberta }\end{array}$ & $\begin{array}{c}\text { Abrindo } \\
\text { normalmente }\end{array}$ & $\begin{array}{c}\text { Dificuldade Dificuldade } \\
\text { normalmente }\end{array}$ & He fechar & de abrir & \\
\hline PV-830 & $(90,40)$ & $(90,-16)$ a $(0,-8)$ & $\begin{array}{c}(0,40) \text { a } \\
(90,-16)\end{array}$ & $(90,-10)$ & $(0,-10)$ & Conforme \\
& & & & & tabela 19 \\
\hline
\end{tabular}

Tabela 18: Histerese da válvula PV830.

\begin{tabular}{cccccc}
\hline Excvalv & Aberta & $1 / 4$ & $1 / 2$ & $3 / 4$ & Fechada \\
\hline PV-830 & $(90,-19)$ e & $(67.5,-16)$ e & $(45,-14)$ e & $(22.5,-12)$ e & $(0,-10) \mathrm{e}$ \\
& $(90,-14)$ & $(67.5,-12)$ & $(45,-10)$ & $(22.5,-8)$ & $(0,-6)$ \\
\hline
\end{tabular}

As regras utilizadas estão descritas na Tabela 19. Neste caso, a válvula tem a ação de funcionamento, ar para fechar - falha abre.

Tabela 19 - Base de regras do Sistema de diagnóstico.

\begin{tabular}{|c|}
\hline $\begin{array}{c}\text { RULES } \\
\end{array}$ \\
\hline 1. If (excvalv is closed) and (pressat is open) then (statvalv is closed) \\
\hline 2. If (excvalv is $1 / 4$ ) and (pressat is $1 / 4$ ) then (statvalv is $1 / 4$ ) \\
\hline 3. If (excvalv is $1 / 2$ ) and (pressat is $1 / 2$ ) then (statvalv is $1 / 2$ ) \\
\hline 4. If (excvalv is $3 / 4$ ) and (pressat is $3 / 4$ ) then (statvalv is $3 / 4$ ) \\
\hline 5. If (excralv is open) and (pressat is closed) then (statvalv is open) \\
\hline 6. If (excvalv is closed) and (pressat is $3 / 4$ ) then (statvalv is programar_manut) \\
\hline 7. If (excralv is closed) and (pressat is $1 / 4$ ) then (statvalv is hard to open) \\
\hline 8. If (excvalv is $1 / 4)$ and (pressat is $1 / 2)$ then (statvalv is hard to open) \\
\hline 9. If (excvalv is $1 / 4$ ) and (pressat is $3 / 4$ ) then (statvalv is programar_manut) \\
\hline 10. If (excralv is $1 / 2$ ) and (pressat is $3 / 4$ ) then (statvalv is hard to open) \\
\hline 11. If (excvalv is $3 / 4$ ) and (pressat is closed) then (statvalv is programar_manut) \\
\hline 12. If (excralv is closed) and (pressat is open) then (statvalv is closed) \\
\hline 13. If (excvalv is open) and (pressat is h1) then (statvalv is histerese) \\
\hline 14. If (excvalv is open) and (pressat is h2) then (statvalv is histerese) \\
\hline 15. If (excvalv is $1 / 4$ ) and (pressat is h3) then (statvalv is histerese) \\
\hline 16. If (excralv is $1 / 4$ ) and (pressat is h4) then (statvalv is histerese) \\
\hline 17. If (excralv is $1 / 2$ ) and (pressat is h2) then (statvalv is histerese) \\
\hline 19. If (excralv is $1 / 2$ ) and (pressat is h6) then (statvalv is histerese) \\
\hline 19. If (excralv is $3 / 4$ ) and (pressat is h4) then (statvalv is histerese) \\
\hline 20. If (excvalv is $3 / 4$ ) and (pressat is h7) then (statvalv is histerese) \\
\hline 21. If (excvalv is closed) and (pressat is h6) then (statvalv is histerese) \\
\hline 22. If (excvalv is closed) and (pressat is h5) then (statvalv is histerese) \\
\hline
\end{tabular}


A Tabela 20 mostra as funções de pertinência e as variáveis de entrada e saída. Uma função de pertinência é trapezoidal (situação fortemente fechada) e todas as demais são triangulares.

\begin{tabular}{|c|c|c|c|c|}
\hline PV-830 & Valores (excvalv) & $\begin{array}{l}\text { Valores } \\
\text { (pressat) }\end{array}$ & $\begin{array}{l}\text { Valores } \\
\text { (statvalv) }\end{array}$ & $\begin{array}{l}\text { Função } \\
\text { De } \\
\text { pertinênci } \\
\text { a }\end{array}$ \\
\hline Aberta & {$\left[\begin{array}{lll}75 & 90 & 105\end{array}\right]$} & {$\left[\begin{array}{lll}-40 & -16 & -14\end{array}\right]$} & {$\left[\begin{array}{lll}-1 & 0 & 15\end{array}\right]$} & Trimf \\
\hline $1 / 4$ & {$\left[\begin{array}{llll}5 & 22.5 & 40\end{array}\right]$} & {$\left[\begin{array}{lll}-16 & -14 & -12\end{array}\right]$} & [10 25 40] & Trimf \\
\hline Half open & {$\left[\begin{array}{lll}30 & 45 & 60\end{array}\right]$} & {$\left[\begin{array}{lll}-14 & -12 & -10\end{array}\right]$} & {$\left[\begin{array}{lll}30 & 50 & 70\end{array}\right]$} & Trimf \\
\hline $3 / 4$ & {$\left[\begin{array}{llll}50 & 67.5 & 75\end{array}\right]$} & {$\left[\begin{array}{lll}-12 & -10 & -8\end{array}\right]$} & {$\left[\begin{array}{lllllllll}60 & 75 & 90\end{array}\right]$} & Trimf \\
\hline Fechada & {$\left[\begin{array}{lll}-15 & 0 & 15\end{array}\right]$} & {$\left[\begin{array}{lll}-10 & -8 & -6\end{array}\right]$} & {$\left[\begin{array}{lll}85 & 100 & 105\end{array}\right]$} & Trimf \\
\hline Fortemente fechada & Não aplicável & {$\left[\begin{array}{llll}-10 & -8 & 38 & 40\end{array}\right]$} & $\begin{array}{l}{\left[\begin{array}{lll}88 & 95 & 120 \\
125\end{array}\right]}\end{array}$ & Tramf \\
\hline Emperrada aberta & & & {$\left[\begin{array}{lll}-3 & 0 & 5\end{array}\right]$} & Trimf \\
\hline Dificuldade para fechar & & & {$\left[\begin{array}{lll}3 & 10 & 15\end{array}\right]$} & Trimf \\
\hline $\begin{array}{l}\text { Necessitando de } \\
\text { manutenção }\end{array}$ & & & {$\left[\begin{array}{lll}75 & 80 & 85\end{array}\right]$} & Trimf \\
\hline Emperrada fechada & & & {$\left[\begin{array}{lll}95 & 100 & 120\end{array}\right]$} & Trimf \\
\hline Histerese & $\begin{array}{l}{\left[\begin{array}{lll}85 & 90 & 95\end{array}\right] ;} \\
{\left[\begin{array}{lll}66 & 67.5 & 69\end{array}\right] ;} \\
{\left[\begin{array}{lll}44 & 45 & 46\end{array}\right] ;} \\
{\left[\begin{array}{lll}21 & 22.5 & 24\end{array}\right] ;} \\
{\left[\begin{array}{lll}-1 & 0 & 1\end{array}\right]}\end{array}$ & $\begin{array}{l}{\left[\begin{array}{lll}-17 & -19 & -19\end{array}\right]} \\
{\left[\begin{array}{lll}-13 & -14 & -15\end{array}\right]} \\
{\left[\begin{array}{lll}-15 & -16 & -17\end{array}\right]} \\
{\left[\begin{array}{lll}-11 & -12 & -13\end{array}\right]} \\
{\left[\begin{array}{lll}-13 & -14 & -15\end{array}\right]} \\
{\left[\begin{array}{lll}-9 & -10 & -11\end{array}\right]} \\
{\left[\begin{array}{lll}-11 & -12 & -13\end{array}\right]} \\
{\left[\begin{array}{lll}-7 & -8 & -9\end{array}\right]} \\
{\left[\begin{array}{lll}-9 & -10 & -11\end{array}\right]} \\
{\left[\begin{array}{lll}-5 & -6 & -7\end{array}\right]}\end{array}$ & {$\left[\begin{array}{llll}35 & 35 & 35\end{array}\right]$} & Trimf \\
\hline
\end{tabular}

Nas Figuras 36, 37 e 38 seguem-se respectivamente o gráfico das funções de pertinência das entradas "excvalv", "pressat", da saída "statvalv".

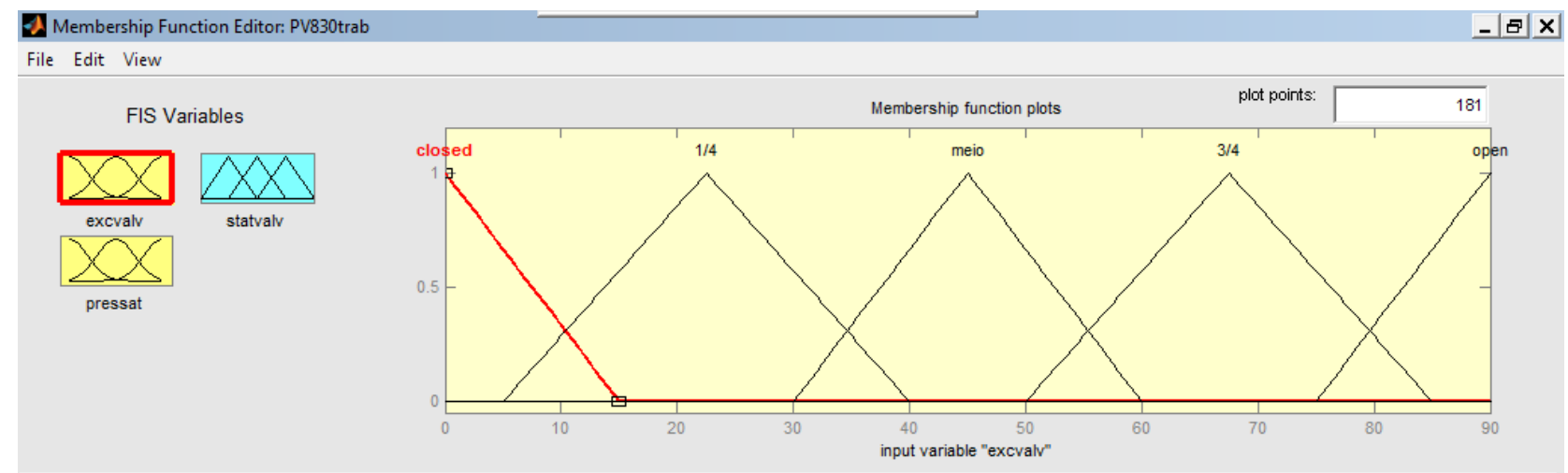

Figura 36 - Entrada "excvalv". 

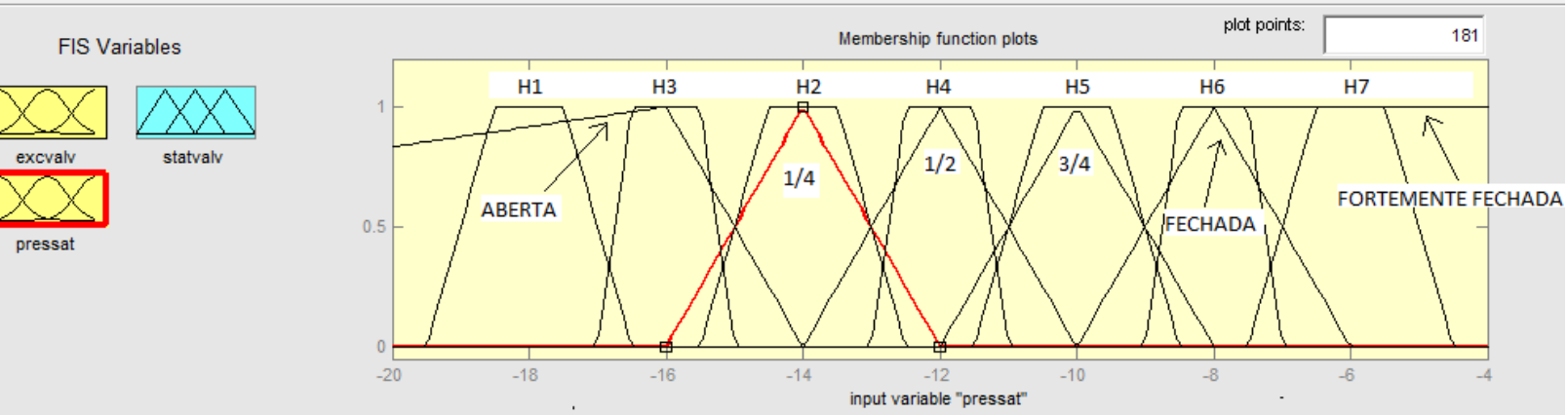

Figura 37 - Entrada "pressat".

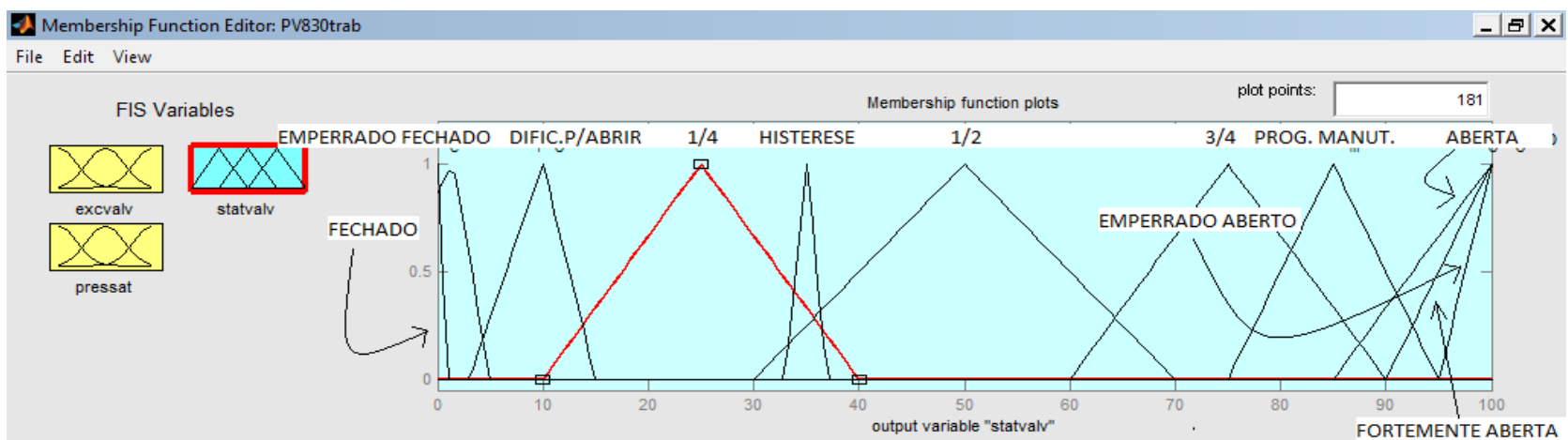

Figura 38 - Saída "statvalv".

$\mathrm{Na}$ Figura 39 tem-se o visor de regras com as regras 11 e 20 acionadas. A regra 11, devido a entrada "excvalv" apresentar "3/4" de seu excursionamento e a variável "pressat" encontrar-se na posição máxima "closed", a saída devida é "programar manutenção". Com a regra 20 tem-se o diagnóstico complementar acionando a saída "histerese", que indica uma folga no conjunto de partes móveis, folga esta que causa um atraso entre o excursionamento da válvula e a pressão no atuador. O referido diagnóstico demonstra uma falha, ainda que incipiente, no movimento da válvula.

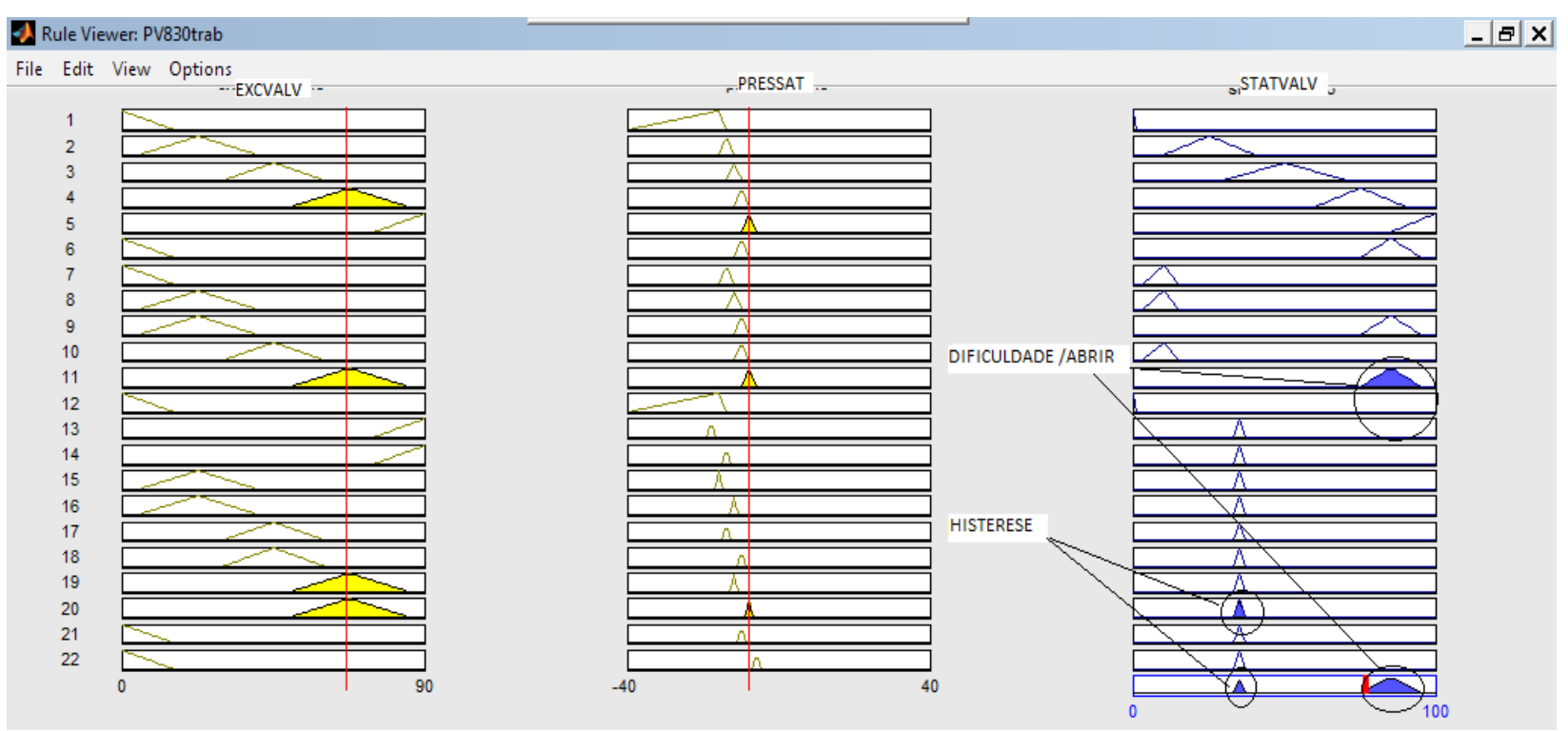

Figura 39 - Visor de regras. 


\section{PV-1200 - Controle de pressão do desaerador}

A Figura 39 mostra a assinatura da válvula PV-1200, que controla a pressão de água de alimentação para resfriamento da caldeira (desaerador). O gráfico apresenta anomalias no excursionamento de sua haste, também apresentando um fim de curso antecipado.

Neste caso não ocorre "Ripple", o que indica que a haste está livre do fenômeno "stiction". Todavia percebe-se uma histerese entre os ciclos de abertura e fechamento. Que é considerado danoso para este componente, e indica uso prolongado da válvula sem a devida manutenção.

Tomando a linha de base, e entre o ciclo de abertura e fechamento, a histerese se faz presente na diferença de pressão de aproximadamente 4 PSI. Este fenômeno ocorre quando há folga entre as conexões de parafusos e porcas das partes móveis do mecanismo haste-posicionador-atuador.

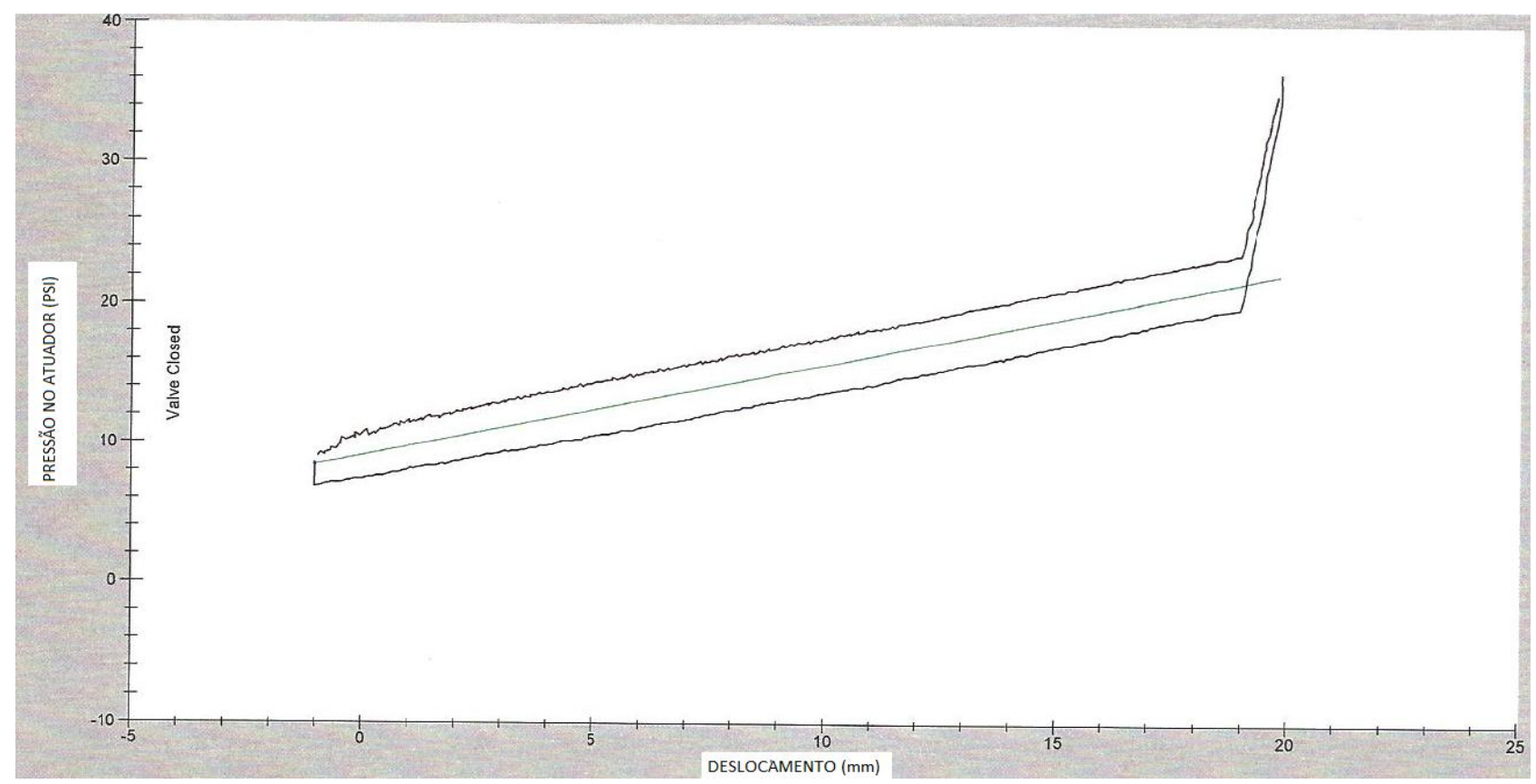

Figura 40 - Assinatura da PV-1200.

A PV-1200 tem suas variáveis conforme se segue:

excvalv $\rightarrow-2$ a $20 \mathrm{~mm}$;

pressat $\rightarrow 9$ a $36 \mathrm{PSI}$ (pressure square inch); e

statvalv $\rightarrow 0$ a $100 \%$ (de abertura ao fechamento).

A Figura 40 representa a assinatura eletrônica da válvula e a Tabela 21 mostra os valores das variáveis e o respectivo "status" da válvula como variável de saída. 
Tabela 21 - Status da válvula e Faixa de entrada.

\begin{tabular}{cccccc}
\hline $\begin{array}{c}\text { Status da } \\
\text { válvula }\end{array}$ & Fechada & $1 / 4$ & $1 / 2$ & $3 / 4$ & Aberta \\
\hline Pares & $(-2,9)$ & $(3.5,12.75)$ & $(9,15.5)$ & $(14.5,19.75)$ & $(20,22)$ \\
\hline
\end{tabular}

O diagnóstico devido ao "status" da válvula é representado pela Tabela 22, que indica quando a haste está trabalhando normalmente, ou emperrada, ou com dificuldades de movimento ou histerese.

Tabela 22 - Status da válvula - Diagnóstico da válvula.

\begin{tabular}{cccccc}
\hline $\begin{array}{c}\text { Status da Emperrada } \\
\text { válvula }\end{array}$ & $\begin{array}{c}\text { Abrindo } \\
\text { fechada }\end{array}$ & $\begin{array}{c}\text { Fechando } \\
\text { normalmente }\end{array}$ & Obstrução & Histerese \\
normalmente & & \\
\hline PV-1200 & 2,2 & $(-2,9)$ a $(20,22)$ & $(20,22)$ a $(-2,9)$ & 19,32 & Conforme tabela 23 \\
\hline
\end{tabular}

Tabela 23 - Histerese da válvula PV1200.

\begin{tabular}{cccccc}
\hline Excvalv & Fechada & $1 / 4$ & $1 / 2$ & $3 / 4$ & Aberta \\
\hline PV-1200 & $(-2,7) \mathrm{e}$ & $(3.5,9.5) \mathrm{e}$ & $(9,17.5) \mathrm{e}$ & $(19.75,21.75) \mathrm{e}$ & $(20,20) \mathrm{e}$ \\
& $(-2,10)$ & $(3.5,14.75)$ & $(9,13.5)$ & $(19.75,17.75)$ & $(20,24)$ \\
\hline
\end{tabular}

As regras utilizadas estão descritas na Tabela 24. Neste caso, a válvula tem a ação de funcionamento, ar para abrir - falha fecha.

Tabela 24 - Base de regras do Sistema de diagnóstico.

1. If (excvalv is closed) and (pressat is closed) then (statvalv is closed)

2. If (excvalv is $1 / 4$ ) and (pressat is $1 / 4$ ) then (statvalv is $1 / 4$ )

3. If (excvalv is $1 / 2$ ) and (pressat is $1 / 2$ ) then (statvalv is $1 / 2$ )

4. If (excvalv is $3 / 4$ ) and (pressat is $3 / 4$ ) then (statvalv is $3 / 4$ )

5. If (excvalv is open) and (pressat is open) then (statvalv is open)

6. If (excvalv is closed) and (pressat is h1) then (statvalv is histerese)

7. If (excvalv is 1/4) and (pressat is h2) then (statvalv is histerese)

8. If (excvalv is $1 / 2$ ) and (pressat is h3) then (statvalv is histerese)

9. If (excvalv is $3 / 4$ ) and (pressat is h4) then (statvalv is histerese)

10. If (excvalv is open) and (pressat is h5) then (statvalv is histerese) 
A Tabela 25 mostra funções de pertinência e variáveis de entrada e saída. As funções utilizadas neste caso são todas triangulares.

Tabela 25 - Funções de pertinência e seus valores.

\begin{tabular}{|c|c|c|c|c|}
\hline PV-1200 & Valores (excvalv) & Valores (pressa & $\begin{array}{l}\text { Valores } \\
\text { (statvalv) }\end{array}$ & $\begin{array}{l}\text { Função } \\
\text { De } \\
\text { pertinênci } \\
\text { a }\end{array}$ \\
\hline Fechada & {$\left[\begin{array}{lll}-6 & -2 & 2\end{array}\right]$} & {$\left[\begin{array}{lll}6 & 9 & 12\end{array}\right]$} & {$\left[\begin{array}{lll}-1 & 0 & 15\end{array}\right]$} & Trimf \\
\hline $1 / 4$ & {$\left[\begin{array}{lll}-1 & 3 & 7\end{array}\right]$} & {$\left[\begin{array}{llll}10 & 12.75 & 15.5\end{array}\right]$} & {$\left[\begin{array}{llll}10 & 25 & 40\end{array}\right]$} & Trimf \\
\hline Half open & {$\left[\begin{array}{lll}5 & 9 & 13\end{array}\right]$} & {$\left[\begin{array}{lll}-14 & -12 & -10\end{array}\right]$} & {$\left[\begin{array}{lll}30 & 50 & 70\end{array}\right]$} & Trimf \\
\hline $3 / 4$ & {$\left[\begin{array}{lll}11 & 14.5 & 19\end{array}\right]$} & {$\left[\begin{array}{lll}-12 & -10 & -8\end{array}\right]$} & {$\left[\begin{array}{llll}60 & 75 & 90\end{array}\right]$} & Trimf \\
\hline Aberta & {$\left[\begin{array}{lll}16 & 20 & 24\end{array}\right]$} & {$\left[\begin{array}{lll}-10 & -8 & -6\end{array}\right]$} & {$\left[\begin{array}{lll}85 & 100 & 105\end{array}\right]$} & Trimf \\
\hline Histerese & $\begin{array}{l}{\left[\begin{array}{lll}85 & 90 & 95\end{array}\right] ;} \\
{\left[\begin{array}{lll}66 & 67.5 & 69\end{array}\right] ;} \\
{\left[\begin{array}{lll}44 & 45 & 46\end{array}\right] ;} \\
{\left[\begin{array}{lll}21 & 22.5 & 24\end{array}\right] ;} \\
{\left[\begin{array}{lll}-1 & 0 & 1\end{array}\right]}\end{array}$ & 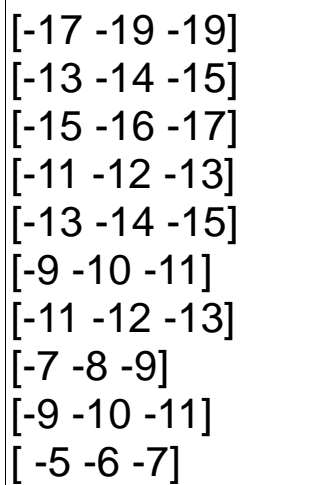 & {$\left[\begin{array}{llll}35 & 35 & 35\end{array}\right]$} & Trimf \\
\hline
\end{tabular}

Nas Figuras 41, 42 e 43 seguem-se respectivamente o gráfico das funções de pertinência das entradas "excvalv", "pressat", da saída "statvalv".

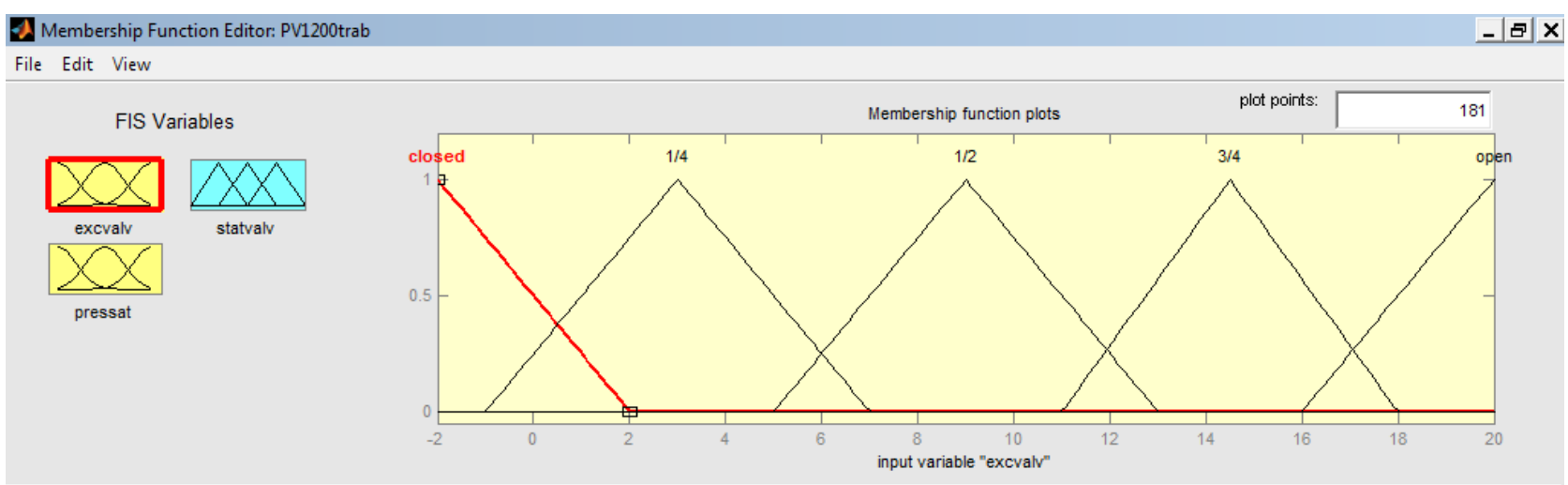

Figura 41 - Entrada "excvalv". 

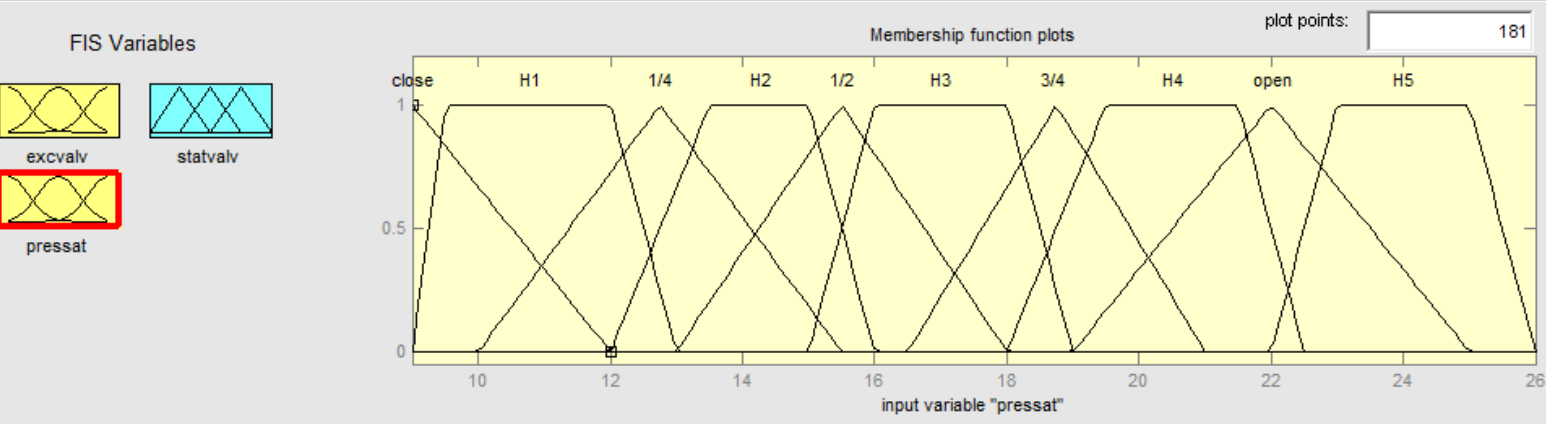

Figura 42 - Entrada "pressat".

Dembership Function Editor: PV-1200TRAB :ile Edit View

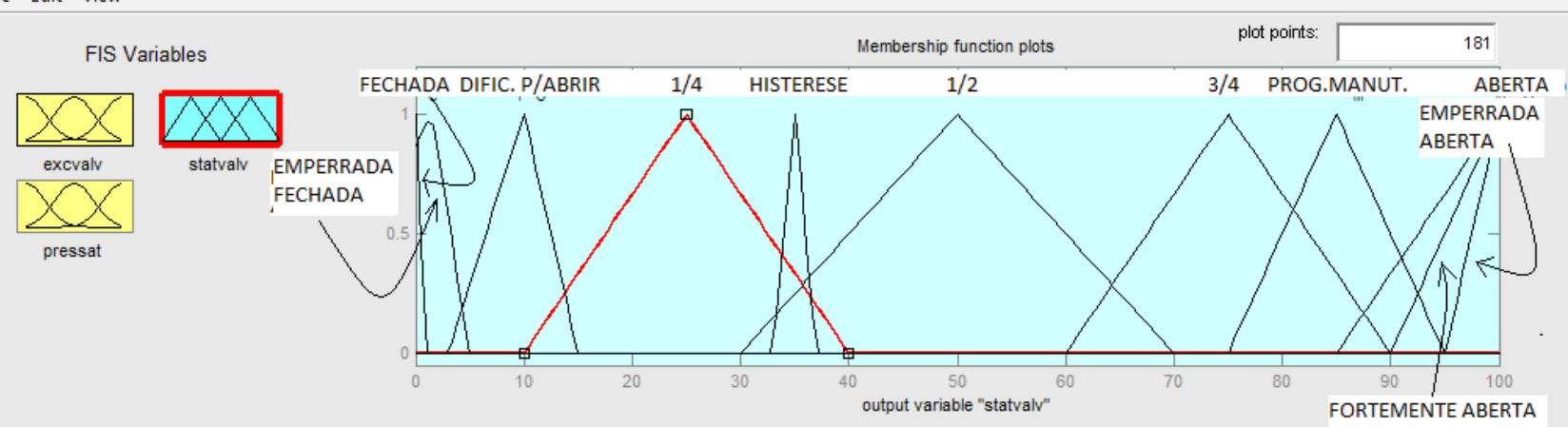

Figura 43 - Saída "statvalv".

$\mathrm{Na}$ Figura 44 abaixo tem-se o visor de regras com as regras 3 e 8 acionadas. A regra 3, apenas indica a posição que a válvula está a $1 \frac{1}{2}$ (meio). Na regra 8 tem-se 0 diagnóstico complementar acionando a saída "histerese", que indica uma folga no conjunto de partes móveis. Esta folga causa um atraso entre o excursionamento da válvula e a pressão no atuador. O referido diagnóstico demonstra uma falha, ainda que incipiente, no movimento da válvula.

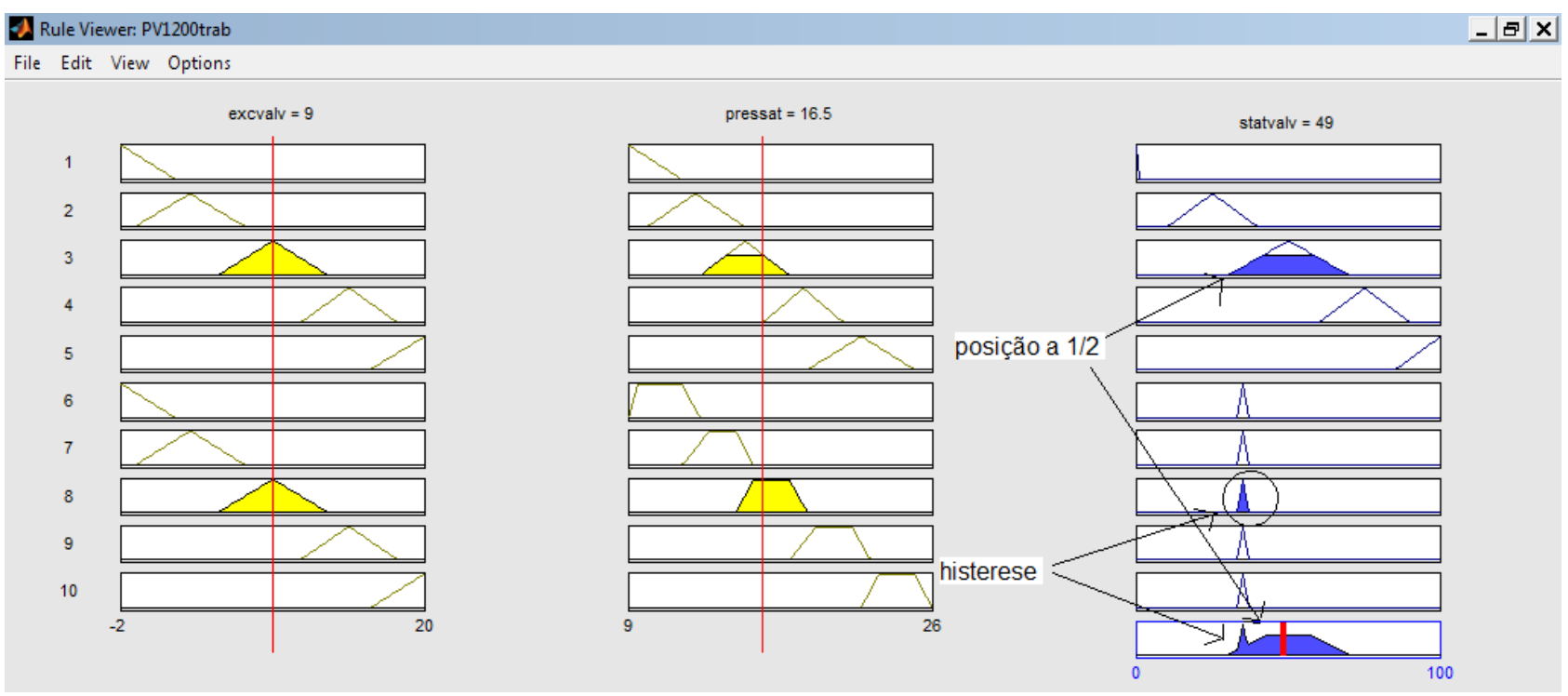

Figura 44 - Visor de regras. 


\section{PV-1110 - Controle de pressão de vapor de alta}

A Figura 45 mostra a assinatura da válvula que controla a pressão de vapor de alta de alimentação da turbina. O gráfico apresenta anomalias no início, meio e fim do ciclo de abertura e no início do ciclo de fechamento.

Neste caso não ocorre "Ripple", o que indica que a haste está livre do fenômeno "stiction", que é considerado danoso e um indicador de uso prolongado da válvula sem a devida manutenção. Todavia, tomando a linha de base, e entre o ciclo de abertura e fechamento, percebe-se ainda, uma diferença de pressão de aproximadamente 2 PSI. Ainda que muito incipiente, trata-se de histerese, fenômeno que ocorre quando há folga entre as conexões de parafusos e porcas das partes móveis do mecanismo haste-posicionador-atuador. As anomalias existentes no início e fim do excursionamento da haste denotam uma dificuldade de movimento nas extremidades, indicando um emperramento, ainda que de pequeno grau. Ademais, a anomalia existente no meio do ciclo de abertura deve-se a alguma "calosidade" existente entre as partes móveis e físicas da válvula, que necessita de um aporte de ar comprimido para que se vença essa obstrução ao movimento.

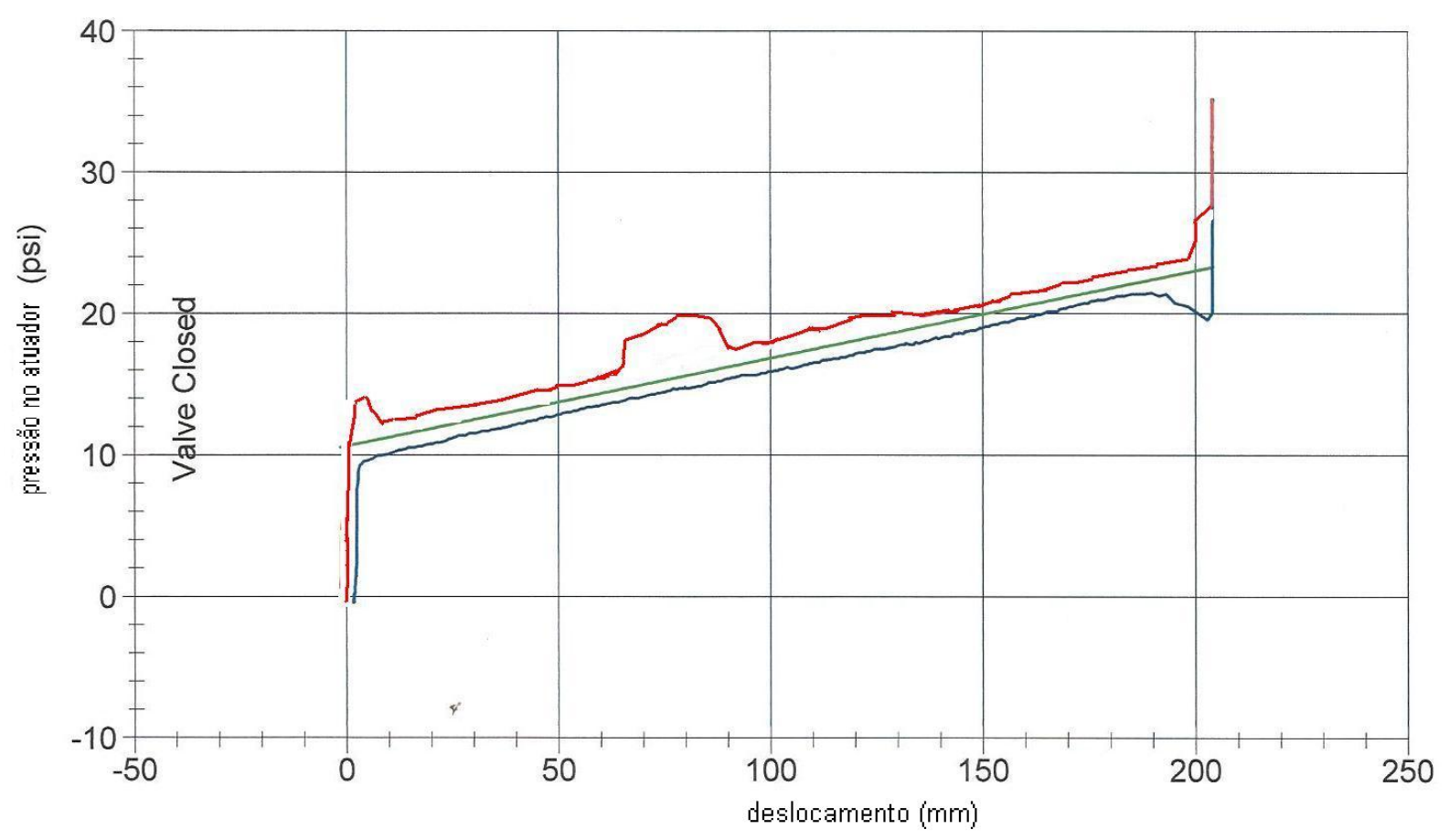

Figura 45 - Assinatura da PV-1110.

A PV-1110 tem suas variáveis conforme se segue: 
excvalv $\rightarrow 0$ a $205 \mathrm{~mm}$;

pressat $\rightarrow 0$ a $36 \mathrm{PSI}$ (pressure square inch); e

statvalv $\rightarrow 0$ a $100 \%$ (de abertura ao fechamento).

A Figura 45 representa a assinatura eletrônica da válvula e a Tabela 26 mostra os valores das variáveis e o respectivo "status" da válvula como variável de saída. O "status" fechado representa que a haste tocou a sede da válvula e o excesso de ar garante que não haverá passagem de fluido.

Tabela 26: Status da válvula e Faixa de entrada.

\begin{tabular}{cccccc}
\hline $\begin{array}{c}\text { Status da } \\
\text { válvula }\end{array}$ & Fechada & $1 / 4$ & $1 / 2$ & $3 / 4$ & Aberta \\
\hline Pares & $(0,11)$ & $(51.75,14)$ & $(102.5,17)$ & $(154.25,17)$ & $(205,23)$ \\
\hline
\end{tabular}

O diagnóstico devido ao "status" da válvula é representado pelas tabelas 27 e 28, que mostra quando a haste está trabalhando normalmente, ou com obstrução, ou com dificuldades de movimento, ou emperrada, ou com histerese.

Tabela 27 - Status da válvula - Diagnóstico da válvula.

\begin{tabular}{|c|c|c|c|c|c|}
\hline $\begin{array}{cc}\text { Status } & \text { Emperra } \\
\text { da } & \text { da } \\
\text { válvula fechada }\end{array}$ & $\begin{array}{c}\text { Abrindo Fechando } \\
\text { normalmente normalmente }\end{array}$ & $\begin{array}{l}\text { Dificuldade } \\
\text { de abrir }\end{array}$ & $\begin{array}{l}\text { Dificuldade } \\
\text { de fechar }\end{array}$ & Obs & \\
\hline PV-1110 $(0,28)$ & $\begin{array}{c}(205,36) a \\
(0,11)\end{array}$ & $(0,14)$ & $(205,20)$ & $\begin{array}{c}(65,19) \mathrm{a} \\
(90,20)\end{array}$ & $\begin{array}{l}\text { Conforme } \\
\text { tabela } 27\end{array}$ \\
\hline
\end{tabular}

Tabela 28 - Histerese da válvula PV1110.

\begin{tabular}{cccccc}
\hline Excvalv & Fechada & $1 / 4$ & $1 / 2$ & $3 / 4$ & Aberta \\
\hline PV-1110 & $(0,10) \mathrm{e}$ & $(51.75,13) \mathrm{e}$ & $(102.5,16) \mathrm{e}$ & $(154.25,19) \mathrm{e}$ & $(205,22) \mathrm{e}$ \\
& $(0,12)$ & $(51.75,15)$ & $(102.5,19)$ & $(154.25,21)$ & $(205,24)$ \\
\hline
\end{tabular}

As regras utilizadas estão descritas na tabela 29. Neste caso, a válvula tem a ação de funcionamento, ar para abrir - falha fecha.

Tabela 29 - Base de regras do Sistema de diagnóstico.

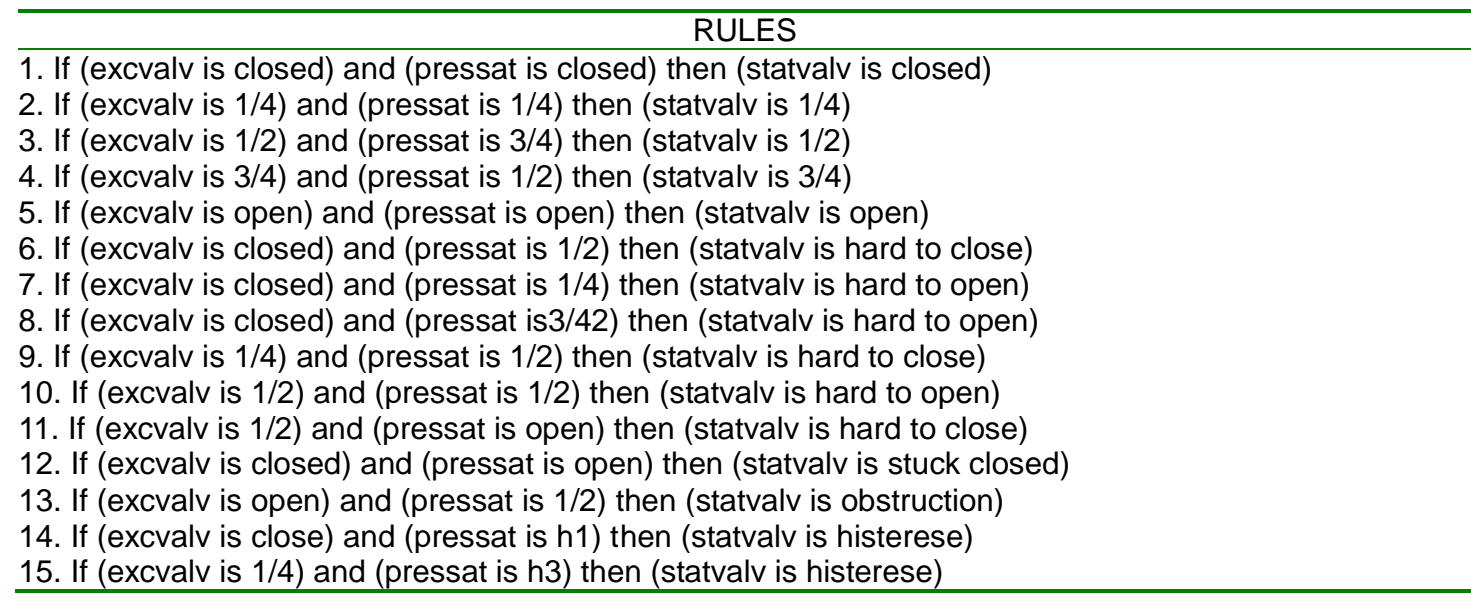


16. If (excvalv is $1 / 4)$ and (pressat is h4) then (statvalv is histerese)

17. If (excralv is close) and (pressat is h2) then (statvalv is histerese)

19. $f$ (excvalv is $1 / 2$ ) and (pressat is h5) then (statvalv is histerese)

19. If (excvalv is 1/2) and (pressat is h6) then (statvalv is histerese)

20. If (excvalv is 3/4) and (pressat is h7) then (statvalv is histerese)

21. If (excvalv is $3 / 4$ ) and (pressat is h8) then (statvalv is histerese)

22. If (excvalv is open) and (pressat is h8) then (statvalv is histerese)

23. If (excvalv is open) and (pressat is h9) then (statvalv is histerese)

A Tabela 30 mostra funções de pertinência e variáveis de entrada e saída. Uma função de pertinência é trapezoidal (situação fortemente fechada) e as demais são triangulares.

Tabela 30 - Funções de pertinência e seus valores.

\begin{tabular}{|c|c|c|c|c|}
\hline PV-1110 & Valores (excvalv) & \begin{tabular}{|l|} 
Valores \\
(pressat)
\end{tabular} & $\begin{array}{l}\text { Valores } \\
\text { (statvalv) }\end{array}$ & $\begin{array}{l}\text { Função } \\
\text { De } \\
\text { pertinênci } \\
\text { a }\end{array}$ \\
\hline Fechada & {$\left[\begin{array}{llll}-30 & 0 & 30\end{array}\right]$} & {$\left[\begin{array}{lll}0 & 11 & 14\end{array}\right]$} & {$\left[\begin{array}{lll}-1 & 0 & 15\end{array}\right]$} & Trimf \\
\hline $1 / 4$ & {$\left[\begin{array}{lllll}20 & 50 & 80\end{array}\right]$} & {$\left[\begin{array}{lll}11 & 14 & 17\end{array}\right]$} & {$\left[\begin{array}{lll}10 & 25 & 40\end{array}\right]$} & Trimf \\
\hline $1 / 2$ & {$\left[\begin{array}{lll}70 & 100 & 130\end{array}\right]$} & {$\left[\begin{array}{lll}14 & 17 & 20\end{array}\right]$} & {$\left[\begin{array}{lll}30 & 50 & 70\end{array}\right]$} & Trimf \\
\hline $3 / 4$ & {$\left[\begin{array}{lll}120 & 150 & 190\end{array}\right]$} & {$\left[\begin{array}{lll}17 & 20 & 23\end{array}\right]$} & {$\left[\begin{array}{lllll}60 & 75 & 90\end{array}\right]$} & Trimf \\
\hline Aberta & {$\left[\begin{array}{llll}175 & 205 & 235\end{array}\right]$} & {$\left[\begin{array}{lll}20 & 23 & 36\end{array}\right]$} & {$\left[\begin{array}{llll}85 & 100 & 105\end{array}\right]$} & Trimf \\
\hline Obstrução & & & {$\left[\begin{array}{lll}30 & 35 & 40\end{array}\right]$} & Trimf \\
\hline Dificuldade para abrir & & & {$\left[\begin{array}{lll}3 & 10 & 15\end{array}\right]$} & Trimf \\
\hline Dificuldade para fechar & & & {$\left[\begin{array}{llll}80 & 85 & 90\end{array}\right]$} & Trimf \\
\hline Emperrada fechada & & & {$\left[\begin{array}{lll}-3 & 0 & 25\end{array}\right]$} & Trimf \\
\hline Histerese & & $\begin{array}{l}{\left[\begin{array}{lll}9 & 10 & 11\end{array}\right] \mathrm{H} 1} \\
{\left[\begin{array}{lll}11 & 12 & 13\end{array}\right] \mathrm{H} 2} \\
{\left[\begin{array}{lll}12 & 13 & 14\end{array}\right] \mathrm{H} 3} \\
{\left[\begin{array}{lll}14 & 15 & 16\end{array}\right] \mathrm{H} 4} \\
{\left[\begin{array}{lll}15 & 16 & 17\end{array}\right] \mathrm{H} 5} \\
{\left[\begin{array}{lll}17 & 19 & 19\end{array}\right] \mathrm{H} 6} \\
{\left[\begin{array}{lll}19 & 19 & 20\end{array}\right] \mathrm{H} 7} \\
{\left[\begin{array}{lll}20 & 21 & 22\end{array}\right] \mathrm{H} 8} \\
{\left[\begin{array}{lll}23 & 24 & 25\end{array}\right] \mathrm{H} 9}\end{array}$ & {$\left[\begin{array}{lll}65 & 65 & 65\end{array}\right]$} & Trimf \\
\hline
\end{tabular}

Nas Figuras 46, 47 e 48 seguem-se respectivamente o gráfico das funções de pertinência das entradas "excvalv", "pressat" e da saída "statvalv". 
File Edit View
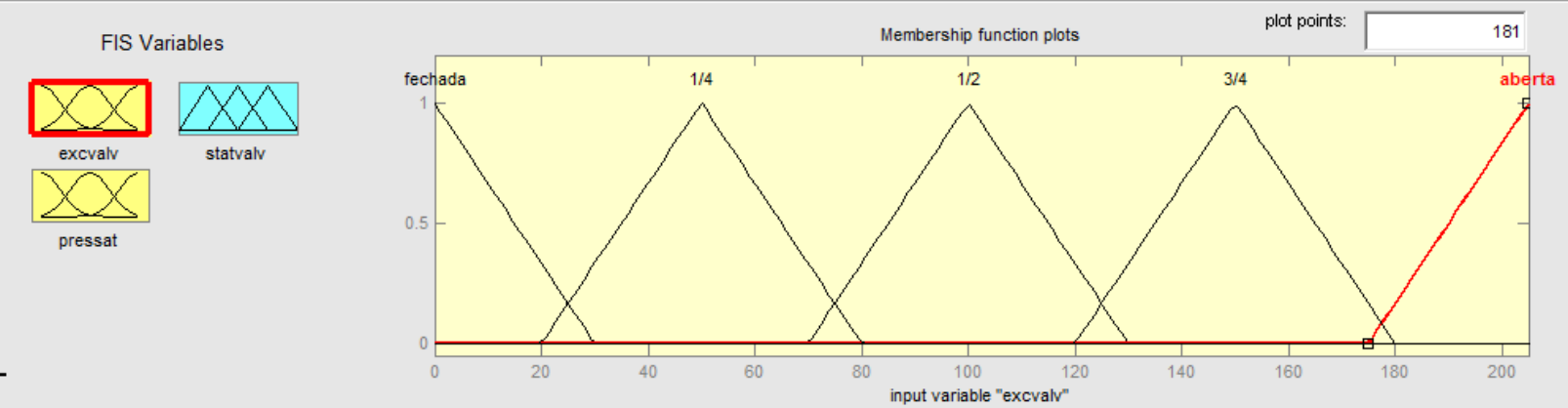

Figura 46 - Entrada "excvalv".

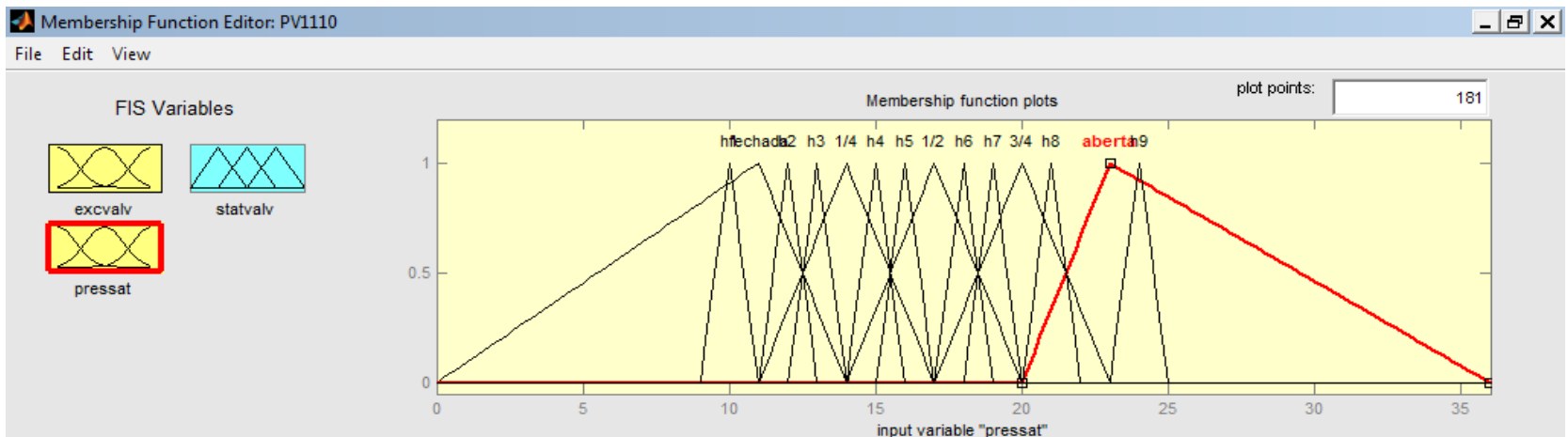

Figura 47 - Entrada "pressat".

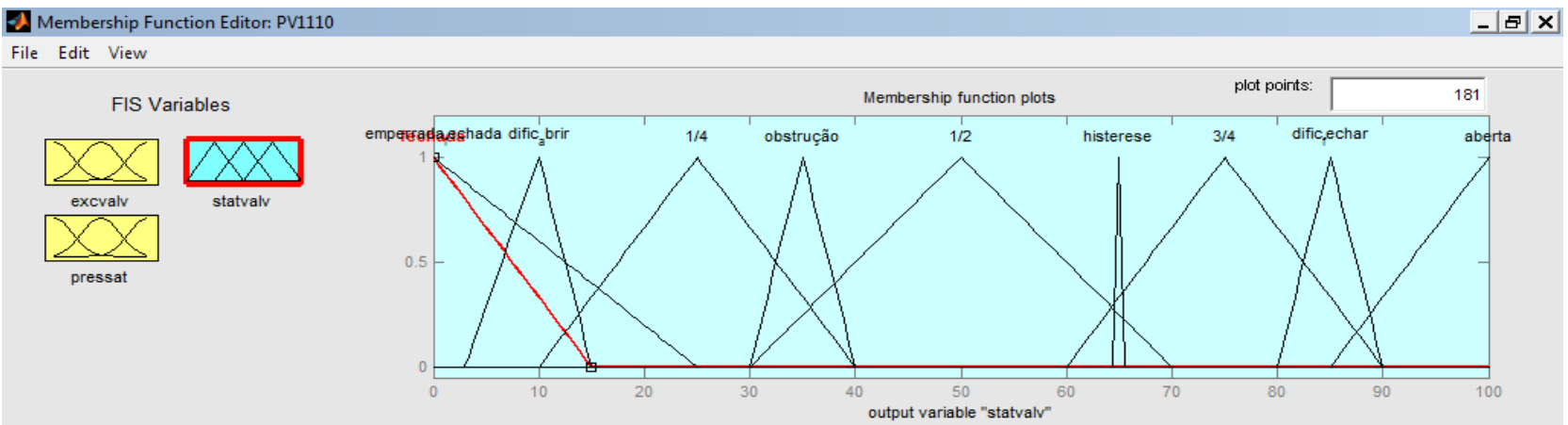

Figura 48 - Saída "statvalv".

Na Figura 49 tem-se o visor de regras com as regras 3 e 10 acionadas. A regra 3, está com a entrada "excvalv" na posição "1/2" de seu excursionamento e a variável "pressat" encontra-se na posição "3/4", com a saída em “1/2". E, na regra 11, tem-se o diagnóstico complementar indicando a saída "dificuldade de abrir", que demonstra um indício de emperramento, ou seja, uma falha incipiente. 


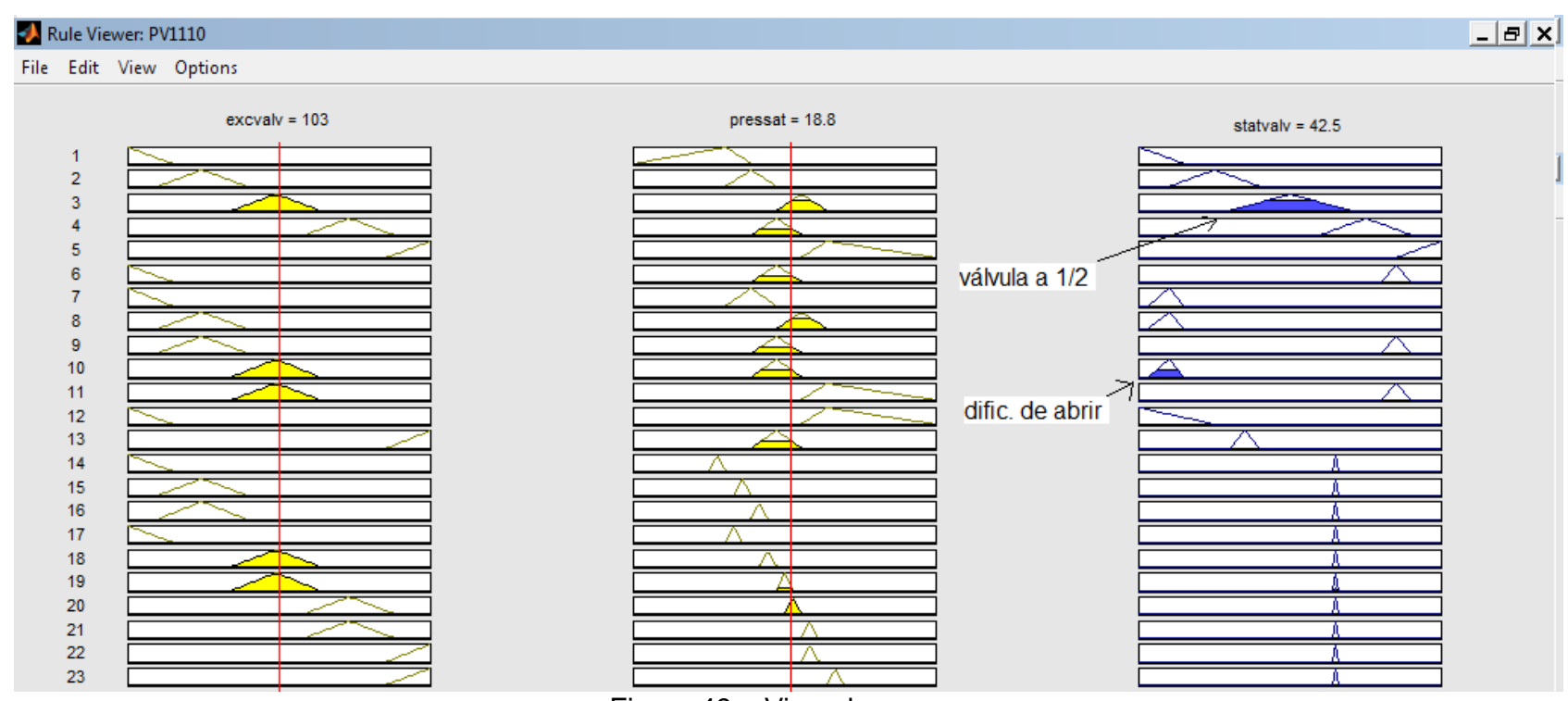

Figura 49 - Visor de regras.

\section{PV-482 - Controle de pressão no cabeçote de alta pressão}

A Figura 50 mostra a assinatura da válvula que controla a pressão de vapor no cabeçote de alta da turbina. O gráfico apresenta anomalias no início do excursionamento da válvula.

Neste caso, também ocorre "Ripple", o que indica que a haste não está livre do fenômeno "stiction", que é considerado danoso e indicador de uso prolongado da válvula sem a devida manutenção. A linha de base entre o ciclo de abertura e fechamento não foi respeitada pelo movimento de abertura e fechamento quando considerado as pressões mais baixas. Percebe-se, ainda, uma diferença de pressão de aproximadamente 2 PSI entre os ciclos de fechamento e abertura. Ainda que muito incipiente, trata-se de histerese, fenômeno que ocorre quando há folga entre as conexões de parafusos e porcas das partes móveis do mecanismo haste-posicionador-atuador.

As anomalias existentes no excursionamento da haste denotam uma dificuldade de movimento, indicando um emperramento, ainda que de pequeno grau. Ademais, a anomalia existente da diferença da linha de base para o movimento efetivamente traçado pela haste a baixas pressões indica um "desajuste de zero" nos momentos iniciais do movimento. 


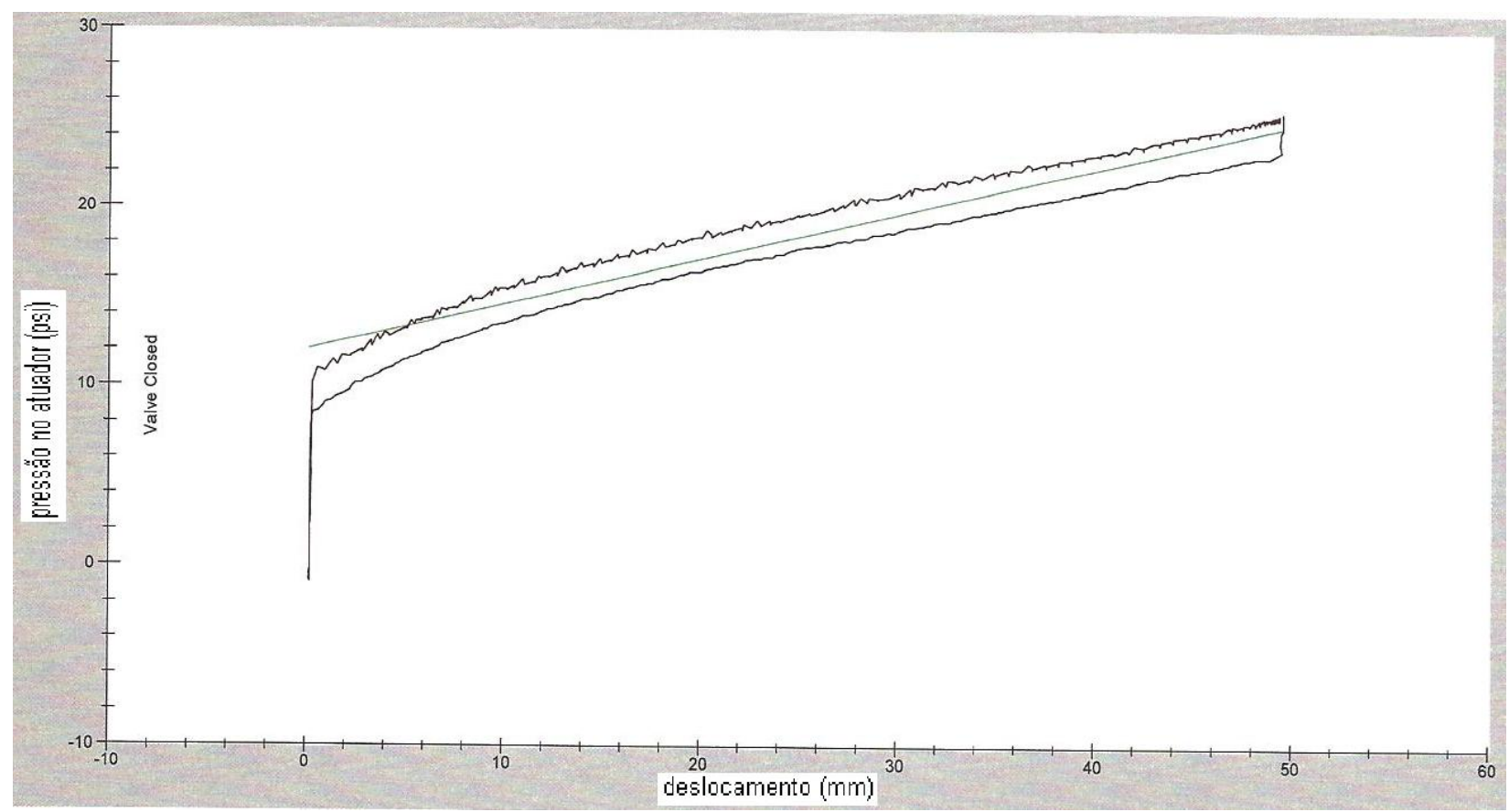

Figura 50 - Assinatura da PV-482.

A PV-482 tem suas variáveis conforme se segue:

excvalv $\rightarrow 0$ a $50 \mathrm{~mm}$;

pressat $\rightarrow 0$ a $24 \mathrm{PSI}$ (pressure square inch); e

statvalv $\rightarrow 0$ a $100 \%$ (de abertura ao fechamento).

A Figura 50 representa a assinatura eletrônica da válvula e, a Tabela 31, mostra os valores das variáveis e o respectivo "status" da válvula como variável de saída. O "status" fechado representa que a haste tocou a sede da válvula e a pressão da mola do atuador garante que não haverá passagem de fluido.

Tabela 31 - Status da válvula e Faixa de entrada.

\begin{tabular}{cccccc}
\hline Status da válvula & Fechada & $1 / 4$ & $1 / 2$ & $3 / 4$ & Aberta \\
\hline Pares & $(0,12)$ & $(12.5,15)$ & $(25,19)$ & $(37.5,21)$ & $(50,24)$ \\
\hline
\end{tabular}

O diagnóstico devido ao "status" da válvula é representado pelas tabelas 32 e 33, que indica quando a haste está trabalhando normalmente, ou com obstrução, ou com dificuldades de movimento, ou emperrada, ou com histerese.

Tabela 32 - Status da válvula - Diagnóstico da válvula.

\begin{tabular}{cccccc}
\hline $\begin{array}{c}\text { Status da } \\
\text { válvula }\end{array}$ & $\begin{array}{c}\text { Zero } \\
\text { desajustado }\end{array}$ & $\begin{array}{c}\text { Abrindo } \\
\text { normalmente }\end{array}$ & $\begin{array}{c}\text { Fechando } \\
\text { normalmente }\end{array}$ & Histerese \\
\hline PV-482 & $(0,8)$ a $(2,10)$ & $(0,12)$ a $(50,24)$ & $(50,24)$ a $(0,12)$ & Conforme tabela 32 \\
\hline Tabela 33 - Histerese da válvula PV-482. & $1 / 4$ & $1 / 2$ & $3 / 4$ & Aberta \\
\hline Excvalv & Fechada & $(12.5,13)$ e & $(25,16)$ e & $(37.5,19)$ e & $(50,22) \mathrm{e}$ \\
& $(0,10) \mathrm{e}$ & $(12.5,17)$ & $(25,20)$ & $(37.5,23)$ & $(50,26)$ \\
\hline
\end{tabular}


As regras utilizadas estão descritas na Tabela 34. Neste caso, a válvula tem a ação de funcionamento, ar para abrir - falha fecha.

Tabela 34 - Base de regras do Sistema de diagnóstico.

\section{RULES}

1. If (excvalv is closed) and (pressat is closed) then (statvalv is closed)

2. If (excvalv is $1 / 4$ ) and (pressat is $1 / 4$ ) then (statvalv is $1 / 4$ )

3. If (excvalv is $1 / 2$ ) and (pressat is $3 / 4$ ) then (statvalv is $1 / 2$ )

4. If (excvalv is $3 / 4$ ) and (pressat is $1 / 2$ ) then (statvalv is $3 / 4$ )

5. If (excvalv is open) and (pressat is open) then (statvalv is open)

6. If (excvalv is 1/4) and (pressat is zero disajustment) then (statvalv is zero misadjustment)

7. If (excvalv is closed) and (pressat is h1) then (statvalv is histerese)

8. If (excvalv is 1/4) and (pressat is h2) then (statvalv is histerese)

9. If (excvalv is $1 / 4$ ) and (pressat is h3) then (statvalv is histerese)

10. If (excvalv is $1 / 2)$ and (pressat is h4) then (statvalv is histerese)

11. If (excvalv is 1/2) and (pressat is h5) then (statvalv is histerese)

12. If (excvalv is $3 / 4$ ) and (pressat is h6) then (statvalv is histerese)

13. If (excvalv is $3 / 4$ ) and (pressat is h7) then (statvalv is histerese)

14. If (excvalv is open) and (pressat is h8) then (statvalv is histerese)

15. If (excvalv is open) and (pressat is h9) then (statvalv is histerese)

A Tabela 35 mostra as funções de pertinência e as variáveis de entrada e saída. Uma função de pertinência é trapezoidal (situação fechada) e todas as outras são triangulares.

Tabela 35 - Funções de pertinência e seus valores.

\begin{tabular}{|c|c|c|c|c|}
\hline$P V-482$ & Valores (excl & Valores (pressat) & $\begin{array}{l}\text { Valores } \\
\text { (statvalv) }\end{array}$ & $\begin{array}{l}\text { Função } \\
\text { De } \\
\text { pertinênci } \\
\text { a }\end{array}$ \\
\hline Fechada & {$\left[\begin{array}{lll}-7 & 0 & 7\end{array}\right]$} & {$\left[\begin{array}{lll}0 & 12 & 14\end{array}\right]$} & {$\left[\begin{array}{lll}-1 & 0 & 15\end{array}\right]$} & Trimf \\
\hline $1 / 4$ & {$\left[\begin{array}{llll}5 & 12.5 & 20\end{array}\right]$} & [13 15 17] & {$\left[\begin{array}{lll}10 & 25 & 40\end{array}\right]$} & Trimf \\
\hline $1 / 2$ & {$\left[\begin{array}{llll}17.5 & 25 & 32.5\end{array}\right]$} & [16 19 20] & {$\left[\begin{array}{lll}30 & 50 & 70\end{array}\right]$} & Trimf \\
\hline $3 / 4$ & {$\left[\begin{array}{llll}30 & 37.5 & 45\end{array}\right]$} & [19 21 23] & {$\left[\begin{array}{llll}60 & 75 & 90\end{array}\right]$} & Trimf \\
\hline Aberta & {$\left[\begin{array}{lll}43 & 50 & 55\end{array}\right]$} & [ [22 24 26] & {$\left[\begin{array}{lll}85 & 100 & 105\end{array}\right]$} & Trimf \\
\hline Zero desajustado & & {$\left[\begin{array}{llll}5 & 6 & 10 & 11\end{array}\right]$} & {$\left[\begin{array}{llll}2 & 8 & 12 & 19\end{array}\right]$} & Trapmf \\
\hline Histerese & & 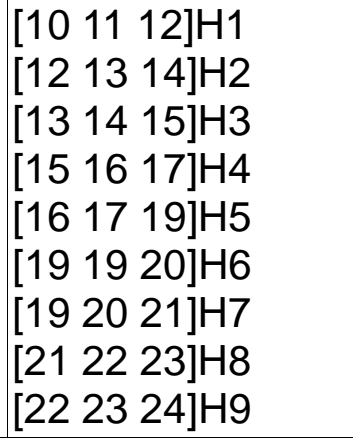 & [84 88 92] & Trimf \\
\hline
\end{tabular}

Nas Figuras 51, 52 e 53 seguem-se respectivamente o gráfico das funções de pertinência das entradas "excvalv", "pressat", da saída "statvalv". 


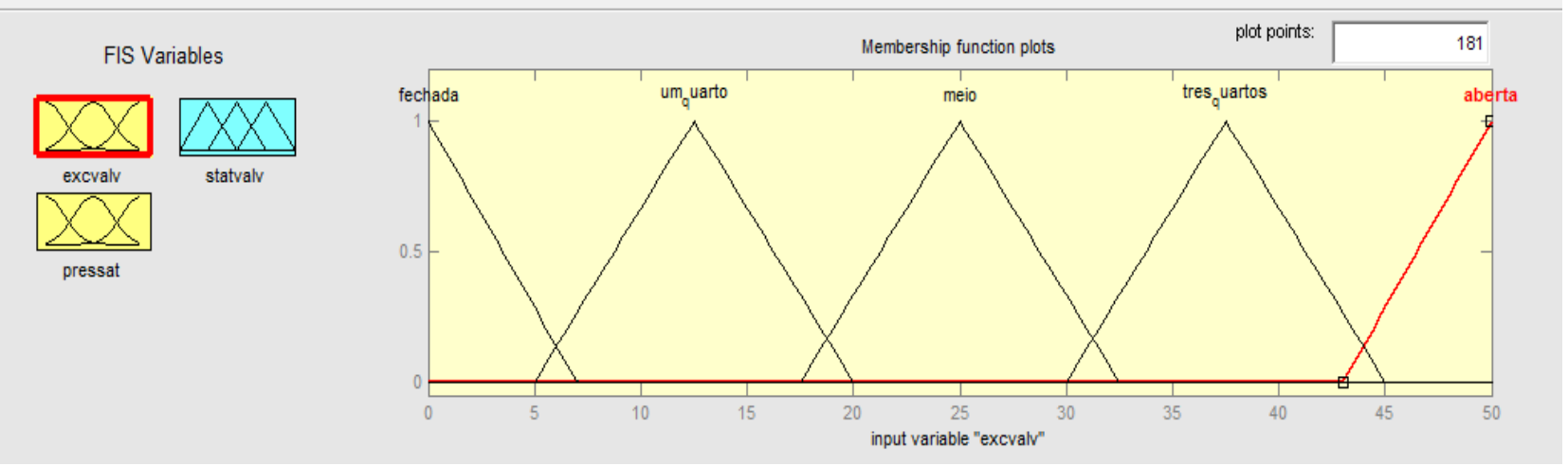

Figura 51 - Entrada "excvalv".

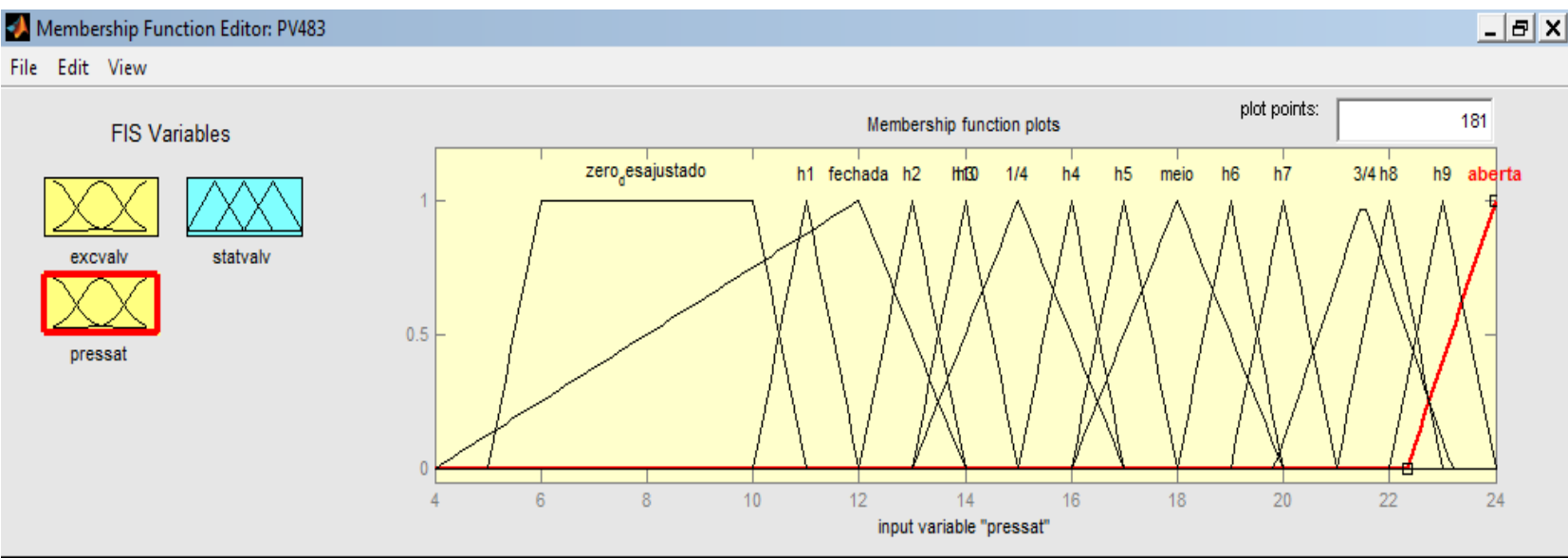

Figura 52 - Entrada "pressat".

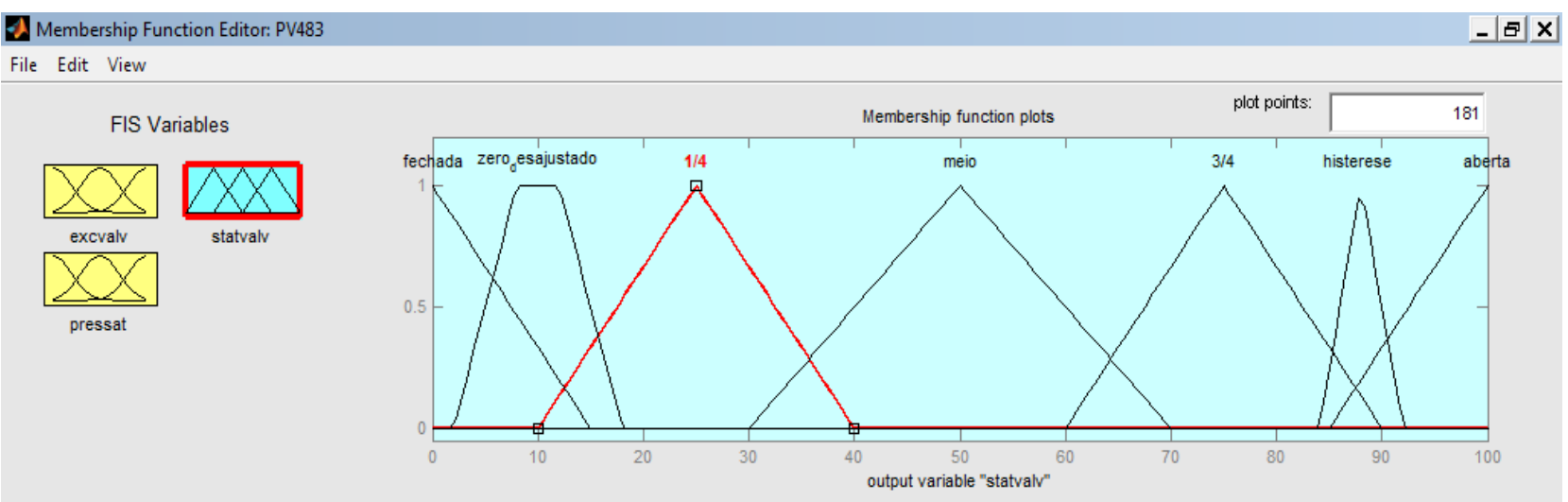

Figura 53 - Saída "statvalv".

$\mathrm{Na}$ Figura 54 tem-se o visor de regras com a regra 6 acionada. A entrada "excvalv" na posição " $1 / 4$ " de seu excursionamento e a variável "pressat" encontra-se no intervalo de 6 a 10 PSI. Esta regra acionada tem o diagnóstico de "desajuste de zero", presente no início do excursionamento da haste da válvula. 
excralv $=12.4$

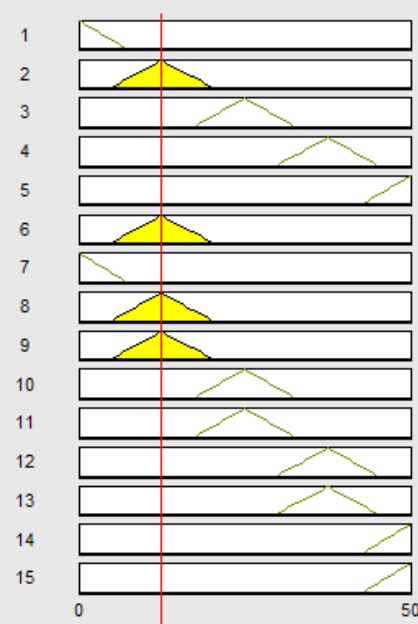

pressat $=8.61$

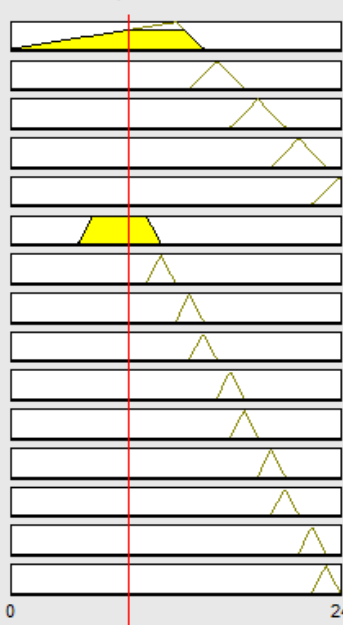

Figura 54 - Visor de regras.

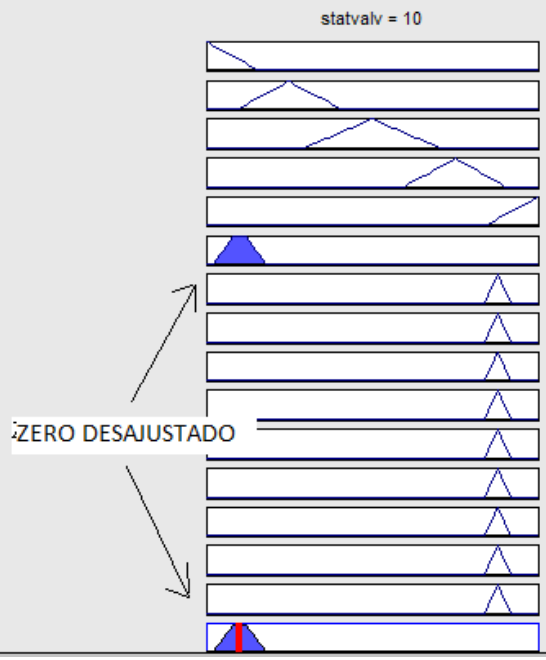

statvalv $=10$

\section{TV-462A - Controle de vazão de óleo na linha de alta pressão}

O caso apresentado trata-se da análise e diagnóstico da válvula de controle de temperatura de resfriamento do óleo lubrificante da turbina de propulsão principal do circuito secundário de uma planta nuclear tipo PWR, que, indiretamente, controla a vazão de óleo na linha de alta pressão de vapor.

A Figura 55 representa a assinatura eletrônica da válvula.

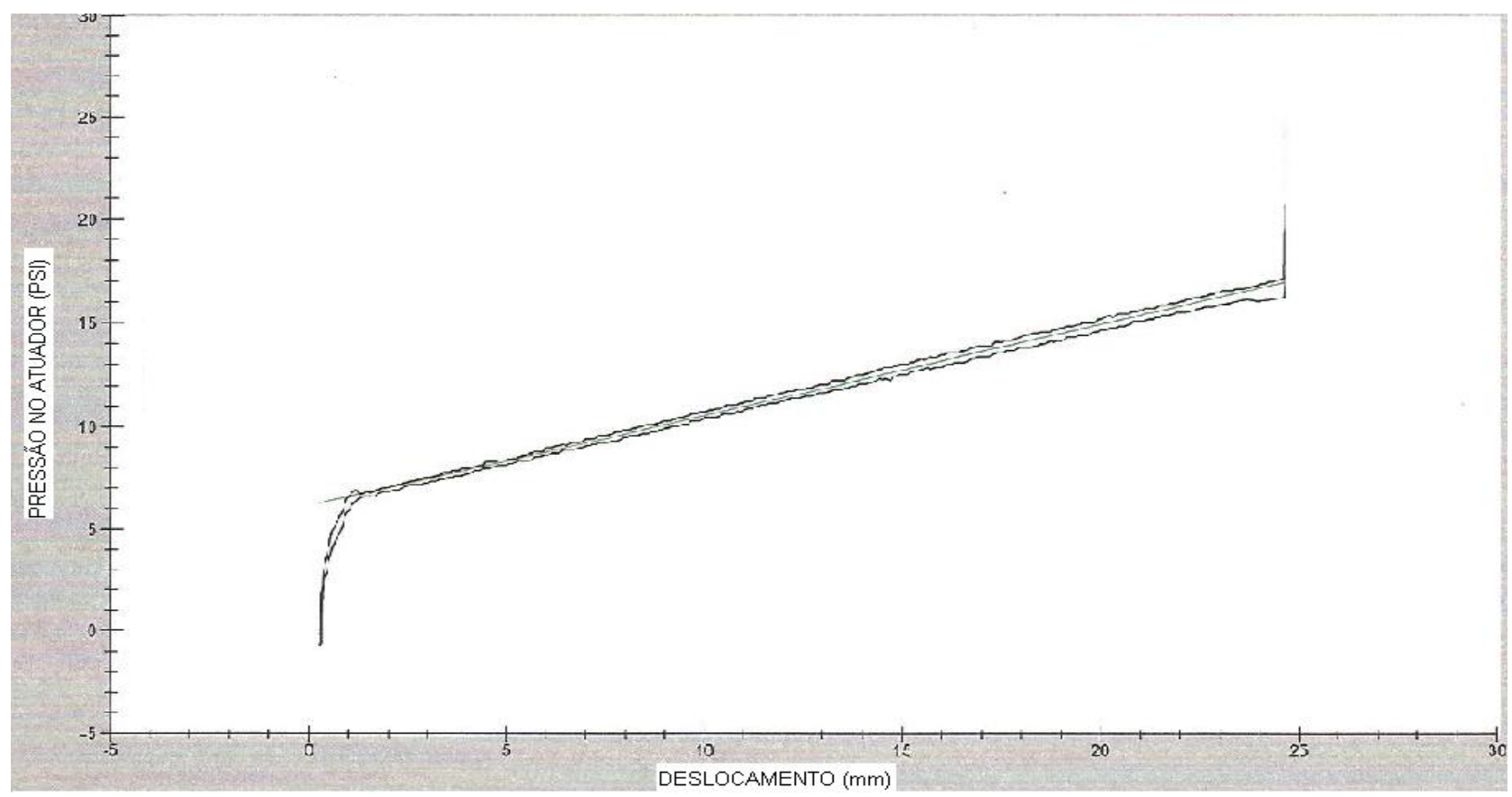

Figura 55 - Assinatura da TV-462A.

A válvula tem as seguintes características:

excvalv $\rightarrow 0$ to $25 \mathrm{~mm}$;

pressat $\rightarrow 6$ to $24 \mathrm{PSI}$; e 
statvalv $\rightarrow 0$ to $100 \%$ (da abertura ao fechamento).

A Tabela 36 apresenta os valores das variáveis e o respectivo "status" da válvula como variável de saída. O "status" fechado representa que a haste tocou a sede da válvula e o excesso de ar garante que não haverá passagem de fluido. O diagnóstico devido ao "status" da válvula é representado pela Tabela 36, que indica quando a haste está trabalhando normalmente, ou com desajuste de zero.

Tabela 36: Status da válvula - Faixa de entrada.

\begin{tabular}{ccccccc}
\hline $\begin{array}{c}\text { Status da } \\
\text { válvula }\end{array}$ & Aberta & $1 / 4$ & $1 / 2$ & $3 / 4$ & Fechada & Fortemente Fechada \\
\hline Pares & 0,6 & $(6.25,8.5)$ & $(12.5,11)$ & $(19.75,13.5)$ & 25,16 & de $(25,16)$ até(25,25) \\
\hline
\end{tabular}

Tabela 37: Status da válvula - Diagnóstico da válvula.

\begin{tabular}{cccc}
\hline Status da válvula & Desajuste de zero & Fechando normalmente & Abrindo normalmente \\
\hline TV462A & $(0,3) \mathrm{a}(2,6)$ & $(0,6) \mathrm{a}(25,16)$ & $(25,16) \mathrm{a}(0,6)$ \\
\hline
\end{tabular}

As regras utilizadas estão descritas na tabela 38. Devido a sua ação de funcionamento, ar para fechar - falha abre. A Figura 54 demonstra no ciclo superior (fechamento) uma anomalia. Esta anomalia de acordo com a base de regras proporcionará uma saída, diagnosticando uma falha, ainda que incipiente, chamada de "desajuste de zero", apresentando um movimento da haste da válvula com uma pressão menor do que a programada para o movimento.

Tabela 38: Base de regras do Sistema de diagnóstico.

1. If (excvalv is open) and (pressat is open) then (statvalv is open)

2. If (excralv is $1 / 4$ ) and (pressat is $1 / 4$ ) then (statvalv is $1 / 4$ )

3. If (excralv is $1 / 2$ ) and (pressat is $3 / 4$ ) then (statvalv is $1 / 2$ )

4. If (excralv is $3 / 4$ ) and (pressat is $1 / 2$ ) then (statvalv is $3 / 4$ )

5. If (excvalv is closed) and (pressat is closed) then (statvalv is closed)

6. If (excvalv is 1/4) and (pressat is zero misadjustment) then (statvalv is zero misadjustment)

7. If (excvalv is closed) and (pressat is strongly closed) then (statvalv is strongly closed)

A Tabela 39 apresenta as funções de pertinência e as variáveis de entrada e saída. Duas funções de pertinência são trapezoidais (situação fortemente fechada e desajuste de zero) e todas as outras são triangulares. 
Tabela 39 - Funções de pertinência e seus valores.

\begin{tabular}{|c|c|c|c|c|}
\hline TV462A & Valores (excvalv) & $\begin{array}{l}\text { Valores } \\
\text { (pressat) }\end{array}$ & $\begin{array}{l}\text { Valores } \\
\text { (statvalv) }\end{array}$ & $\begin{array}{l}\text { Função De } \\
\text { pertinênci } \\
\text { a }\end{array}$ \\
\hline Aberta & {$\left[\begin{array}{lll}-3 & 0 & 4\end{array}\right]$} & {$\left[\begin{array}{lll}0 & 6 & 7.5\end{array}\right]$} & {$\left[\begin{array}{lll}-1 & 0 & 15\end{array}\right]$} & Trimf \\
\hline $1 / 4$ & {$\left[\begin{array}{llll}2.5 & 6.25 & 10\end{array}\right]$} & {$\left[\begin{array}{llll}6.5 & 8.5 & 10.5\end{array}\right]$} & {$\left[\begin{array}{lll}10 & 25 & 40\end{array}\right]$} & Trimf \\
\hline Half open & {$\left[\begin{array}{lll}8.75 & 12.5 & 16.25\end{array}\right]$} & {$\left[\begin{array}{lll}9 & 11 & 13\end{array}\right]$} & {$\left[\begin{array}{lll}30 & 50 & 70\end{array}\right]$} & Trimf \\
\hline $3 / 4$ & {$\left[\begin{array}{lll}14.5 & 19.75 & 23\end{array}\right]$} & [11.5 13.5 15.5] & {$\left[\begin{array}{lll}60 & 75 & 90]\end{array}\right]$} & Trimf \\
\hline Fechada & {$\left[\begin{array}{lll}21 & 25 & 27\end{array}\right]$} & {$\left[\begin{array}{lll}14 & 16 & 17\end{array}\right]$} & {$\left[\begin{array}{llll}85 & 100 & 105\end{array}\right]$} & Trimf \\
\hline Fortemente fechada & Não aplicável & {$\left[\begin{array}{llll}16 & 16.5 & 24 & 25\end{array}\right]$} & {$\left[\begin{array}{llll}88 & 90 & 93 & 96\end{array}\right]$} & Trapmf \\
\hline Desajuste de zero & & {$\left[\begin{array}{llll}1 & 2 & 4\end{array}\right]$} & [2 $\left.8 \begin{array}{lll}2 & 12 & 19\end{array}\right]$ & Trapmf \\
\hline
\end{tabular}

Nas Figuras 56, 57 e 58 seguem-se respectivamente o gráfico das funções de pertinência das entradas "excvalv", "pressat", da saída "statvalv".

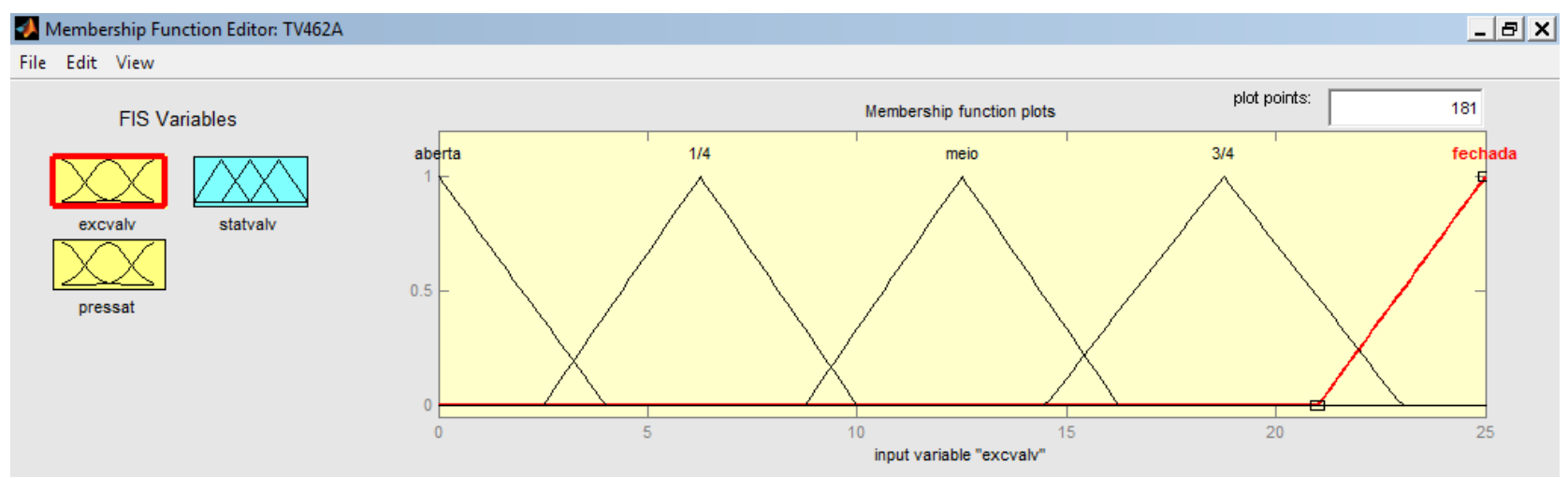

Figura 56 - Entrada "excvalv".

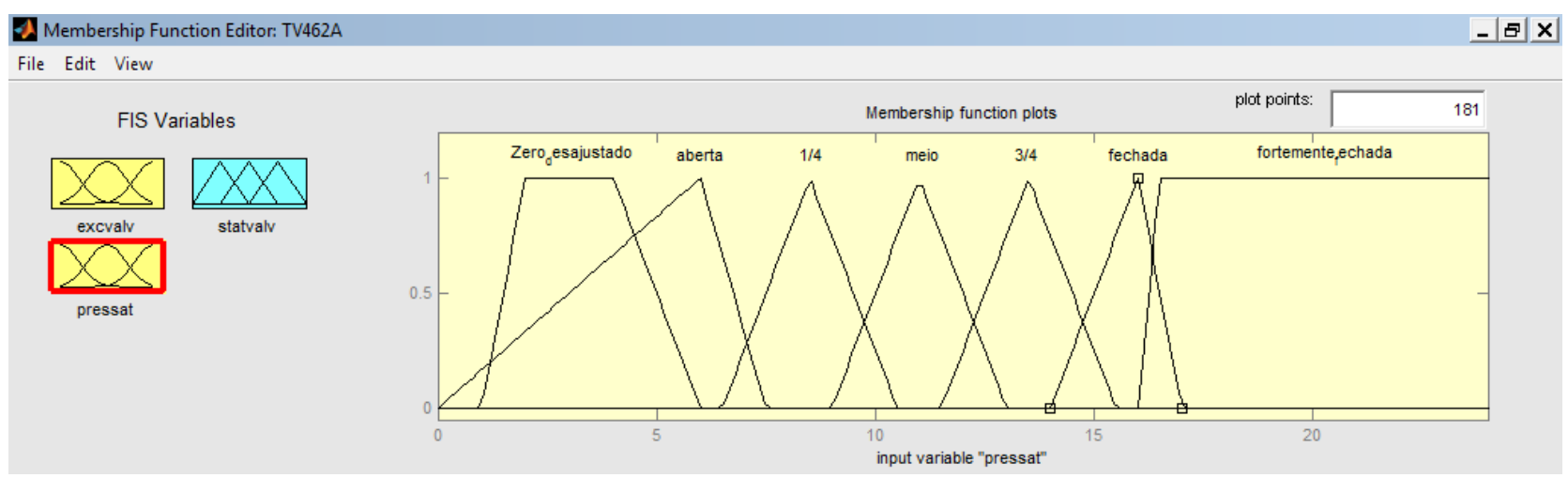

Figura 57 - Entrada "pressat". 


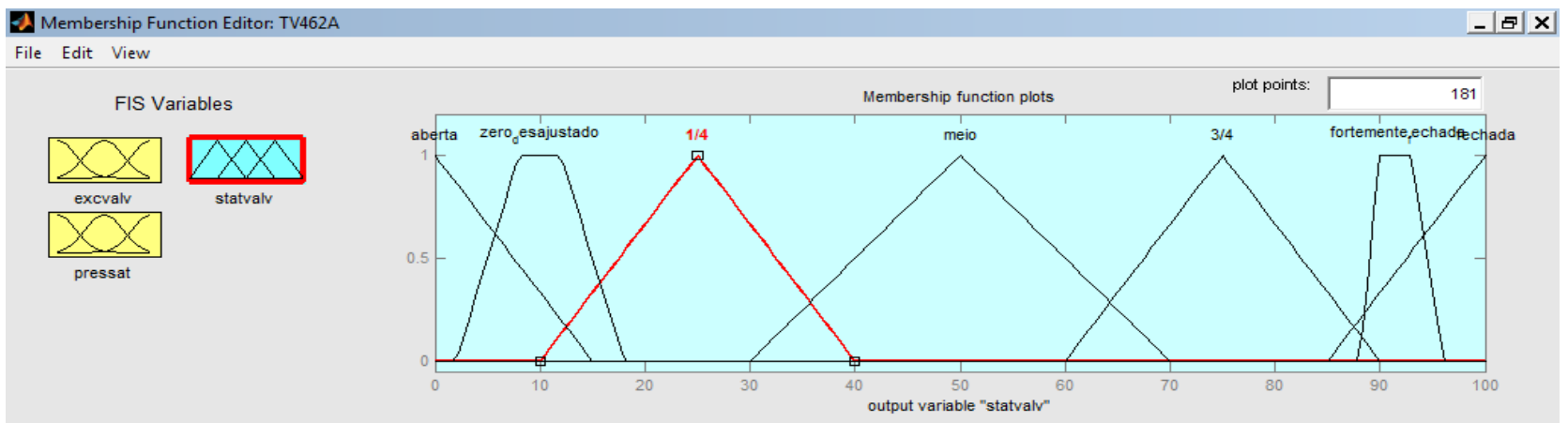

Figura 58- Saída "statvalv".

Na Figura 59 tem-se o visor de regras com o exemplo da regra 6. Devido as entradas "excvalv" e "pressat" apresentarem-se como "um quarto" e "desajuste de zero", tem-se a variável "statvalv" com o diagnóstico "desajuste de zero" ou "zero misadjustment", demonstrando uma falha ainda que incipiente, ou seja, um movimento antecipado da válvula.
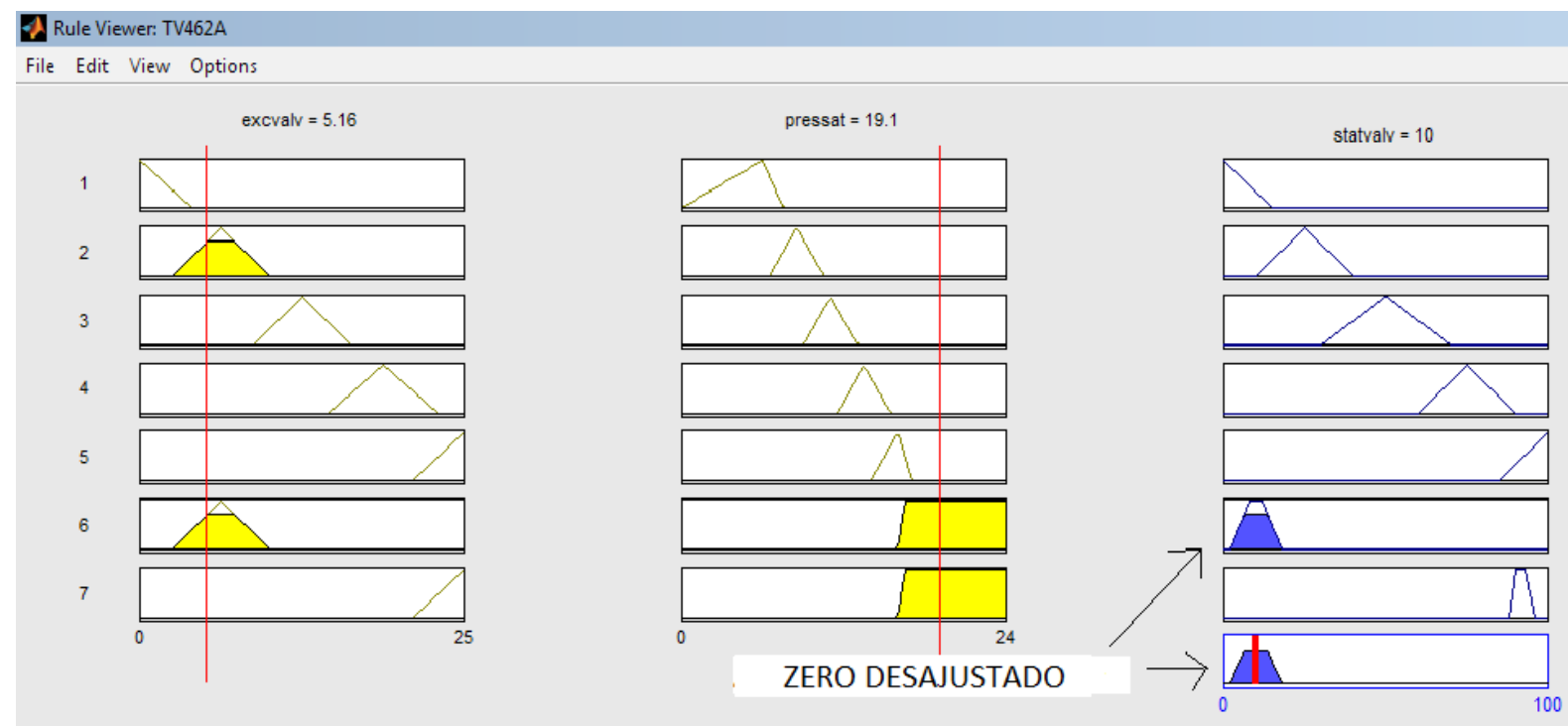

Figura 59 - Visor de regras.

\section{8- Conclusão}

Verificou-se, no estudo realizado com as válvulas escolhidas, que é possível constatar/diagnosticar defeitos e/ou anomalias. O primeiro caso refere-se a emperramento da haste na posição fechada, o segundo caso, um defeito incipiente indicando a dificuldade de fechamento do dispositivo.

Seguem-se outros exemplos onde foram detectados vários tipos de diagnósticos: emperramento no ciclo de fechamento e dificuldade de abrir a válvula no ciclo de abertura, ou ainda dificuldade de abrir o dispositivo adicionado à presença de histerese, ou ainda dificuldade de abrir, indicando início de emperramento, que é uma falha 
incipiente.

Ademais, os dois últimos casos diagnosticados apresentam desajuste de zero, ou seja, a válvula inicia o movimento com uma pressão menor que a indicada antes, e por último um desajuste de zero, ou seja, o início do movimento de abertura se faz com a pressão mais baixa que a indicada.

Usou-se exaustivamente o módulo valvelink, do sistema de automação Delta $\mathrm{V}$, adquirido pela MB, na coleta da assinatura eletrônica das válvulas, explorando as informações técnicas operacionais dos dispositivos em questão. Implementou-se os recursos de IA, baseando-se na lógica fuzzy. Tornou-se possível a identificação, de forma preditiva, dos defeitos e seus sintomas, inclusive em estado incipiente.

A área de IA já está bem desenvolvida, e dentro dela, as aplicações com lógica fuzzy. Todavia, tende a crescer mais, conforme novas tecnologias vão surgindo. Com o desenvolvimento da lógica computacional, e dos programas de simulação de alto desempenho e/ou largo espectro (MATLAB ${ }^{\circledR}$ ), os sistemas tendem a evoluir em proporção igual, atingindo novos patamares de usabilidade.

O futuro da lógica de SE abrange cada vez mais outras áreas do conhecimento. A quantidade de informações que transitam atualmente na internet e são processadas por computadores tem crescido significativamente. Nesta visão, logo os SE terão uma base de conhecimento tão grande, que poderão chegar a conclusões de horizontes de desenvolvimento superiores aos horizontes previstos pelos homens.

Quanto ao sistema de monitoração e diagnóstico desenvolvido, pode-se afirmar que atingiu os objetivos propostos para o trabalho. O sistema foi direcionado a uma metodologia de monitoração e obtenção de diagnóstico qualitativo das condições operacionais das válvulas de controle de processo do circuito secundário de uma planta nuclear de potência. E verifica-se a sua eficácia, quando se fornece ao operador de reator o status em que se encontra a válvula de controle. Status que somente o profissional com conhecimentos de instrumentação tem capacidade de perceber, estando ainda ele, presente no local em que a válvula se encontra. 
O enfoque principal da dissertação consistiu na aplicação de métodos de processamento e análise de sinais de pressão de ar comprimido dos atuadores a diafragma e do deslocamento realizado pelas hastes das válvulas, buscando identificar, caracterizar e diagnosticar falhas, e graduá-las em grau de severidade. Este objetivo foi contemplado no sistema desenvolvido.

A utilização do SE com aplicação da lógica fuzzy contribuiu significativamente, proporcionando o diagnóstico qualitativo da situação de cada válvula estudada de forma sistemática e simples, para situações que inicialmente aparentam complexidade, devido ao processamento e análise de gráficos muitas das vezes de comportamento anômalo.

A sensibilidade do sistema para a detecção de falhas, com a devida gradação de severidade, dificuldade para abrir, dificuldade para abrir, emperrada aberta, emperrada fechada, histerese, foi atingida, sendo esta o principal objetivo do SE no diagnóstico.

Do ponto de vista prático, alguns pontos são importantes ressaltar, como repercussão da disponibilidade do sistema desenvolvido para uma planta nuclear de potência:

a) o Subsídio importante para o operador da planta, estabelecendo uma monitoração das condições operacionais da válvula;

b) a Não interferência na operação normal da planta;

c) a Redução de exposição do ser humano à dose de radiação; e

d) a Contribuição para programação de manutenção durante a parada da planta.

Aspectos a serem considerados como benefícios devido a este trabalho:

a)Técnico: capacitação para soluções de problemas nas plantas nucleares da MB;

b)Científico: intercâmbio com instituições internacionais de excelência na área de monitoração e diagnóstico; e

c)Econômico: possibilidade de prestação de serviços com alta qualidade, baixos custos, evitando contratação de empresas estrangeiras.

\section{1- Contribuição e desenvolvimento no campo da pesquisa}

a)Diagnóstico de válvulas de controle através da análise da assinatura eletrônica de suas variáveis;

b)Uso de ferramentas de Inteligência Artificial (lógica fuzzy) para análise gráfica das 
assinaturas de válvulas;

c)Uso das potencialidades existentes no Sistema de automação Delta V; e

d)Identificação de falhas incipientes, sintomas de defeito, desgaste, e dano em válvulas de controle, através da verificação de sua assinatura eletrônica.

\section{2- Recomendações para trabalhos futuros}

Desenvolvimento de bancadas de testes com válvulas de controle para levantamento de ensaios com falhas e diagrama de causa e efeito;

Enriquecimento do banco de conhecimento e, por consequência, da base de regras estabelecidas no SE;

Realizar a predição do tempo de vida útil da válvula; e

Implementação do sistema no LABGENE e no Submarino de Propulsão Nuclear Brasileiro (SnBr).

\section{Referências Bibliográficas}

[01]Marinha do Brasil. Projetos desenvolvidos pelo Centro Tecnológico da Marinha em São Paulo. Disponível em https://www.mar.mil.br/pnm/pnm.htm, acesso em 13/6/2011. [02]Bialkowski, W.L.; Dreams vs. Reality: A view from both sites of the gap; Control Systems, Whistler, British Columbia, Canada, pp 283-294.

[03]Gerry, John; Expert Tune Inc.; Ruel, Michel; TOP Control; How to measure and Combat Valve Stiction on Line; ISA 2001, Houston, TX, Sep. 11 ${ }^{\text {th }}, 2001$.

[04]Desborough, L. and Miller, R.; Increasing customer value of Industrial control performance monitoring - Honeywell's experience; AIChE Symposium, pp. 172-192, Series 2001.

[05]Choudhury, M.A.A.S.; Shah S.L.; Dept. of Chemical and Material Engineering; Univ. of Alberta, Edmonton, Canada; Thornhill, N.F., Dept. of Electronic and Electric Eng., UCL, London; Detection and Quantification of Control Valve Stiction, IFAC 2004.

[06] Choudhury, M.A.A.S.; Shah S.L.; Kariwala, Vinay; Dept. of Chemical and Material Engineering; Univ. of Alberta, Edmonton, Canada; Douke, Hisato, Mitsubishi Chemical Corporation; Thornhill, N.F., Dept. of Electronic and Electric Engineering, UCL, London; A simple test to confirm control valve stiction, IFAC 2005.

[07]Pinto, Camila; M. de Almeida, Gustavo; Detecção de falhas em um elemento final de controle via modelo de Markov; UFSJ, Ouro Branco, MG, Encontro Regional de Matemática aplicada e Computacional - ERMAC 2010.

[08]Bartys, M. e de Las Heras, S.; Actuator simulation of the DAMADICS benchmark actuator system; pp. 963-968, IFAC 2003. 
[09]Syfert, M.; Patton, R.; Bartys, M.; Quevedo, J.; Development and App. of the methods for actuator diagnosis in industrial control system - DAMADICS: A benchmark study.

[10]Sharif, M. A. and Grosvenor, R. I.; Process plant condition monitoring and fault diagnosis. Proceedings of Institute of Mechanical Engineers (Part E) 212, 13-30, 1998.

[11] Gerry, J and Ruel, M; How to measure and combat valve stiction online. Proc ISA International Fall Conference, Houston 2001.

[12] Horch, A.; A simple method for detection of stiction in control valves; Department of Signals and Systems, Royal Institute of Technology, Stockholm, Sweden; PERGAMON CONTROL Eng. Practice 7, 1221-1231; www.elsevier.com/locate/conengprac, 1999.

[13] Rengaswamy, R. et al.; A reliable measure for model based stiction detection approaches; Department of Chemical Engineering, Texas Tech University; $8^{\text {th }}$ IFAC Symposium on Advanced Control of Chemical Processes, Singapure 2012;

[14] Stenman, A. et al; A segmentation-based method for detection of stiction in control valves; Department of Electrical Engineering, Linkopings Universitet, Sweden, International Journal of Adaptative Control and Signal Processing, Vol 17, Issue 7-9, pages 625-634, 2003.

[15]Guimarães Carneiro, A. L., Desenvolvimento de sistemas de monitoração e diagnóstico aplicado à válvulas moto-operadas utilizadas em Centrais Nucleares, Tese de Doutorado, IPEN-USP, Iv 22710, 2003.

[16]Uehara, Daniel, Detecção e quantificação de atrito em válvulas de controle, Dissertação de mestrado, p.69 Poli-USP, São Paulo 2009.

[17]Hossain, A.; Rahman, A.; Mohiuddin, A.K.M.; Dept. of Mech. Eng., Int. Islamic Univ. Malaysia (IIUM), Kuala Lumpur, Malaysia, Mechatronics (ICOM), 2011 4th International Conference On, 17-19 May 2011, page(s): 1 - 6.

[18] Ross, Timothy J.; Fuzzy Logic with Engineering applications, $3^{\text {rd }}$ ed. 2010.

[19]L.A. Zadeh, Coping with the Imprecision of the Real World: An Interview with Lofti Zadeh. Comm. ACM 27 (1984): 304-311.

[20]www.ic.uff.br/ferraz/IA/Ppt/SistemasEspecialistas/Expert01.ppt acesso em 09/01/2014.

[21]www.din.uem.br/ia/intelige/especialistas/especialistas/caracter.htm acesso em 09/01/2014.

[22]Barreto, Luiz Rodolfo; Prezoto, Marcelo Godoi; Introdução a Sistemas Especialistas, UNICAMP, Faculdade de Tecnologia, Trabalho de Pós-Graduação da disciplina Inteligência Artificial, requisito de conclusão de matéria do curso de Mestrado em 
Tecnologia para Sistemas e Fenômenos Complexos, 2010.

[23]L. A. Zadeh, "Fuzzy sets, "Information and Control, vol 8pp.338-353, 1965.

[24]Mamdani, E.H.; Application of Fuzzy Logic to Approximate Reasoning using Linguistic Synthesis, Department of Electrical and Electronic Engineering, Queen Mary College (University of London), 1974.

[25]Lemos Pinto, Raphael; Aplicação de um Sistema Especialista Fuzzy para redução de manobras de dispositivos Shunt chaveados automaticamente por um compensador estático, Dissertação de Mestrado, Programa de Pós-Graduação em Engenharia Elétrica, COPPE-UFRJ, Setembro de 2010.

[26]Guimarães Carneiro, A. L., Porto Jr., A. C. S., "Development of an Integrated Condition Monitoring and Diagnostic System for Process Control Valves Used in Nuclear Power Plant", AIDIC PHM Milano Italy, set 2013, vol 2 pages 872.

[27]Coble, J.B.; Upadhyaya, B.R.; Prognostic and Health Management in Nuclear Power Plants: A Review of Tech. and Applications, National Technical Information Service, 2012. [28]Zio, Enrico; A data-driven fuzzy approach for predicting the remaining useful life in dynamic failure scenarios of a nuclear system; Reliability Engineering and System Safety, vol.95, 2010.

[29]Attaway, S., MATLAB ${ }^{\circledR}$ A practical introduction to programming and problem solving, Elsevier, ISBN 978-0-75-068762-1, 2009.

[30]Rajagopalan A. et al, Development of Fuzzy Logic and Neural Network Control and Advanced Emissions Modeling for Parallel Hybrid Vehicles, Ohio State Univ., dec, 2003. [31]Mendel, Jerry M., Fellow, IEEE, Fuzzy Logic Systems for Engineering: A Tutorial, Proceedings of the IEEE, vol 83, march 1995.

[32]Guimarães Carneiro, A. L., Porto Jr., A. C. S., "Expert System for fault diagnosis in process control valves using fuzzy-logic", INAC, Recife, Brasil, nov 2013, ISBN: 978-8599141-05-2

[33] http://www.smar.com/brasil/produtos acessado em 20/02/2014.

[34]http://www.sr.ifes.edu.br/ rafael/ii2/apostilas/valvulas/Apostila\%20Valvulas.pdf acessado em 28/02/2014.

[35]DeltaV-DigitalAutomationSystemv.10-d:snap-ons/valvelink/quick-startguide.pdf. 